\title{
Roles of non-coding RNAs in islet biology
}

Claudiane Guay ${ }^{1,2}$, Cécile Jacovetti ${ }^{1,2}$, Mustafa Bilal Bayazit ${ }^{1,2}$, Flora Brozzi ${ }^{1,2}$, Adriana Rodriguez-Trejo ${ }^{1,2}$, Kejing $\mathrm{Wu}^{1,2}$ and Romano Regazzi ${ }^{1,2 *}$

${ }^{1}$ Department of Fundamental Neurosciences, University of Lausanne, Lausanne, Switzerland ${ }^{2}$ Department of Biomedical Sciences, University of Lausanne, Lausanne, Switzerland

*Corresponding author: Dr. Romano Regazzi Department of Fundamental Neurosciences

Rue du Bugnon 9, 1005 Lausanne, Switzerland Tel. ++41 2169252 80/Fax. ++41 216925255

E-mail: $\underline{\text { Romano.Regazzi@unil.ch }}$ 


\begin{abstract}
The discovery that most mammalian genome sequences are transcribed to RNA has revolutionized our understanding of the mechanisms governing key cellular processes and of the causes of human diseases, including diabetes mellitus. Pancreatic islet cells were found to contain thousands of noncoding RNAs, including microRNAs, Piwi-associated RNAs, small nucleolar RNAs, tRNAderived fragments, long non-coding RNAs and circular RNAs. While the involvement of microRNAs in islet function and in the etiology of diabetes is now well documented, there is emerging evidence indicating that other classes of non-coding RNAs are also participating in different aspects of islet physiology. The aim of this review will be to provide a comprehensive and updated view of the studies carried out in human samples and rodent models over the last 15 years on the role of non-coding RNAs in the control of $\alpha$ - and $\beta$-cell development and function and to highlight the recent discoveries in the field. We will not only describe the role of non-coding RNAs in the control of insulin and glucagon secretion but will also address the contribution of these regulatory molecules in the proliferation and survival of islet cells under physiological and pathological conditions. It is now well established that most cells release part of their non-coding RNAs inside small extracellular vesicles allowing the delivery of genetic material to neighboring or distantly located target cells. The role of these secreted RNAs in cell-to-cell communication between $\beta$-cells and other metabolic tissues as well as their potential use as diabetes biomarkers will be discussed.
\end{abstract}




\section{Didactic synopsis}

Major teaching points:

- Several classes of non-coding RNAs, including miRNAs, piRNAs, snoRNAs, tRFs, lncRNAs and circRNAs, are expressed in islet cells.

- Bioinformatics tools have been developed to identify new non-coding RNAs, to understand their mode of action and to predict their targets.

- Non-coding RNAs are essential regulators of pancreatic development, $\beta$-cell differentiation and maturation.

- Dysregulation of non-coding RNAs has been observed in islets of diabetic animal models and diabetic human donors.

- Non-coding RNAs can be released in extracellular vesicles and transferred to other islet cells or to metabolic organs to regulate glucose and insulin homeostasis.

- Circulating non-coding RNAs represent promising biomarkers.

Keywords: Pancreas, islet, $\beta$-cell, $\alpha$-cell, miRNA, tRNA fragments, piRNA, snoRNA, circRNA, lncRNA, pancreas development, maturation, $\beta$-cell differentiation, ageing, Type 1 diabetes, Type 2 diabetes, gestational diabetes, exosome, extracellular vesicle, biomarker 


\section{Introduction}

Diabetes mellitus is a metabolic disorder currently affecting about $8 \%$ of adults around the world (https://www.idf.org/). Population aging and obesity pandemics is expected to dramatically increase diabetes incidence in the coming decades. Diabetes mellitus is an important risk factor for a variety of other disorders and constitutes a major public health concern $(15,136)$. Indeed, if untreated, diabetes can lead to devastating long-term complications that significantly affect life expectancy and quality. These include heart and kidney failure, stroke, neuropathic pain, blindness and lower limb amputations.

Diabetes mellitus is characterized by chronically elevated blood glucose levels resulting from the release of insufficient insulin to cover the organism needs. Pancreatic $\beta$-cells are the only source of this essential anabolic hormone that governs glucose uptake in skeletal muscles and adipocytes, and glucose production and storage in hepatocytes. Diabetes mellitus can have different etiologies but all forms of the disease are associated with dysfunction and/or loss of the insulinsecreting cells (Fig. 1). Type 1 diabetes (T1D), representing about $10 \%$ of the diabetes cases, is caused by an autoimmune reaction directed against the $\beta$-cells (15). Since the immune attack results in a near complete elimination of the $\beta$-cells, the individuals suffering from this form of the disease necessitate multiple daily insulin injections. Type 2 diabetes (T2D) is the most frequent form of the disease ( $\sim 90 \%$ of the diabetes cases). It is usually associated with obesity and results from the failure of $\beta$-cells to compensate for a diminished sensitivity of insulin target tissues (136). Usually, this form of the disease is treated with drugs that increase the sensitivity of insulin target tissues and/or stimulate insulin secretion, but part of the patients may also require daily insulin injections. Gestational diabetes is a form of the disease occurring in about $5 \%-10 \%$ of the pregnancies and usually resolves after delivery (247). However, women suffering from gestational diabetes as well as their offspring have a higher propensity to develop T2D later in life. While diabetes mellitus usually results from a combination of metabolically inappropriate environmental conditions and unfavorable genetic background, the disease can also be caused by mutations in single genes. These monogenic forms of the disease can manifest already at birth (neonatal diabetes) or appear much later in life (maturity onset diabetes of the young). 


\section{Involvement of pancreatic islets in glucose homeostasis and in diabetes development}

Pancreatic $\beta$-cells are highly specialized cells localized within the islets of Langerhans, which contain also $\alpha$-cells (secreting glucagon), $\delta$-cells (secreting somatostatin) and $\varepsilon$-cells (secreting ghrelin). $\beta$-cells are the only cells in the body capable of producing and secreting insulin in response to a rise in blood glucose levels. This peculiar property is only acquired after a complex maturation process that is completed during the neonatal period. Indeed, newborn $\beta$-cells are capable of producing appropriate amounts of insulin but are still inefficient in secreting the hormone in response to elevated glucose levels $(5,6,18,96,124)$. This unique functional feature involves the activation of specialized metabolic pathways that are only fully operational after a neonatal gene reprogramming. Beside differences in the secretory properties, newborn $\beta$-cells display also a proliferation rate that is much higher than that of adult $\beta$-cells $(124,213)$. This permits an important expansion of the insulin-secreting cells during the neonatal period (Fig. 1). $\beta$-cell proliferation strongly declines thereafter and is almost undetectable in adults, particularly in humans (327). Thus, defects in the events necessary for the expansion and the functional maturation of the $\beta$-cells occurring early in life can potentially impact on the capacity to meet conditions of increased insulin demand occurring later in life such as pregnancy or obesity, predisposing to the development of gestational diabetes and T2D at adulthood (Fig. 1) (236).

The molecular mechanisms triggering the autoimmune attack of the $\beta$-cells in T1D or underlying the failure of $\beta$-cells to compensate for insulin resistance in T2D or gestational diabetes remain to be fully elucidated. In the last decades, large efforts have been undertaken to determine the contribution of changes in gene expression in the development of different forms of diabetes. Most of these investigations focused on genes coding for proteins that play essential roles in $\beta$-cell differentiation and/or function. However, protein-coding genes account for less than $2 \%$ of the 3.2 billion base pairs constituting the human genome and we now know that the majority of the genome sequences can be transcribed to RNA $(1,141)$. Consequently, mammalian cells contain a very large number of RNA molecules without coding potential (Fig. 2) that are emerging as important regulators of many physiological and pathological processes, including diabetes development (37, 224). These recently discovered non-coding RNAs (ncRNAs) are categorized according to their length and physico-chemical properties (Fig. 3). Small ncRNAs are shorter than 200 nucleotides

and include RNAs with regulatory functions such as microRNAs (miRNAs), Piwi-associated RNAs (piRNAs), small nucleolar RNAs (snoRNAs) and tRNA-derived fragments (tRFs). Long 
non-coding RNAs (lncRNAs) are longer than 200 nucleotides and constitute a heterogeneous class of transcripts. Until recently, the mammalian transcriptome was thought to be formed almost exclusively by linear transcripts. However, in depth analysis of high throughput sequencing data combined with ad hoc computational approaches highlighted the presence of thousands of circular RNAs (circRNAs) originating from both exons and introns of protein-coding genes $(114,160,170)$. Since most circRNAs are longer than 200 nucleotides, they are sometimes considered as a subgroup of lncRNAs. Contrary to miRNAs, the function and mode of action of piRNAs, snoRNAs, tRFs, lncRNAs and circRNAs are just starting to be uncovered, but there is already evidence for their involvement in several human diseases, including diabetes (28, 40, 160, 233, 292). Other classes of ncRNAs will most probably emerge in the coming years, completing the broad picture of this RNA family. For example, enhancer RNAs (eRNAs) that were initially thought to be the result of transcriptional noise were recently shown to have enhancer function $(183,335)$. The role of this particular ncRNA family in islet physiology remains however to be investigated.

The aim of this review will be to provide a comprehensive and updated picture of the role of miRNAs, piRNAs, snoRNAs, tRFs, lncRNAs and circRNAs in the control of islet function and in the development of diabetes mellitus. The major challenge of this comprehensive review was to discuss the contribution of many classes of ncRNAs in a variety of islet functions since each ncRNA class is involved in many aspects of islet biology, and most physiological or pathological conditions are affected by several types of ncRNAs. Since part of the readers will be mainly concerned by selected classes of ncRNAs while others will focus on specific physiological or pathological conditions, we will first discuss the general involvement of each class of ncRNAs in islet biology. The following sections will then describe in more detail the role of ncRNAs in specific physiological or pathological conditions. Finally, the last two sections will briefly summarize the literature on extracellular ncRNAs and the therapeutic potential of ncRNAs for diabetes treatment and will discuss the obstacles that need to be overcome before considering their introduction in the clinic.

\section{Identification and function of non-coding RNAs in pancreatic islets under physiological conditions}

miRNAs

miRNAs are small RNA molecules of 21-23 nucleotides that regulate post-transcriptional gene expression by binding to the 3' untranslated regions (UTR) of target messenger RNAs (21). These 
small ncRNAs are produced from 70 nucleotide-long RNA transcripts forming a hairpin structure that is successively cleaved by the endonucleases Drosha and Dicer to yield a 21-23 nucleotide double-stranded RNA. Once separated, one of the strands (guide strand) binds to an Argonaute (Ago) protein and is uploaded into the RNA-induced silencing complex (RISC), permitting the recognition of complementary sites within the 3'UTRs of target mRNAs (21). This class of ncRNAs has been initially discovered in Caenorhabditis elegans in 1993 (178, 332) but has now been extensively studied also in vertebrates and plants $(10,22)$. Thousands of miRNAs have been identified in mammals and collectively regulate the expression of up to $60 \%$ of the human transcripts. In fact, each miRNA can silence the expression of hundreds of genes and every transcript can be regulated by several miRNAs $(83,284)$. Therefore, miRNAs are involved in the regulation of most cellular pathways and their dysregulation has been observed in several diseases, including diabetes.

The importance of the miRNA network in islet physiology has been demonstrated by genetic modification of Dicer1 and Ago2 in different mouse models. Downregulation of Dicer1 impaired pancreas development and $\beta$-cell maturation and function (see Section titled "Pancreatic islet development and $\beta$-cell differentiation”) $(137,140,197,203,214)$ while specific knockdown of Ago2 under the control of the insulin promoter decreased the $\beta$-cell mass but favored insulin release and improved glucose tolerance (306). Opposite results were obtained in mice overexpressing Ago2 in $\beta$-cells (306). Since the first report in 2004 (254), a large number of miRNAs have been reported to be involved in the regulation of $\beta$-cell functions. Several high quality and exhaustive reviews have already been published on this topic $(72,78,99,169)$ and include a detailed list of the different models used to investigate the function of theses miRNAs in the context of islet physiology. Herein, we will focus exclusively on miRNAs for which a role in mature $\beta$ - or $\alpha$-cells has been confirmed in vivo, in human islets and/or by several research group and the next sections will cover the role of miRNAs in different aspects of islet physiology and pathophysiology.

Involvement of specific miRNAs in the control of $\beta$-cell functions $\operatorname{miR}-375$

Poy et al. were the first to establish a role for miR-375, one of the most abundant and islet-enriched miRNAs, in the regulation of $\beta$-cell function. Silencing of mir-375 increases glucose-stimulated 
insulin secretion in pancreatic $\beta$-cell lines and isolated mouse $\beta$-cells (254). Two independent studies identified myotrophin (MTPN) and PDK1, a key component of the PI3K signaling pathway whose reduction leads to a drop in insulin gene transcription, as direct targets of miR-375. Both, MTPN and PDK1 mRNA and protein levels are strikingly reduced upon miR-375 overexpression in insulin-secreting cell lines $(65,254)$. A follow up study showed that at 8 and 12 -weeks of age, mice lacking mir-375 (375KO) display fed and fasting hyperglycemia, respectively (255). Insulin sensitivity and plasma insulin levels were unaffected in these animals and measurements performed on isolated islets revealed that the hyperglycemia observed in $375 \mathrm{KO}$ mice is not due to defective insulin secretion but rather to elevated glucagon secretion and plasma glucagon levels in both fasted and random-fed states. Morphological analysis of the islets of $375 \mathrm{KO}$ mice revealed a $31 \%$ decrease in the $\beta$-cell mass and an increased proportion of $\alpha$-cells. These results indicate that $375 \mathrm{KO}$ mice hyperglycemia is primarily caused by hyperglucagonemia resulting from the expansion of the $\alpha$-cell mass (255) (see Section title "Involvement of miRNAs in the control of $\alpha$-cell functions"). Finally, miR-375 was also found to be important for proper pancreas development (see Section titled “Pancreatic islet development”).

$\operatorname{miR}-7$

miR-7 family members are highly conserved throughout evolution and are abundantly expressed in pancreatic islet cells. Two independent studies revealed that miR-7 is a negative regulator of insulin secretion in $\beta$-cells $(172,340)$. Latreille et al. reported that conditional inactivation of mir$7 a-2$ in $\beta$-cells results in an increase in insulin exocytosis and in improved glucose tolerance (172). Indeed, miR-7 was found to directly bind to the 3'UTR of mRNAs coding for central regulators of vesicle fusion (Snca, Cspa, and Cplx1), cytoskeleton rearrangement (Pfn2, Wipf2) and membrane targeting (Zdhhc9). Accordingly, mRNA and protein levels of these secretory components were reduced in $\beta$-cells overexpressing miR-7a $(158,172)$. Transgenic mice overexpressing mir-7a-2 selectively in $\beta$-cells (Tg7a2) developed diabetes due to impaired insulin secretion and $\beta$-cell dedifferentiation (172). These animals exhibited marked hyperglycemia, reduced plasma insulin levels, and impaired insulin secretion, while the $\alpha / \beta$-cell ratio was unchanged. The expression of Ins1 and Ins2 as well as of $P d x 1, N k x 6-1, M a f a, P a x 6$, and Neurod1, a group of transcription factors promoting $\beta$-cell differentiation and identity, were reduced in islets of adult Tg7a2 mice. Pax6 and Gata6 were identified as direct targets of miR-7. Interestingly, a reduction of about $80 \%$ of miR- 
7a selectively in $\beta$-cells, resulted in improved glucose tolerance due to increased insulin release (172). As discussed in the next Sections, miR-7 expression was found to regulate the development and differentiation of pancreatic endocrine cells and the expansion of the $\beta$-cell mass, and to be modulated in islets of diabetic animal models and human donors.

miR-204

$\mathrm{Xu}$ et al. demonstrated that TXNIP, a sensor of glucose and oxidative stress, induces miR-204 expression by repressing signal transducer and activator of transcription 3 (STAT3) (339). Moreover, miR-204 was found to inhibit insulin promoter activity and to reduce insulin mRNA levels by targeting the transcription factor MafA. Successive studies performed by the same group demonstrated that miR-204 regulates ER stress and $\beta$-cell apoptosis by targeting PERK (338).

Glucagon-like peptide 1 receptor (GLP1R) agonists are widely used for the treatment of diabetic patients in order to potentiate insulin secretion induced by elevated glucose concentrations. However, the efficiency of these compounds is dependent of the expression of GLP1R which is reduced in diabetic patients. Interestingly, GLP1R was identified as a direct target miR-204 and the levels of this miRNA were found to be increased in the islets of different mouse models of obesity and/or diabetes (339), but not in the islets of T2D human donors (138). Whole body deletion of mir-204 in mice (miR-204-KO) resulted in increased expression of islet GLP1R, improved glucose tolerance and augmented insulin secretion in response to a combination of high glucose and the GLP1R agonist Exendin-4 (132). Moreover, miR-204-KO mice were protected against diabetes development induced by multiple injections of low doses of streptozotocin (see also Section title “Type 1 Diabetes”). Since TXNIP was previously identified as a regulator of miR-204 expression, the authors verified that $\beta$-cell specific deletion of Txnip led to reduce levels of miR204 with a concomitant increase of GLP1R and enhanced insulin release in response to glucose combined to Exendin-4. Taken together, these results suggest a link between TXNIP, miR-204 and incretin action on $\beta$-cell function.

miR-17-92/miR-106b-25 cluster

$\mathrm{Lu}$ et al. observed increased expression of miR-17 in MIN-6 cells treated with elevated glucose concentrations which led to direct inhibition of Menin, a well-established negative regulator of $\beta$ cell proliferation (195). These data are in agreement with the reported positive impact of miR-17 
in the expansion of the $\beta$-cell mass occurring during the neonatal period (124). Recently, Mandelbaum et al. confirmed these data in vivo using a conditional mouse model in which the miR17-92/miR-106b-25 cluster was deleted (202). These mice displayed a reduced $\beta$-cell mass and up to $50 \%$ reduction in total pancreatic insulin content. Detailed investigations revealed that the miR17-92/miR-106b-25 cluster does not regulate G1/S transition or G2/M checkpoint but is rather involved in the $\mathrm{M}$ phase. Along with reduced $\beta$-cell mass, miR-17-92/miR-106b-25-KO mice displayed defective insulin release in vivo and ex vivo in isolated islets (202). The positive impact of miR-17-92/miR-106b-25 clusters on $\beta$-cell proliferation seems to be maintained throughout different maturation cell stages, from immature newborn $\beta$-cells to adult $\beta$-cells $(124,202)$. In contrast, while inhibition of miR-17-92/miR-106b-25 in isolated islets of newborn rats promoted the acquisition of $\beta$-cell capacity to release insulin in response to glucose, blockade of these miRNAs in adult mice restrained insulin secretion through the regulation of a yet unknown metabolic process upstream to cell membrane depolarization (202). miR-17 can also promote $\beta$ cell survival under inflammatory conditions. As described above, TXNIP is an important regulator of cellular redox state and its deletion in mice prevents $\beta$-cell apoptosis and diabetes appearance. miR-17 has been shown to target Txnip mRNA (180) and miR-17 overexpression was able to blunt cytokine-induced TXNIP activation in $\beta$-cells (115). Of note, the pro-inflammatory cytokines IL$1 \beta$ and IFN $\gamma$ display opposite effects in the regulation of TXNIP, since IL- $1 \beta$ prevents Txnip expression by inhibiting ChREBP-mediated transactivation, while IFN $\gamma$ increases Txnip expression via activation of IRE $\alpha$. In another cell model, IRE $\alpha$ was found to rapidly diminish miR-17 stability (315), suggesting a regulatory loop between miR-17 and TXNIP expression that could be of importance in the prevention of cytokine-induced $\beta$-cell death and diabetes susceptibility.

\section{miR-200 family}

The miR-200 family is highly expressed in pancreatic endocrine cells and includes five evolutionarily conserved members: miR-200a, miR-200b, miR-200c, miR-141 and miR-429. Except for miR-429, the other four members of the family are induced by TXNIP and are upregulated in islets of B6-obese mice compared to lean controls (79). Transgenic mice expressing mir-141/200c under the control of the rat insulin promoter develop severe hyperglycemia, which over time results in uncontrolled diabetes due to a drastic decrease in plasma insulin levels, pancreatic insulin content and $\beta$-cell mass (24). Glucose-stimulated insulin secretion was unaltered 
in isolated islets of the mir-141/200c transgenic mice and in $\beta$-cell lines after overexpression of miR-200c. However, the mice expressing mir-141/200c displayed a 6-fold-increase of $\beta$-cell apoptosis. The pro-apoptotic activities were attributed to a direct repression of the pro-survival factors Dnajc3, Jazf1, Rps6kb1 and Xiap (24). Further investigations unveiled that overexpression of miR-200c modulates the activity of the Trp53 pathway and results in the up-regulation of proapoptotic transcripts Bax and Bbc3 (encoding PUMA) $(24,79)$. These two genes are associated with a greater $\beta$-cell apoptosis and diabetes development (52, 212). To address whether Trp53 inhibition can rescue miR-200c-induced $\beta$-cell death and diabetes, Belgardt et al. generated $\beta$-cellspecific double transgenic mice, which overexpress Trp53-inhibiting SV40 T antigen and mir141/200c. These mice were protected against $\beta$-cell loss and did not develop T2D associated with mir-141/200c transgenic mice (24). Despite the double transgenic mice showed no hyperglycemia and a similar rate of $\beta$-cell death compared to control mice, the striking glucose intolerance of Rip141/200c mice was not completely rescued following Trp53 inhibition, suggesting the contribution of additional miR-200c-associated pro-apoptotic mechanisms independent of Trp53 pathway $(24,79)$.

$\operatorname{miR}-184$

MiR-184 expression is reduced in islets of insulin resistant animals and is further dropped in islets of diabetic animal models (see Sections titled “ $\beta$-cell mass expansion during obesity and gestation” and “Type 2 Diabetes”) (231, 306). MiR-184 appeared to act as a negative regulator of $\beta$-cell proliferation and survival, without impacting on insulin release (231). Tattikota et al. further characterized the function of miR-184 in vivo. Mice invalidated for mir-184 displayed an increased $\beta$-cell mass consequent to exacerbated $\beta$-cell proliferation, reduced fasting blood glucose levels and elevated plasma insulin concentrations, resulting in improved glucose tolerance without affecting insulin sensitivity (306). The glutamate transporter Slc25a22 identified as a direct target of miR-184 is likely to play a major role in the effect of this miRNA on mitochondrial respiration and insulin secretion (223, 305). MiR-184 levels were also inversely correlated with Ago2, an essential component of the RISC complex, in the islets of human donors (306). miR-708

This miRNA is transcribed from the first intron of the Chop-regulated gene Odz4 (264). Interestingly, the expression of miR-708, Odz4, and Chop is increased in islets cultured at low 
glucose concentrations, suggesting a common mechanism of regulation between the miRNA and its hosting gene. The islets of mir-708-overexpressing mice displayed reduced insulin secretion, and decreased $\beta$-cell proliferation and survival. The effects of this miRNA were suggested to be driven by silencing Nnat, which codes for a protein localized in the ER and known to regulate intracellular $\mathrm{Ca}^{2+}$ levels and insulin release. Indeed, the expression of miR-708 was negatively correlated to that of Nnat in cultured islets as well as in islets of obese $o b / o b$ mice. These results suggest a contribution of miR-708 in the altered secretory capacities of $\beta$-cells associated with the development of diabetes in ob/ob mice (264).

\section{Let-7 family}

The RNA-binding protein LIN28 can directly repress let-7 family members, which include nine slightly different miRNAs (232). Interestingly, global LIN28a overexpression in mice results in altered body size and increased glucose metabolism and insulin sensitivity (356). Pancreas-specific induction of let-7 in transgenic mice under the control of the $P d x 1$ promoter, confirmed that let-7 overexpression reduces insulin secretion and results in impaired glucose tolerance (84). To test whether inhibition of let-7 was sufficient to prevent diet-induced glucose intolerance, C57BL/6 mice fed a high-fat diet received weekly for 8 consecutive weeks a systemic injection of let-7 antimiR. In contrast to control mice, antimiR-treated mice maintained a normal glucose tolerance. Nonetheless, the positive impact of antimiR-induced knockdown of let-7 on glucose metabolism is most likely due to increased insulin sensitivity rather than improved $\beta$-cell function. Indeed, systemic inhibition of let-7 resulted in enhanced insulin sensitivity, likely by restoring insulin receptor signaling pathway in muscles and liver $(84,357)$. Of interest, let-7 targets several genes containing SNPs associated with T2D and the control of fasting glucose in human genome-wide association studies (GWAS) (357). Therefore, Lin28/let-7 signaling may be a central regulator of glucose metabolism. However, further investigations in animal models with $\beta$-cell specific let-7 invalidation are necessary to precisely define the contribution of insulin-secreting cells to the beneficial impact of let-7 silencing.

$\operatorname{miR}-132$

This miRNA is produced from the miR-212/132 cluster located on mouse chromosome 11. Both miR-132 and miR-212 were reported by different groups to be upregulated in pancreatic islets of 
obese and/or diabetic rodent models $(69,228,231,351)$ but not in islets from T2D human donors (27). The increased expression of miR-132 was also observed in mouse islets following partial pancreatectomy (229). Overexpression of miR-132 in rodent $\beta$-cells in vitro and in vivo promoted insulin secretion in response to glucose and other secretagogues, as well as increased $\beta$-cell proliferation and survival (228, 229, 231, 298) (also discussed in the Section titled " $\beta$-cell mass expansion during obesity and gestation”). Interestingly, overexpression of miR-212 was also found to favor insulin release in INS 832/13 cells (298). Mice with whole body knockout of mir-132/212 showed normal glucose tolerance, but their $\beta$-cells displayed a limited capacity to increase their proliferative rate upon pancreatectomy, supporting a role for miR-132 in $\beta$-cell regeneration (229). Mechanistically, the positive impact of miR-132 on insulin secretion was suggested to be mediated by direct down-regulation of carnitine acylcarnitine translocase (CACT), a mitochondrial protein involved in $\beta$-oxidation (298). In contrast, the proliferative effect was attributed to the repression of Pten, a negative regulator of $\beta$-cell mass expansion (229). As discussed in the next Section, miR132 regulates also the proliferation and survival of $\alpha$-cells.

\section{Involvement of miRNAs in the control of $\alpha$-cell functions}

Pancreatic islets are intricate cell aggregates comprising $\alpha$ - and $\beta$-cells as main endocrine cell types, which secrete the counter-regulatory hormones glucagon and insulin in response to low or high levels of glucose, respectively. Similar to insulin, glucagon production and exocytosis is tightly regulated by multiple factors, including neuronal, paracrine, and cell autonomous signaling pathways (7). Diabetes is now established as a bi-hormonal disease rather than an "insulin-centric disorder," emphasizing the critical role of glucagon in the regulation of glucose homeostasis (7, 314). MiRNAs are likely to be important players in the regulation of $\alpha$-cell functions and glucagon release, but this issue remains largely unexplored (72). Drastic reduction of the $\alpha$-cell number upon inactivation of the miRNA-processing enzyme Dicer1 in the developing mouse pancreas (197), emphasizes the need to unveil miRNA expression patterns and to define their roles in glucagonsecreting-cells.

A miRNA profiling performed in human FACS-sorted $\alpha$ - and $\beta$-cells identified 7 miRNAs (miR-146a, miR-181a, miR-192-3p/-5p, miR-194-5p, miR-221 and miR-708) enriched by more than 2-fold in $\alpha$-cells versus 141 miRNAs more abundant in $\beta$-cells (151). Of the seven miRNAs identified in human $\alpha$-cells, only miR-146a was confirmed to by enriched also in mouse FACS- 
sorted $\alpha$-cells and in TC1-6 $\alpha$-cell line (19, 62). In FACS-sorted mouse islet cells, 35 miRNAs displayed 2-fold higher levels in $\alpha$-cells and 31 in $\beta$-cells (62) whereas 50 miRNAs were enriched in $\alpha \mathrm{TC} 1-6$ cells compared to 74 miRNAs in the $\beta \mathrm{TC1}$ cell line (19). Despite these discrepancies, these studies highlighted differences in the expression of several miRNAs, which could be important for proper function of $\alpha$ - and $\beta$-cells. For example, miR-483 is greatly enriched in mouse FACS-sorted $\beta$-cells and TC3 $\beta$-cells compared to $\alpha$-cells (219). Interestingly, overexpression of miR-483 in MIN6 cells favored insulin secretion, while this miRNA repressed glucagon transcription and secretion in TC1-6 $\alpha$ cells by modulating IRS2 and SOCS3 expression at the protein level. More precisely, miR-483 favored IRS2 levels but suppressed SOCS3 in both cell lines (219). IRS2 is known to favor insulin secretion but to reduce glucagon secretion (12), while silencing of Socs3 positively correlates with insulin transcription and secretion in MIN6 $\beta$-cells (184) and inhibits glucagon secretion and transcription in TC1-6 $\alpha$-cells (219). Therefore, these data suggest that miR-483 counter-regulates both insulin and glucagon release by modulating the activity of IRS2 and SOCS3 proteins. Another example is cMaf, a transcription factor expressed selectively in $\alpha$-cells and controlling glucagon expression. This transcription factor is regulated by miR-200c, miR-182 and miR-125b which are enriched in $\beta$-cells, enabling cMaf repression. Indeed, downregulation of each of these miRNAs resulted in increased cMaf expression in MIN6 $\beta$-cells while their overexpression in a TC6 $\alpha$-cells led to reduced cMaf mRNA and protein levels (151).

MiR-155 was also identified as a key player in co-regulating $\alpha$ - and $\beta$-cell physiology to improve the adaptive response of islet cells to insulin resistance (358). Invalidation of mir-155-5p in mutant mice lacking the LDL receptor favored the development of atherosclerosis, obesity and diabetes when the mice were fed on a cholesterol-rich diet. Moreover, these mice displayed reduced plasma insulin levels and pancreatic insulin content, and elevated plasma glucagon levels and pancreatic glucagon staining compared to mice fed on control diet. In vitro, overexpression of miR$155-5 p$ in human and murine islets, and in $\alpha$ - and $\beta$-cell lines promoted multiple changes in the level of key genes involved in insulin, glucagon and GLP-1 production and secretion. Moreover, increased levels of miR-155-5p in human islet cells and in MIN6 cells led to the up-regulation of IL-6 through direct regulation of the transcription factor MAFB. These results suggest that miR155-5p stimulates the expression and secretion of IL-6 in $\beta$-cells, which in turn promotes GLP-1 production from $\alpha$-cells (358). To better understand the regulation of glucagon secretion by 
miRNAs, Zhang et al. (348) quantified the level of these small RNAs in islets of 12h-fasted, glucagonemic C57BL/6J mice. Using this approach, they found that the expression of miR-124a3p was strongly reduced while the level of its targets, the ionotropic glutamate receptors, iGluR2 and iGluR3, which are located on $\alpha$-cells (45), were elevated. Interestingly, similar results were obtained in vitro when mouse islets were exposed to $25 \mathrm{mM}$ glucose for $72 \mathrm{~h}$, a condition known to enhance glucagon secretion (348).

Besides glucagon secretion, miRNAs are also important regulators of $\alpha$-cell proliferation. As mentioned in the previous Section, downregulation of miR-375 promotes $\alpha$-cell mass expansion and, consequently, results in enhanced fasting and fed plasma glucagon levels, increased gluconeogenesis and exacerbated hyperglycemia (255). Interestingly, treatment with liraglutide, a GLP1 receptor agonist commonly used in the treatment of T2D patients, raised miR-375 levels in TC1-6 $\alpha$-cells and reduced those of TC-tet $\beta$-cells (341). Moreover, exposure to liraglutide impaired TC1-6 $\alpha$-cell proliferation and survival, and, on the contrary, favored the proliferation and survival of TC-tet $\beta$-cells. These results are in line with previous reports indicating that liraglutide promotes $\beta$-cell functions and insulin release while repressing $\alpha$-cell activities and preventing excessive glucagon release (90). According to the finding described above, part of these effects could be mediated by miR-375.

To obtain a broader view on miRNA deregulation in islet cells under pre-diabetic condition, Dusaulcy et al. performed microarray analyses on FACS-separated $\alpha$-versus $\beta$-cells from mice fed on a low fat diet (LFD) or high fat diet (HFD) (62). More than hundred miRNAs were found to be differently expressed between $\alpha$ - and $\beta$-cells in both diet conditions. In the $\alpha$-cell fraction, HFD induced the dysregulation of 16 miRNAs, of which 14 were downregulated and 2 upregulated. Interestingly, 8 of the 14 decreased miRNAs were located in a common genomic Meg3/DLK1 cluster. The authors focused on miR-132, a miRNA previously identified to be upregulated in islets of obese and/or diabetic animals $(231,351$ ) (see Section title " $\beta$-cell mass expansion during obesity and gestation”). The observed rise of miR-132 in $\beta$-cells in response to HFD was confirmed, but the miRNA was found to be downregulated in $\alpha$-cells (62). As was the case for $\beta$-cells (200, 231, 285), the expression of miR-132 in primary mouse $\alpha$-cells was shown to be modulated by cAMP and to favor proliferation and survival, without affecting glucagon secretion (62). In contrast, inhibition of miR-132 reduced $\alpha$-cell proliferation and increased apoptosis. Therefore, reduced expression of miR-132 in glucagon-secreting cells of HFD mice is likely to restrain $\alpha$-cell 
proliferation and to promote apoptosis. This effect is important to balance the mass of $\alpha$ - and $\beta$ cells in a pre-diabetes context in order to maintain glucose homeostasis. Indeed, a rise in miR-132 levels contributes to compensatory $\beta$-cell mass expansion and to the increase in insulin secretion under insulin resistant conditions $(228,231)$.

Investigating the role of miRNAs in $\beta$ - and $\alpha$-cells in parallel may provide precious information about the fine tuning of the two main cell types of pancreatic islets that are highly interdependent and release counter regulatory hormones. Henceforth, several miRNAs seem to have opposite effects on $\alpha$ - and $\beta$-cells in order to optimize the metabolic control.

\section{piRNAs}

P-element induced Wimpy testis (PIWI)-interacting RNAs (piRNAs) are 21-35 nucleotide long RNAs that constitute a distinct class of small ncRNAs. The biosynthesis and function of piRNAs are dependent on their interaction with Argonaute proteins of the PIWI subfamily. piRNAs carry 2'-O-methyl-modified 3' termini, and are processed from single-stranded precursor transcripts (242). In animals, piRNAs are predominantly expressed in the germ line. Two populations of piRNA clusters have been described in mammalian testis. The first cluster is transcribed embryonically. These fetal piRNAs bind and guide PIWI proteins to silence transposable elements and thereby protect the integrity of the genome (242). The second cluster is expressed postnatally in spermatogenic cells undergoing the first meiotic division at a substage called pachytene (86). These pachytene piRNAs lack transposon sequences. While a consensus function of pachytene piRNAs is lacking, they are shown to facilitate the progression of meiotic division by regulating gene expression via mechanisms reminiscent of somatic miRNAs (95).

piRNAs and pancreatic islets

A growing body of literature describes piRNA expression and function in somatic tissues, with mammalian studies focusing mainly on cancer development (201, 233, 268). Analyses carried out by Henaoui et al. illustrated that components of the piRNA pathway are also expressed in pancreatic islets (113). Indeed, two PIWI-like genes, Piwil2 and Piwil4 were detected in rat pancreatic islets and in FACS-sorted $\beta$-cells and their orthologues PIWIL2 and PIWIL4 were detected in human islets. The expression of these genes was much lower than in testis but was comparable to other somatic tissues such as adipose tissue, brain, liver and skeletal muscle. In 
addition to the two piwi genes, several genes involved in piRNA biogenesis such as Henmt1, Mael, Ddx4, Pld6 and Prmt5 were identified in rat islets. Moreover, piRNA-specific microarray analyses of rat islets revealed the presence of 18'450 of the 40’000 analyzed piRNAs (113) (summarized in Table 1). Taken together, these findings suggest that the PIWI/piRNA pathway is active in pancreatic islets of rats and possibly humans.

\section{SnoRNAs}

Small nucleolar RNAs (snoRNAs) form ribonucleoprotein complexes and are classified into two subfamilies, the C/D-box (SNORㅁ) or H/ACA-box (SNORA), depending on their nucleotide motifs and their protein partners. Their canonical function is to guide post-transcriptional modifications on ribosomal RNAs (rRNAs) and small nuclear RNAs (snRNAs). These non-coding RNAs are therefore mainly present in nucleoli but some snoRNAs have recently been found in other cellular compartments in association with non-canonical protein partners. Additional functions have been suggested for snoRNAs, including regulation of mRNA abundance, alternative splicing, translational efficiency and tRNA methylation (reviewed in (28)). Furthermore, snoRNAderived RNAs (sdRNAs) were detected by advanced RNAseq technologies suggesting that some snoRNAs may act after being processed into stable shorter RNA species (28).

snoRNAs and pancreatic islets

The non-canonical roles of snoRNAs in pancreatic islets are just starting to be unveiled (see Table 1). Lee et al. investigated the impact on glucose and insulin homeostasis of the deletion of 4 box C/D snoRNAs (U32a, U33, U34 and U35a) produced from introns of the protein-coding gene Rpl13a, without affecting RPL13a at both mRNA and protein levels (177). Homozygous Rpl13a snoRNA loss-of-function (Rpl13a-snoless) mice had similar body weight, fasting plasma glucose and insulin levels, and insulin sensitivity compared to control mice. Interestingly, Rpl13a-snoless mice showed increased insulin release in response to glucose both in vivo and ex vivo, leading to enhanced glucose tolerance. As previously observed in another cell model (217), Rpl13a-snoless islets were resistant to oxidative stress. Consequently, Rpl13a-snoless mice were protected against the development of hyperglycemia following a streptozotocin treatment or after crossing them with diabetic Akita and non-obese diabetic (NOD) mice (177).

While comparing the impact of Snord116 loss-of-function in mice with clinical symptoms analogous to Prader-Willi syndrome (PWS) patients, Burnett and colleagues observed an effect on 
islet-cell development (see Section titled "Pancreatic islet development and $\beta$-cell differentiation") (30) and proinsulin processing (31). PWS is caused by a loss of paternally expressed genes in an imprinted region of chromosome 15q and leads to hyperphagic obesity, central hypogonadism, growth hormone deficiency, hyperghrelinemia and relative hypoinsulinemia (11). Deletion of only the paternal allele of Snord116 in mice (Snord116 $6^{\mathrm{p}-/ \mathrm{m}+}$ ), reproduced most of the features of the phenotype observed in PWS patient (31). Interestingly, Snord116 $6^{\mathrm{p}-\mathrm{m}+}$ mice were normoglycemic

but, as observed in PWS patients, they secreted a higher ratio of proinsulin/C-peptide in response to glucose. This increase may be caused by a defect in insulin maturation since the expression of both PC1 and PC2, two enzymes required to process proinsulin into insulin and C-peptide, were downregulated in Snord116 $6^{\mathrm{p}-\mathrm{m}+}$ islets (31).

\section{tRNA-derived fragments}

Transfer RNAs (tRNAs) are non-coding RNAs that help decode messenger RNA (mRNA) sequences into proteins. They function as carriers and adapters of amino acids between mRNAs and newly synthesized polypeptides. In most cells, approximately $12 \%$ of total RNA is comprised of tRNAs (243). There are over 260 different tRNAs in humans encoded by more than 400 genes. The average mammalian cytoplasmic tRNAs contain 13-14 modifications per tRNA, with methylation being one of the most commons (310). tRNA-modifying enzymes are present in the nucleus, cytosol or mitochondria, and modulate the function, folding and/or stability of the tRNA. tRNAs are the most stable RNAs in vivo, but hypomodified tRNAs are targeted for degradation (198). In addition to elimination of dysfunctional tRNAs by degradation, these ncRNAs may also undergo fragmentation induced by endonucleases (302). These tRNA fragments (tRFs) are evolutionarily conserved and subcategorized based on the region of the tRNAs they stem from. The most common types of tRFs are generated from the cleavage at either arms (12-20 nucleotide tRFs) or at the anticodon loop (32-50 nucleotide tRFs, also known as tiRNAs). Moreover, a double cleavage along the length of tRNAs generates internal tRNA fragments (16 nucleotides or longer, also known as i-tRFs). The generation of shorter tRFs is mediated by various endonucleases including Dicer, while generation of tiRNAs are mediated by Angiogenin (163) (Fig. 4).

In recent years, in depth analyses of sequencing data, unveiled regulatory roles of tRFs in several cellular processes both in vitro and in vivo. So far tRFs have been shown to be implicated in stress responses and cancer (94, 302), cell-to-cell signaling via extracellular vesicles (43, 47, 
107, 286), the response to viral infection (120), brain aging (142), and metabolic diseases (40, 50). The function of tRFs are diverse and may depend on the cell type, the condition, and the tRF subtype. The reported functions include the control of mRNA stability $(94,164)$, the regulation of translation and ribosome biogenesis through binding to ribosomal proteins and eIF4G/eIF4A (121, 149), the protection of apoptosis through binding to cytochrome c $(41,273)$, and epigenetic regulations exerted by inhibiting the reverse transcription of endogenous retroviruses (280).

\section{tRFs and pancreatic islets}

Initial evidence potentially bridging tRFs to diabetes were obtained in sperm (40). In mice, HFD was shown to change the landscape of tRFs in sperm. Injection of tRFs isolated from HFD sperm into control zygotes altered the embryonic and islet transcriptome of the $F_{1}$ offspring and predisposed these animals to glucose intolerance and insulin resistance. Using computational target predictions, the sperm tRFs differentially expressed in mice kept on HFD were predicted to match

promoter regions of 62 impacted genes in early embryos. Among these were Maea, Ccnc, and Deptor, which have been reported to be involved in pancreatic $\beta$-cell function or to be associated with diabetic conditions $(46,57,130)$. These results highlighted the potential impact of tRFs on pancreatic $\beta$-cell function.

The role and the mechanisms of action of tRFs in the control of $\beta$-cell function under normal or pathophysiological conditions remains to be fully elucidated (summarized in Table 1). Highthroughput and unbiased analyses also need to be performed to measure their abundance in different rodent models and in human islets. However, as described in the Section titled "Type 2 Diabetes”, there is now emerging evidence indicating that this newly described class of ncRNAs contributes to the regulation of the activities of insulin-secreting cells.

\section{Long non-coding RNAs}

LncRNAs include all linear transcripts of more than 200 nucleotides having no, or very low, protein-coding potential (252). This heterogeneous class of RNAs shares several characteristics with protein-coding mRNAs: they are transcribed by RNA polymerase II, they are capped, spliced and, in some case, polyadenylated, and their expression can be modulated by histone modifications $(105,106)$. They are mainly located in the nucleus but can also be found in the cytoplasm. LncRNAs are often classified based on their genomic proximity to protein-coding genes, for 
example overlapping, intronic, cis-antisense or bidirectional (216) (Fig. 5). In contrast, long intergenic non-coding RNA (lincRNA) do not have relationship and do not share open reading frames with protein-coding genes. However, because of the vast heterogeneity of this class of RNA transcripts, a consensus on their nomenclature and classification is still missing (299).

Interestingly, compared to protein-coding RNAs and miRNAs, lncRNA expression is more tissue and developmental stage specific, suggesting that these transcripts may be involved in the fine-tuning of specialized cellular functions $(56,58)$. These ncRNAs can exert their regulatory activities at different levels in view of their capacity to bind other RNAs, DNA and/or proteins and to act as signals, guides, decoys and/or scaffolds (296) (Fig. 6). For example, lncRNAs can regulate chromatin organization and epigenetic modifications, modulate gene transcription or control mRNA processing by facilitating trans-chromosomal interactions, by recruiting epigenetic modifiers, by blocking the transcription factors access to gene promoters or by bringing in close proximity genes involved in similar biological pathways (108, 148, 205). LncRNAs can also increase mRNA stability, promote mRNA degradation, regulate mRNA translation and splicing $(33,74,93,311)$ or act as miRNA sponges $(38,251)$. LncRNAs can therefore be implicated in a wide variety of cellular mechanisms, and dysregulation in their expression has been associated with several diseases, including diabetes (70, 139, 227, 257, 292, 333). Finally, in addition to their noncoding regulatory activities, some lncRNAs were found in different organisms to produce functional micropeptides, adding another layer of complexity to the role of these RNA molecules (182). However, none of these micropeptides have so far been reported in pancreatic islets.

De novo annotation of IncRNAs specifically expressed in islets and $\beta$-cells

The advent of ultra-deep RNA sequencing enabled the identification of islet- and $\beta$-cell specific lncRNA transcripts since these ncRNAs are generally expressed at low levels $(56,58)$. LncRNAs display restricted cell distribution and are less evolutionarily conserved than protein-coding genes with $30 \%$ of the human lncRNAs being primate specific (56). Before understanding the functional role of these non-coding transcripts, deep RNA sequencing of human and rodent islet cells followed by de novo annotation were necessary to identify the lncRNAs expressed in $\beta$-cells.

Moran and colleagues integrated sequence-based transcriptome and chromatin maps from human islet and FACS-purified $\beta$-cells and observed that 19\% of the transcribed genome maps outside of annotated protein-coding genes (221). From this analysis, 1128 transcripts were selected 
as islet-cell lncRNAs since they were detected in all samples, were longer than 200 nucleotides, had low protein-coding potential, did not overlap with any coding gene, and were generated from genomic loci showing enrichment of the transcriptionally active histone H3K4me3 mark. Of these, 761 transcripts were antisense, 32 convergent, 335 were intergenic (lincRNAs) and 55 overlapping antisense. Importantly, the expression of all tested lncRNAs was confirmed in human islets by qPCR measurements and most of them were also detected in the human $\beta$-cell-line EndoC- $\beta \mathrm{H} 1$. While being expressed at lower levels compared to protein-coding genes, lncRNAs were found to be 4 to 5 times more islet-specific and some of them were actually solely detected in islet cells when a panel of 18 different tissues was analyzed (221). Similar results were also obtained upon de novo annotation of IncRNAs expressed in mouse islets and in FAC-sorted $\beta$-cells (162, 221, 226). Furthermore, intergenic and antisense islet lncRNAs were often found to be located in the same genomic region as islet-enriched protein-coding genes, like HNF1A, PDX1, PAX6, NKX2.2, $M A F B$ and FOXA2 (221).

While comparing the human and murine transcriptional landscape of FACS-purified $\beta$ cells, Benner and colleagues identified a $\beta$-cell transcriptome core of more than 9'900 proteincoding genes common between the two species (25). However, they observed marked differences between human and mouse IncRNA repertoire, confirming that also in $\beta$-cells these transcripts are more species-specific than protein-coding genes (25). As observed for human lncRNAs, some murine lncRNAs were found to be located in close vicinity of loci coding for important $\beta$-cell transcription factors, including $P d x 1$ and $N k x 6.1$. The expression of these lncRNAs and their neighboring protein-coding genes were co-enriched in $\beta$-cells over $\alpha$-cells $(25,162)$. Finally, $\beta$-cell specific lncRNAs were found to be highly dysregulated in different mouse models of diabetes and in islets exposed to elevated glucose or cytokine concentrations, suggesting that lncRNAs may be implicated in $\beta$-cell dysfunction associated with diabetes $(25,226)$ (see Sections titled "Type 1 Diabetes” and “Type 2 Diabetes”).

\section{Involvement of IncRNAs in the control of $\beta$-cell functions}

Among the thousands of lncRNAs identified in pancreatic islets, the precise role of only few of them has been so far unveiled in $\beta$-cells (see Table 1) (reviewed in (70, 139, 227, 257, 292, 333)). Here we elected to describe in detail only the role of HI-LNC15/ßlinc1, PLUTO (HI-LNC71), HI- 
LNC78 and Meg3 for which the function has been investigated in human $\beta$-cells and/or in vivo in mice.

\section{HI-LNC15/Blinc1}

The function of the human HI-LNC15 (221) and its mouse orthologue Blinc1 (13) has been investigated both in vitro and in vivo $(8,13)$. HI-LNC15 is a $6.8 \mathrm{~kb}$ human islet-specific transcript without coding potential located on chromosome 20, in a region upstream of the essential islet transcription factor $N K X 2.2$ (221). Interestingly, inhibition of HI-LNC15 in the human $\beta$-cell line EndoC- $\beta \mathrm{H} 1$ resulted in gene expression changes correlating to those observed in response of NKX2.2 knockdown, suggesting that HI-LNC15 and NKX2.2 are part of a common regulatory network (8). The sequence of HI-LNC15 is relatively well conserved in mammals and was named $\beta$ linc1 ( $\beta$-cell long intergenic noncoding RNA 1 ) in mice because of its specific expression in $\beta$ cells (13). The mouse Blincl locus spans $8 \mathrm{~kb}$ and is located on chromosome 2 in a gene desert region between $N k x 2.2$ and Pax1. Blinc1 is expressed at relatively low levels and is mainly nuclear. To investigate the functional role of $\beta$ linc1, Arnes and colleagues generated a whole-body knockout mice (13). Consistent with its islet-specific expression profile, e15.5 and neonate $\beta$ lincl-null mice displayed a $50 \%$ reduction in $\beta$-cell mass without other major changes in pancreas morphology. At adult age, Blincl-null mice showed elevated blood insulin levels under basal glucose concentration and were both glucose- and insulin-intolerant. Mechanistically, the deletion of Blincl led to a dysregulation of several genes involved in the specification of endocrine progenitors (including NeuroD1 and NeuroG3), in the maturation (including MafA, MafB, Nkx2.2, Nkx 6.2 and Pax6) and the function of the $\beta$-cells (including Ins1, Ins2, Slc2a2 and Slc30a8). To distinguish the effects due to impaired pancreas development to those linked to Blincl deletion at adult age, the phenotype of the heterozygous mice was also investigated (13). Heterogeneous $\beta$ lincl $^{+/-}$mice did not show any defect in islet development or glucose homeostasis but some genes were dysregulated in E15.5 pancreas of mice lacking one copy of Blinc1, as for Blinc1-null mice. Importantly, five of the top 10 most dysregulated genes in $\beta$ linc $1^{+/-}$mice were located in the genomic vicinity of the lncRNA, suggesting that $\beta$ linc1 may coordinate $\beta$-cell gene expression through the structural organization of the chromatin (13). 


\section{LncRNAs PLUTO (HI-LNC71) and HI-LNC78}

Akerman and colleagues investigated the implication of several lncRNAs enriched in pancreatic $\beta$ cells in the regulation of gene expression by inhibiting their level in the human EndoC- $\beta \mathrm{H} 1$ cell line (8). Among them, HI-LNC71 was found to be the most downregulated in islets of T2D or IGT donors compared to controls. This nuclear-enriched transcript is produced from a promoter located $\sim 3 \mathrm{~kb}$ upstream of PDX1 and was therefore named PLUTO for "PDX1 Locus Upstream Transcript”. Downregulation of PLUTO in primary human islets or in EndoC- $\beta \mathrm{H} 1$ cells reduced $P D X 1$ expression, which resulted from an impaired three dimensional contact between the PDX1 promoter and its enhancer cluster (8) (Fig. 6A). Moreover, inhibition of the mouse orthologue Pluto in the $\beta$-cell line MIN6 led to a decrease in $P d x 1$ expression suggesting that the mode of action of PLUTO is conserved in mammals. Functional assays in EndoC- $\beta \mathrm{H} 1$ cells showed that reduction of PLUTO expression lead to diminished insulin content and a consequent impairment in insulin secretion under stimulatory conditions (8).

In the same study, knockdown of nine other $\beta$-cell lncRNAs caused a dysregulation, by cisor trans-regulatory mechanisms, of several genes (8). For example, inhibition of HI-LNC78 and $H I-L N C 15$ resulted in gene expression changes correlating closely to the ones observed in response the knockdown of $H N F 1 A$ and $M A F B$, and $N K X 2.2$, respectively. Further analysis suggested that a group of $\beta$-specific lncRNAs and transcription factors are part of common regulatory transcriptional networks that target clusters of pancreatic islet enhancers (8). In addition, the expression of HI-LNC78 was found to be regulated by glucose in human islets (221) and downregulation of this lncRNA in EndoC- $\beta \mathrm{H} 1$ cells led to a reduction in insulin content and defective insulin release (8). Finally, HI-LNC78 orthologues were found in mouse (Tunar) and zebrafish (megamind/linc-birc6) (8).

\section{MEG3}

The lncRNA MEG3 (Maternally Expressed Gene 3) is encoded from an imprinted gene transcribed from the maternal allele that resides on human chromosome 14 and mouse chromosome 12 (218). Of interest, MEG3 gene is part of the DLK1-MEG3 locus that codes for snoRNAs, the non-coding genes MEG8 and anti-sense RLT1, the protein-coding genes DLK1, RTL1 and DIO3 and a cluster of miRNAs (138). The epigenetic and transcriptional regulation of the ubiquitously expressed lncRNA MEG3 are well-conserved between human and mouse. In humans, decreased in MEG3 
expression has been associated with several cancers (355). In mouse, Meg3 was found to be differentially expressed during embryonic development and deletion of this gene caused diverse growth and survival defects (53).

The expression and the functional role of MEG3/Meg3 were also studied in human and mouse islets. Interestingly, MEG3 was found to be downregulated in islets of T2D donors (138) and in islets of both T1D (NOD) and T2D (db/db) mouse models compared to aged-matched nondiabetic Balb/c mice $(326,343)$. However, these results will need to be reproduced using the appropriate SCID and db/+ aged-matched control mice. The exact mechanism controlling MEG3 expression remains to be uncovered. In mouse, Meg3 is enriched in islets compared to exocrine pancreas and to some other tissues and is modulated by glucose (343). In human, reduction of MEG3 expression observed in diabetic donors could not be reproduced by incubating control islets in vitro with high glucose concentration, but the decrease appeared to be related to the methylation status of the MEG3 promoter (138). MEG3 promoter methylation was also associated with the enrichment of this lncRNA in FACS-purified human $\beta$-cells versus $\alpha$-cells. More precisely, the MEG3 promoter is bivalently marked by the activating histone H3 lysine 4 trimethylation (H3K4me3) and the repressive lysine 27 trimethylation (H3K27me3) modifications in glucagonsecreting cells, while it is almost only marked by activating H3K4me3 in insulin-secreting cells (138).

To investigate the functional role of this lncRNA, a siRNA directed against Meg3 (siMeg3) was injected into the tail vein of Balb/c female mice resulting in about 50\% downregulation of Meg3 in islets (326, 343). Mice that received siMeg3 showed an impaired glucose tolerance and a reduction in serum insulin levels following an intra-peritoneal glucose tolerance test (IPGTT). In vitro, inhibition of Meg3 expression in MIN6 cells favored apoptosis, reduced Ins2 expression and impaired insulin synthesis and secretion (343). Further studies performed in MIN6 cells and/or mouse islets showed that Meg3 is mainly localized in the nucleus where it interacts with the methyltransferase EZH2 which is responsible for the trimethylation of H3K27 at Rad21, Smc3, and Sin3a promoters. These 3 transcriptional repressors were found to directly interact with MafA promotor (326). Consequently, downregulation of lncRNA Meg3 resulted in the loss of EZH2 binding and H3K27 trimethylation occupancy of Rad21, Smc3, and Sin3a promoters, leading to an increase in the levels of these transcription factors and concomitant decrease in MafA expression which negatively impact insulin synthesis and secretion (326). The islets of siMeg3 injected mice 
and of NOD and $d b / d b$ mice showed reduced levels of Meg3, elevation of Rad21, Smc3 and Sin3a expression and altered level of MAFA at both mRNA and protein levels (Fig. 6B) (326, 343). Taken together, these results suggest that the lncRNA Meg3 regulates MafA expression, and insulin production and secretion. However, since intravenous injection of a siRNA in mice cannot be directed specifically to $\beta$-cells and that downregulation of a nuclear lncRNA is very hard to achieve using siRNA, the generation of a transgenic model is required to confirm the role of Meg3 in the regulation of insulin synthesis and secretion.

\section{Circular RNAs}

Circular RNAs (circRNAs) are covalently closed RNAs initially identified in plant viroids and later in eukaryotic cells. Eukaryotic circRNAs can be produced from the sense or antisense sequences of protein-coding genes or from ncRNAs. Furthermore, one or more circRNAs isoforms composed of intronic and/or exonic sequences can be generated from a parent gene. Circular intronic RNAs derive from introns linearly spliced from pre-mRNAs and are typically circularized by 2'-5' junctions at the 5' nucleotide and a branchpoint nucleotide near the 3' end of the intron. These branched circRNAs termed lariats (circular introns with a linear 3' tail) can be debranched (i.e. linearized) and degraded, or evade debranching and lose their 3'tail, thus becoming stable circular transcripts. In contrast, circular exonic and exonic-intronic RNAs can be formed by backsplicing of pre-mRNAs, a process in which an upstream 3' splice site is joined to a downstream 5' splice site leading to the generation of circular transcripts with 3'-5' junctions (Fig. 7). The median length of circRNAs is 547 nucleotides, although some can consist of less than a hundred or up to thousands of nucleotides. CircRNAs are neither capped nor polyadenylated (in contrast to linear mRNAs) and are resistant to exoribonuclease degradation. Moreover, the lifespan of circRNAs can be longer (19-48 h) than that of some linear mRNAs (4-9 h). Once produced, circRNAs can remain in the nucleus or be exported to the cytoplasm $(114,160,170)$.

circRNAs and pancreatic islets

It is estimated that there are over 100'000 circRNAs in human cells. Some of them are conserved in other species, are present in particular cell types, and modulate mRNA transcription, splicing, and translation, thus affecting diverse cellular processes $(114,160,170)$. Likewise, human islet cells can produce between 3,441 and 10,374 distinct circRNAs, and around 500 of them are conserved in mouse islets $(145,300)$. Moreover, 36 circRNAs derived from 30 parent genes are 
more or less abundant in $\beta$-cells compared with $\alpha$-cells, and about 400 circRNAs are generated particularly in one or the other islet cell type. Of these, seven circRNAs are highly selective for $\alpha$ cells and one for $\beta$-cells. They originate from the most enriched and selectively expressed genes in each cell type, i.e. FAP, SYTL5, PTPRT, STK32B, and BVES in $\alpha$-cells, and TGFBR3 in $\beta$-cells (2, 145). However, their biological role in islet cells remains to be elucidated. Actually, the islet function of only three circRNAs has been published (summarized in Table 1). These are circAFF1, ciRS-7/Cdr1as, and circHIPK3, which originate from exonic sequences of the genes Aff1, Cdr1, and Hipk3, respectively. Modulation of their levels in the mouse $\beta$-cell line MIN6 or in rodent islet cells revealed that they contribute to the regulation of $\beta$-cell insulin secretion and/or mass (300, 340). Indeed, circAFF1 deficiency enhances cell apoptosis, although it has no effect on $\beta$-cell proliferation or glucose-stimulated insulin secretion (300). Instead, ciRS-7/Cdr1as overexpression increases insulin release in response to glucose (340), while its silencing appears to decrease glucose-induced insulin secretion. Moreover, ciRS-7/Cdrlas knockdown reduces $\beta$-cell proliferation stimulated by prolactin, although it does not affect apoptosis (300). In contrast, low levels of circHIPK3 promote apoptosis but reduce prolactin-stimulated $\beta$-cell proliferation and glucose-induced insulin release (300). CiRS-7 and circHIPK3 act as miRNA sponges, thus blocking the action of the bound miRNAs, which results in augmented levels of the corresponding miRNA target genes. CiRS-7 binds miR-7 while circHIPK3 contains binding sites for miR-29b3p, miR-30, miR-124-3p, and miR-338-3p. Sponging of these miRNAs can thus contribute to the upregulation of genes implicated in islet differentiation and in $\beta$-cell insulin secretion and mass (300, 340).

\section{The use of bioinformatic tools for analysis and target prediction of ncRNAs}

A large panel of specific bioinformatic tools have been developed to identify the different classes of ncRNAs and to predict their potential targets. These tools not only permitted to generate comprehensive lists of ncRNAs expressed in mammalian cells but have also be instrumental for the definition of their possible mode of action (summarized in Table 2).

miRNAs

miRNAs are pivotal factors in defining the specificity and sensitivity of post-transcriptional gene silencing. Thus, great efforts have been made to discover new miRNAs, to identify their targets and further characterize their functions. The conventional techniques used for the discovery of new 
miRNAs include cloning, northern blotting, microarray and in situ hybridization even when little or no genomic information is available. However, it is not possible to explore all the complexity and diversity of miRNAs empirically with biological methods. Fortunately, a variety of computational algorithms are available to identify and validate new miRNAs. Early bioinformatic methods $(165,186)$ predicted putative miRNAs in genome sequences based on structural features, like hairpin and minimal folding free energy, and sequence conservation with known miRNAs. However, these tools essentially focus on evolutionarily conserved miRNAs and have limitations for the discovery of novel miRNAs. Machine-learning algorithms have subsequently been devised to predict novel miRNAs (summarized in Table 2) (91, 117, 135, 230, 240, 241, 307, 345). Previously validated miRNAs were used to train the learning processes to discriminate between true predictions and false positives. With the advance of next-generation sequencing (NGS), other tools have been developed to predict miRNAs from NGS data (81, 82, 109, 110, 128). Once predicted, experimental techniques are used to validate the predictions. In recent years, biological and bioinformatic approaches have enabled the discovery of thousands of miRNAs that are now documented in the miRbase (157), the primary online repository of miRNA sequences and annotation. The latest miRbase (release 22) contains miRNA sequences from 271 organisms, for a total of 38'589 hairpin precursors and 48'860 mature miRNAs.

The next challenge of the miRNA field was the characterization of the biological function of the identified miRNAs. Additional and more sophisticated bioinformatic tools were therefore required. The growing understanding of miRNA properties has significantly accelerated the development of the bioinformatics tools used for miRNA-target prediction (summarized in Table 2) (3, 66, 147, 161, 168, 190). For example, the latest version of TargetScan (3) (v7) uses an improved model (the context++ model) which considers site type and 14 other features, and performs significantly better than existing models. In most cases, miRNA-target prediction algorithms were developed based on a set of canonical rules for miRNA-target interactions. However, there is substantial evidence for exceptions to these rules, including non-canonical bindings that lack obvious seed pairing and contain multiple mismatches, bulges, and wobbles, highlighting the complexity in predicting miRNA targets. To help the identification of direct miRNA targets, some biochemical approaches have been developed. The most commonly used methods are high-throughput sequencing of RNA isolated by crosslinking immunoprecipitation 
(HITS-CLIP) (330) and crosslinking, ligation, and sequencing of hybrids (CLASH) (112), providing an extensive insight into the miRNA-binding sites.

piRNAs

Identification of new piRNAs can be performed by immunoprecipitation of PIWI proteins followed by RNA sequencing $(175,235,244,328)$. However, using experimental methods alone is laborious, expensive, and not sensitive enough to detect piRNAs expressed at very low level or only in certain tissues. With the advancement of deep RNA sequencing, computational methods provided an alternative approach for de novo annotation of piRNAs (Table 2). However, these algorithms which are based on general properties from validated piRNAs must be trained to predict novel piRNAs. The first algorithm to identify piRNAs was based on a position-specific method that classified the sites along the genome susceptible to generate piRNAs starting with a uridine at their 5' ends (26). Zhang et al. developed a model called piRNA predictor by combining the k-mer scheme and support vector machine (SVM) (350). Subsequently, Wang et al. proposed a different model for predicting piRNAs by using the transposon interaction and SVM (323). Recently, three more papers were published for identifying piRNAs (summarized in Table 2). One was developed based on sequential and physicochemical features of piRNA (196), another developed a genetic algorithm-based weighted ensemble method for predicting transposon-derived piRNAs (181) and the last one, named 2L-piRNA, was a two-layer ensemble classifier for identifying PIWIinteracting RNAs and their function (188).

Identification of piRNA targets has proven to be rather difficult due to limited knowledge in the field. Zhang et al. recently proposed piRNA targeting rules explaining how these ncRNAs can find mRNA targets in Caenorhabditis elegans (347). Additionally, crosslinking, ligation, and sequencing of hybrids (CLASH) approaches have been applied to the PIWI Argonaute in $C$. elegans, which permitted to identify endogenous interactions between piRNAs and target RNAs in vivo (287). Both piRNA targeting rules and PIWI CLASH data were used to construct tools pirScan (337) and piRTarBase (336) to allow researchers explore how piRNAs recognize the target sites and exert their regulatory effects (Table 2). These computational tools may be utilized to identify piRNAs and their targets, and thereby unravel the contribution of piRNAs in the control of $\beta$-cell function under normal or pathophysiological conditions. 
tRNA-derived fragments

In recent years, the development of high-throughput small RNA sequencing approaches enabled the detection of small RNAs at unprecedented depth. However, many problems associated with the identification of tRFs have been noted. First, sequencing biases may occur due to tRNA structure and the presence of post-transcriptionally modified residues, which block reverse transcription (51). Second, the presence of tRNA isodecoders that share the same amino acid sequence in different genomic locations prevents the determination of the exact source of tRFs (191). Third, identifying the actual tRFs can be challenging due to difficulties in discriminating tRFs from random degradation fragments in a large pool of sequenced small RNAs (354). Certain experimental methods have been developed to overcome some of these biases, including artificial removal of methylated bases on tRNAs (DMtRNA-Seq and ARM-Seq) (51, 353). In addition, several tools have been developed to improve tRNA-Seq bioinformatics analyses (Table 2). For instance, the sequence-centric based tool MINTmap (191) catalogs both raw and normalized abundances of tRFs using published small RNA-seq data of human tissues under various physiological and pathological conditions. The labeling scheme of MINTmap can unambiguously calculate and report both raw and normalized abundances for the discovered tRFs. Another freely available prediction tool tRF2Cancer (354) has introduced the binomial test to evaluate whether reads from a small RNA-seq data set represent tRFs or degraded fragments and evaluate their expression in multiple cancers.

As discussed previously, tRFs have been proposed to be involved in various cellular processes. Several computational tools and software have been used to predict the potential targets of tRFs. RNAhybrid software (161) has been used to find pairing sites for 3'ETS ${ }^{\text {leuZ }}$ with the small regulatory RNAs RyhB and RybB, suggesting that tRFs may function as sponges for small RNAs to prevent transcriptional noise (167). TargetScan has identified binding sites for a tRFs CU1276, possessing characteristics of a miRNA, and predicted its target gene RPA1, an essential gene involved in proliferation and DNA damage response (211). Blat has also been utilized to predict potential target sites of sperm derived tRFs in mouse genome (40). However, the number of validated tRF targets is still relatively small and inadequate to provide an un-biased assessment of the binding patterns. In addition, the short length of tRFs limits the sensitivity of detection using most statistical techniques. Given these limitations of computational predictions, experiments may 
be complemented with pull-down experiments using either biotinylated tRFs or candidate target proteins as baits (167).

$\operatorname{lncRNAs}$

Recent advances in RNA-sequencing technologies led to the discovery of thousands of previously unannotated lncRNAs. Generally, lncRNA analysis is a two-layer process, in which the first consists in transcript sequencing and assembly, and the second in building a stringent selection pipeline to systemically identify the lncRNAs. This pipeline aims at removing known non-lncRNA transcripts, unreliable lowly expressed transcripts or with protein-coding potential. Additional methods such as quantitative reverse-transcription PCR, 5' and 3' rapid amplification of cDNA ends (RACE), 5' capture sequencing (cap-analysis gene expression, CAGE) and 3' Polyadenylation signals (PAS-Seq) can be useful to confirm the ends and isoform structures of specific transcripts.

\section{Circular RNAs}

Information about the circRNAs detected so far in human and other species can be found in annotation databases such as circBase (92). These predicted circRNAs have been identified in RNA sequencing data from ribosomal RNA-depleted libraries or from circRNA-enriched libraries treated with the exoribonuclease RNase $\mathrm{R}$ and depleted of ribosomal RNA. CircRNAs are identified using algorithms that detect reads spanning their unique inverted or backsplice junction (summarized in Table 2) (42, 89, 215, 297, 303, 324, 331, 344, 349) and reviewed in (111). Their sensitivity (number of backsplice-spanning reads) and specificity (lack of false positives) are nevertheless different. Hence, it is advised to use at least two prediction algorithms to obtain a more accurate annotation of circRNAs.

\section{Regulation of islet differentiation, functional maturation and ageing Pancreatic islet development and $\beta$-cell differentiation}

Pancreas development is a complex and tightly regulated process that has been characterized in detail in mice but is less well defined in human because of the limited access to human fetal specimen. In brief, the pancreas develops from the primitive gut by formation of dorsal and ventral buds (mouse E9-10) at the junction of the foregut and the midgut endoderm. Between mouse E12.5 and E16.5, these pancreatic buds grow and undergo branching morphogenesis. The ventral bud 
then rotates and fuses with the dorsal bud (E15.5-16.5), forming the definitive pancreas. Of note, the ventral bud will become the pancreas head and the main pancreatic duct while the dorsal bud will form the tail and the body of the pancreas, and the accessory pancreatic duct. Throughout this process, a tight spatio-temporal control of the expression of several transcription factors (including Pdx1, Ngn3, NeuroD1, Nkx2.2, Nkx6.1, Pax6, Isl1) is required for the formation and maturation of all endocrine and exocrine cell lineages (48). Growing evidence suggest that ncRNAs are also important regulators of pancreas and $\beta$-cell development (reviewed in $(209,333)$ ).

miRNAs

Evidence for a key role of miRNAs for proper pancreas and $\beta$-cell development has been obtained by the downregulation of the miRNA processing enzyme Dicer1 in different mouse models. Conditional deletion of Dicer1 in early pancreatic lineage (E9.5) using Pdx-Cre mice led to pancreas agenesis and a strong reduction in various pancreatic endocrine cell types, including $\beta-$, $\alpha-, \delta$ - and PP-cells. Pdx-Cre Dicer KO mice survived until birth but died few days after (197). Deletion of Dicer1 specifically in pancreatic endocrine progenitor cells (E12.5) in Ngn3-Cre Dicer mice did not affect endocrine cell lineages but caused the production of abnormal hormone levels after birth leading to chronic hyperglycemia and diabetes onset by the age of 2 weeks (140). By inspecting the endocrine pancreas, the authors observed an altered islet architecture, reduced $\beta$-cell mass and decreased insulin expression and content (140).

To address the importance of the miRNA network in $\beta$-cell development independently from the differentiation of pancreatic progenitor cells, Dicer1 was conditionally deleted under the control of the rat insulin promoter 1 (RIP1) or 2 (RIP2) (E15.5) (137, 197, 203, 214). No fetal or neonatal $\beta$-cell differentiation defects were reported in RIP1-Cre Dicer1-null mice. However, these animals showed a reduced $\beta$-cell mass, impaired islet number, size and organization, and decreased insulin expression by 12 weeks of age. Consequently, these mice displayed diminished insulin release in response to glucose and gradually became glucose intolerant and overtly diabetic by 25 weeks of age (137). Two independent studies investigated the effect of Dicer1 deletion using RIP2Cre mice. Similar to the phenotype observed for RIP1-Cre Dicer1-null mice, Mandelbaum et al. reported that RIP2-Cre Dicer1-null mice have a reduced $\beta$-cell mass and impaired insulin synthesis and, consequently, develop fasted and fed hyperglycemia and glucose intolerance by 1-2 months of age. In contrast, Lynn and colleagues did not observe any islet morphological changes in 8- 
month-old null mice (197). This discrepancy might be explained by the fact that not all $\beta$-cells undergo Cre recombination. Overtime, Cre-positive cells may be progressively lost and replaced by wild-type Cre-negative $\beta$-cells (203). Therefore, the phenotype observed in young animals was progressively reversed by the age of 8-10 months (203).

Finally, to study the effect of Dicer1 deletion more specifically in adult $\beta$-cells, MelkmanZehavi and colleagues developed a tamoxifen-inducible RIP-Cre Dicer1 mice that showed a 50\% reduction in Dicer levels in $\beta$-cells with a concomitant reduction of miRNA abundance 2 weeks after Tamoxifen injection (214). Pancreatic insulin content, and Ins1 and Ins2 expression were reduced in Tamoxifen-treated mice (214). Moreover, these mice displayed lower plasma insulin levels, impaired insulin release in response to glucose, and became glucose intolerant and hyperglycemic in both fasted and fed state. Overall, these studies underline the critical role played by DICER 1 and the associated miRNA network in the regulation of pancreas development, $\beta$-cell mass and function.

The role of specific miRNAs in pancreas development has also been investigated (reviewed in $(209,333))$. In human, the expression of two islet-enriched miRNAs, miR-7 and miR-375, were found to be increased during pancreatic endocrine cell development and differentiation $(49,133)$. Similar results were obtained for mouse pancreas development (158, 159, 234). Both miR-7 and miR-375 expression were blunted in Ngn3-null mice that lack hormone-producing cells (158), suggesting an involvement of these miRNAs in endocrine cell development. Several research groups attempted to define the role played by miR-7 during $\beta$-cell differentiation using different animal models $(158,172,234)$. Kredo-Russo and colleagues found that miR-7 reduces insulin expression by limiting PAX6 levels in $\beta$-cells both ex vivo, in E12.5 pancreatic buds transfected with miR-7 inhibitors or mimics, and in vivo in E15.5 pancreata of Pdx1-Cre mir-7 transgenic mice (158). The authors found also that miR-7 inhibits glucagon expression and favors the appearance of ghrelin-positive cells (158). Latreille and colleagues did not observe defects in islet architecture or in $\beta$-cell mass in RIP-Cre mir-7 transgenic mice at adult age (172). However, they reported a reduction in Ins1 and Ins2 levels in the islets of transgenic mice overexpressing mir-7 and an upregulation of the insulin levels in mir-7 null mice, with a consequent impact on $\beta$-cell function. The role of miR-375 in $\beta$-cell development remains at present unclear. In an earlier study, injection of miR-375 inhibitors in one-cell-stage zebrafish embryo led to aberrant islet formation (152). However whole-body mir-375 null mice did not show any major defect in islet $\alpha$ - and $\beta$-cell 
number, or hormone expression in the first two weeks of life. Disrupted islet architecture could only be observed after 3 weeks of age, suggesting that in mice, miR-375 is not essential for $\beta$-cell formation but is required for maturation and function (255).

Of course, this type of studies cannot be performed in human. However, the role of miRNAs has been investigated by following the differentiation process of human embryonic stem cells (hESCs) into a $\beta$-cell-like phenotype or during the generation of pluripotent stem cell (hiPSC)derived insulin-producing cells $(80,192)$. Three miRNAs (miR-7, miR-375 and miR-373) were found to be highly upregulated in the early stages of hESC differentiation into the definitive endoderm, while miR-15a/b and miR-16a were mainly increased during endocrine induction. Finally, miR-29b and miR-148 reached a peak in the late stage of endocrine proliferation (192). Increased levels of miR-375 and miR-7 favored the differentiation of hESCs into insulinexpressing cells and/or exacerbated insulin secretion in response to glucose $(48,80)$. The rise of miR-7 during early hESC differentiation coincides with an increase in the expression of pancreatic markers, including FOXA2, PDX1, and insulin. In contrast, blockade of miR-7 partially inhibited glucose- and KCl-induced insulin secretion. Several other miRNAs are likely to play a role in $\beta$ cell formation since they regulate the level of important transcription factors, including Ngn3, NeuroD1 and Foxa2 (reviewed in $(80,146,209)$ ).

snoRNAs

Beside miRNAs, other small ncRNAs may also be of importance for $\beta$-cell development and differentiation. Burnett and colleagues investigated the impact Snord116 paternal allele deletion (Snord116 $6^{\mathrm{p}-\mathrm{m}+}$ mice) on endocrine pancreas development (30). Snord116 is a gene cluster containing around $30 \mathrm{C} / \mathrm{D}$ box snoRNAs that are 85\% homologous to each other. SNOD116 snoRNAs are localized into nucleoli but are called "orphan" since they do not have known rRNA targets. Snord $116^{\mathrm{p}-\mathrm{m}+}$ mice displayed a reduced islet size at both neonatal and adult age. Throughout life, the islets of Snord $116^{\mathrm{p}-\mathrm{m}+}$ mice contained a number of $\beta$-cells comparable to WT animals but the proportion of $\delta$ - and $\alpha$-cells was increased and decreased, respectively. Also, Snord $116^{\mathrm{p}-\mathrm{m}+}$ islet cells were characterized by a more polyhormonal profile during the neonatal life, and a lower expression of endocrine pancreas progenitors such as Pdx1, Pax6, and Nkx6.1, during adulthood (30). Therefore, snoRNAs produced from the Snord116 locus may play an important role in islet cell lineage specification. 
$\operatorname{lncRNAs}$

Different studies suggest that lncRNAs are required for proper $\beta$-cell development (reviewed in (333)). As mentioned above, $\beta$ lincl-null mice display a 50\% reduction in $\beta$-cell mass in e15.5 embryos and in newborn without major impacts on pancreas morphology (13). PLUTO may also be involved since it regulates the levels of PDX1 (8), a transcription factor known to be crucial for pancreas development and $\beta$-cell identity (134, 237). Moran and colleagues investigated the involvement of lncRNAs in human $\beta$-cell development by analyzing the expression of 13 lncRNAs (10 intergenic and 3 antisense) in dissected Carnegie stage 17-19 human embryonic pancreas, a progenitor stage that shows scarce signs of cytodifferentiation (221). Of these 13 transcripts, 12 were silent or expressed at very low level in pancreatic progenitors but were readily detectable in adult islets. The expression of most of them were also activated only at the final in vivo maturation step of the human embryonic stem (hES) cells (13). Finally, two lncRNAs, HI-LNC78 and HILNC80, were upregulated in human islets incubated for $72 \mathrm{~h}$ with glucose concentrations (221). A major fraction of the lncRNAs investigated in this study were found to have orthologues in mouse islets that were also displaying expression changes during pancreas development, islet maturation, in response to glucose and/or in islets of obese and diabetic $d b / d b$ mice (221). This suggests that the function of islet-specific lncRNAs may be conserved among mammals Taken together, these results suggest a highly dynamic and cell-specific regulation of islet lncRNAs potentially contributing to $\beta$-cell development.

\section{Functional maturation of $\beta$-cells}

miRNAs

The acquisition of a fully functional phenotype requires a reprogramming of the gene networks expressed in newly generated islet cells that occurs during the neonatal period. MiRNAs have been highlighted as import players in this process and contribute to disallow the expression of more than 60 ubiquitously expressed genes that negatively impact on $\beta$-cell identity and function and need to be specifically silenced in fully differentiated $\beta$-cells (143, 179, 209). Indeed, $\beta$-cell-specific inactivation of the miRNA-processing enzyme Dicer at adulthood leads to the up-regulation of several $\beta$-cell disallowed genes, resulting in reduced insulin content, decreased $\beta$-cell mass and IGT (208). In line with these findings, miR-29a and b, expressed at elevated levels in mature $\beta$ cells directly target the lactate/pyruvate transporter Mct1 (monocarboxylate transporter 1) (256). 
Repression of Mct1 avoids the induction of insulin secretion in response to a rise in lactate generated during physical activities (258). Moreover, direct inhibition of MCT1 by miR-495 in human embryonic stem cells transplanted under the kidney capsule improved glucose tolerance of obese mice fed on a HFD (185).

Changes in the level of several other miRNAs have also been proposed to contribute to postnatal $\beta$-cell maturation and to the acquisition and maintenance of fully mature and functional $\beta$-cells (124). For example, miR-17-5p and miR-181a were found to regulate the expression of several genes involved in glucose metabolism, insulin secretion and proliferation (124). The nutritional switch occurring at weaning from fat-rich maternal milk to a carbohydrate-rich diet drives $\beta$-cell maturation $(124,301)$ and triggers major changes in the miRNA profile that enable the coupling of glucose metabolism with insulin secretion (124). Nutrition-driven islet miRNA changes affects also the control of circadian rhythms during postnatal $\beta$-cell maturation (125). Indeed, the transcriptional oscillations of several core-clock genes over 24 hours observed in freshly isolated adult rat islets are not detected in the islets of P10 rats, suggesting that the circadian clock is not yet fully operational in newborn animals. Indeed, P10 islet cells synchronized in vitro displayed rhythmic oscillations of Bmal1-luc reporter but differed significantly from those of their adult counterparts. Among the miRNAs differentially expressed during neonatal $\beta$-cell maturation, miR-17-3p and miR-29b-3p were shown to directly regulate the expression of clock and per3, respectively. These findings point to a role for miRNAs driving $\beta$-cell maturation in the regulation of adult circadian gene expression (125). However, further investigations are needed to elucidate the mechanisms involved in the initiation of the circadian clock in the developing islets that are likely to result from the cooperative action of multiple miRNAs and of other factors.

Dumortier et al. discovered a perturbation of the pancreatic miRNA expression profile in the offspring of rat dams fed a low-protein (LP) diet during gestation and lactation (60). These offspring are more prone to develop metabolic diseases, including diabetes, later in life compared to offspring of dams fed on normal diet $(76,206)$. In particular, they observed a rise in the level of miR-375 in fetal pancreas that persisted in the islets of adult (3-month-old) rats born from mothers maintained on LP diet. The authors proposed an inhibitory role for miR-375 in embryonic and postnatal $\beta$-cell mass expansion and in insulin secretion, contributing to the establishment of the phenotype observed in the offspring of rat dams kept on LP diet during pregnancy and lactation (60). An independent study, reported that insulin secretion and content in adult mouse islets from 
the offspring of LP-exposed mothers can be improved and returned to normal by preventing the rise of miR-199a-3p, miR-342 and miR-375 and restoring the mTOR signaling pathway. Moreover, transient induction of mTORC1 signaling in vivo during embryonic life until birth, improved glucose tolerance in adult progeny of mothers fed a LP diet (9).

$\ln c R N A s$

The role of lncRNAs in neonatal $\beta$-cell maturation has been investigated by performing a global profiling in islets of newborn (P10) and adult rats (276). This led to the identification of over 2000 differentially expressed IncRNAs. H19, a maternally imprinted lncRNA generated from the Igf2 locus (346) was among the most downregulated transcripts during neonatal $\beta$-cell maturation. This lncRNA was previously reported to be involved in mouse embryonic development and postnatal growth (88) and to sustain cancer cell proliferation (174). H19 expression in neonatal islets appears to be controlled by the transcription factor $\mathrm{E} 2 \mathrm{~F} 1$, an important regulator of $\beta$-cell survival and proliferation (75). H19 was found to promote $\beta$-cell proliferation by sponging miRNAs, including members of the let-7 family, and thus favoring the activation of the PI3K/AKT pathway (Fig. 6C). Interestingly, H19 expression was upregulated in islets of different obese mouse models characterized by insulin resistance and to be downregulated in islets of the offspring of rat dams fed on a LP diet that are prone to develop metabolic diseases later in life (276). Thus, appropriate expression of H19, and probably of other IncRNAs, appears to be required for $\beta$-cell mass expansion.

\section{$\beta$-cell mass expansion during obesity and gestation}

During pregnancy and obesity, reduced insulin sensitivity of target tissues results in increased insulin needs. Pancreatic $\beta$-cells can respond to the rise in the metabolic demand by increasing their number, size, and by augmenting their secretory activity. If this compensatory process fails, gestational or T2D occurs (Fig. 1).

miRNAs

To distinguish the contribution of genetics and obesity on miRNA regulation, Zhao et al. compared islet samples of two mouse strains, diabetes resistant C57BL/6 (B6) and diabetes-susceptible BTBR mice, with those of their morbidly obese peers, B6-ob/ob and BTBR-ob/ob, respectively (351). The authors identified changes in a subset of obesity-dependent miRNAs in islets of both, 
B6-ob/ob and BTBR-ob/ob mice compared with their respective lean controls. Interestingly, the magnitude of the upregulated miR-132 and -212 was much greater in islets of B6 mice compared to BTBR mice whereas miR-204 and miR-7b levels were only modified in response to obesity in the islets of BTBR, but not from B6 mice. The strain differences in the islet miRNA profile in response to obesity may help understanding the relationship between miRNA regulation and diabetes resistance (B6) or susceptibility (BTBR) (351).

Several miRNAs have been found to be important contributors to successful $\beta$-cell adaptation to insulin resistance. Latreille et al. observed a strong reduction of miR-7a in islets of DIO mice, obese non diabetic $o b / o b$ mice and in human islets exposed to an obesogenic environment after transplantation under the kidney capsule of DIO mice (172). MiR-7 expression gradually increased in islets of hyperglycemic animal models, suggesting that low levels of this miRNA are necessary to achieve a successful $\beta$-cell compensation.

The level of miR-206 is increased in islets, brain and liver of DIO mice. Genetic deletion of mir-206 resulted in improved glucose tolerance both in mice fed with chow or high-fat diet. This was associated with enhanced insulin secretion and no changes in insulin sensitivity. Islets isolated from mir-206-knockout mice displayed higher glucokinase (GCK) mRNA levels and activity. Indeed, Gck, a key sensor of $\beta$-cell glucose metabolism, was shown to be a direct target miR-206. Interestingly, haploinsufficiency of Gck led to insufficient $\beta$-cell hyperplasia and failure in $\beta$-cell mass expansion in response to insulin resistance (308). Altogether, these results strongly suggest that miR-206 is vital to achieve successful GCK-dependent $\beta$-cell compensation in the context of obesity (321).

Interestingly, miR-132 is highly increased whereas miR-184 is strongly reduced in obese leptin-deficient $o b / o b$ mice, as well as in diet-induced obese mice (DIO) and in young (6-weekold) leptin receptor-deficient $d b / d b$ mice, which are obese and insulin resistant, but still normoglycemic $(228,231,351)$. As discussed previously, overexpression of miR-132 promotes $\beta$ cell proliferation, cell survival in response to pro-apoptotic conditions and increases insulin release in response to glucose without affecting insulin content (228, 229, 231, 298). Moreover, insulin resistant DIO mice treated with an adeno-associated virus (AAV) vector containing miR-132 under control of the insulin promoter showed improved glucose homeostasis as a result of increased insulin secretion and $\beta$-cell proliferation (228). Altogether, these data suggest a positive impact of 
miR-132 in the control of $\beta$-cell function and a potential contribution to $\beta$-cell adaptation to obesity.

Decreased levels of miR-184 can also favor $\beta$-cell proliferation and therefore contribute to the adaptive metabolic response to counteract diabetes development (231). Studies showing that miR-184 levels are reduced in response to high glucose exposure in vitro while they are elevated in islets of fasted mice or mice fed a low-sugar diet (305), likely in an AMPK-dependent mechanism (207), further suggest that miR-184 depletion plays a central role in the compensatory adaptation of $\beta$-cell activities in response to an obesogenic environment. This essential role was further validated by Tattikota et al., whom enforced the expression of the miRNA in a context of obesity by crossing transgenic miR-184 mice with ob/ob mice (306). The $\beta$-cell mass of transgenic miR-184 ob/ob mice failed to compensate for insulin-resistance and, in contrast to normal $o b / o b$ mice, exhibited a reduced islet insulin content, a drop of plasmatic insulin levels and hyperglycemia.

Interestingly, neither the $\alpha$-cell mass nor the expression of abundant islet miRNAs such as miR-375 were affected in these animals. Though, previous reports by Poy et al. demonstrated that miR-375 is required for $\beta$-cell compensation in obese ob/ob mice (255). Moreover, a study conducted by Jacovetti et al., did not detect any changes in the expression of miR-375 and miR184 in the islets of pregnant rats (122). Interestingly, miR-338-3p, another miRNA displaying expression changes in the islets of obese prediabetic $d b / d b$ and DIO mice is also decreased in islets of pregnant rats. These results further suggest that mechanisms that trigger $\beta$-cell compensation may differ depending on the physiological (pregnancy) or pathological (obesity) conditions driving insulin resistance. It was possible to reproduce the decrease of miR-338-3p by activating the cAMP/PKA-dependent pathway which seems to be elicited by the activation of the non-canonical estrogen receptor GPR30 during gestation and the glucagon-like peptide 1 receptor during obesity. Down-regulation of miR-338-3p did not interfere with the secretory capacity of $\beta$-cells but boosted their proliferation and promoted their survival under pro-apoptotic conditions. Despite the direct targets of the miRNA have still not yet been identified, miR-338-3p inhibition in rat islet cells elicited changes in the expression of several genes important for $\beta$-cell proliferation and survival (122). 
IncRNAs

Beside miRNAs, little is known about the role of other ncRNAs in $\beta$-cell mass expansion observed during pregnancy and/or obesity. To address this question, lncRNA profiling of islets of pregnant mice at gestational day 14.5 (compared to non-pregnant mice) was performed and allowed the identification of 6 lncRNAs (named lnc01-06) that were dysregulated during pregnancy (293). Of them, lnc03 and lnc06 were found to be highly enriched in islets compared to exocrine pancreas and other tissues. The increase of lnc03 and lnc04 in pregnancy was mimicked by incubation of mouse islets in vitro with the gestational hormone prolactin. Furthermore, downregulation of lnc03 in MIN6 cells and mouse islets inhibited prolactin induced $\beta$-cell proliferation, suggesting the involvement for lnc03 in $\beta$-cell mass expansion during pregnancy (293).

\section{Ageing}

$\beta$-cell senescence leading to a loss of function and proliferative arrest increases with age and represents a risk factor for diabetes development $(4,54)$. Moreover, $\beta$-cell dedifferentiation and conversion to non- $\beta$ pancreatic endocrine cells has been reported following physiological stresses such as aging (304). The analysis of the miRNA profile in islets of 3- and 12-month rats led to the identification of 69 differentially expressed miRNAs in aged animals. In vitro modulation of agerelated changes of miR-34a (up-regulated) and miR-181a (down-regulated) prevented GLP1- or PDGF-induced $\beta$-cell proliferation of 3-month rats. These results reproduce the failure of $\beta$-cell to respond to these mitotic stimuli observed in aged rats (312). MiR-34a directly controls the expression of Pdgfra, a disallowed gene that limits the proliferative capacity of adult $\beta$-cells (39). As discussed here after (see Section titled “Type 1 Diabetes”) miR-34a has been demonstrated to affect cell survival and insulin-granule exocytosis $(71,194,266,312)$. The positive correlation of miR-34a levels with age in human islet donors suggests an evolutionarily conserved mechanism for the regulation of this miRNA (312).

\section{Deregulation of non-coding RNAs under pathophysiological conditions}

\section{Type 1 Diabetes}

T1D is an auto-immune disorder caused by the selective attack of pancreatic $\beta$-cells by the immune system leading to the near complete absence of insulin production. The precise mechanisms causing the deregulation of the immune system remain to be elucidated, but part of the detrimental 
effects on $\beta$-cell survival is due to the release by the immune cells of pro-inflammatory cytokines, including TNF $\alpha$, IL-1 $\beta$ and IFN $\gamma$, and exosomes $(64,100)$. Unfortunately, patients suffering from T1D are diagnosed when more than $90 \%$ of the $\beta$-cells have already been destroyed, so it is very difficult to investigate T1D development in human. Therefore, most of the studies are performed in rodent models. The non-obese diabetic (NOD) mice spontaneously develop T1D similarly to what observed in human (246) with a progressive infiltration of immune cells around pancreatic islets starting at 6-8 weeks of age and a total invasion of the islets by 12-14 weeks of age. About $80 \%$ of female NOD mice develop diabetes by the age of 16-20 weeks. A chemical approach consisting in multiple injections of low doses of streptozotocin is frequently used to induce $\beta$-cell death and mimic T1D development (87). The advantage of this model is that $\beta$-cell destruction is achieved in all animals within only a few days. However, streptozotocin injection does not mimic the autoimmune reaction observed during T1D development.

miRNAs

Global miRNA profiling in islets of 4, 8 and 12 weeks-old female NOD mice led to the identification several miRNAs dysregulated during T1D development (267). Among them, miR29 family members were found to be highly upregulated along disease progression. Interestingly, the increase in the expression of miR-29a/b/c could be reproduced by incubating mouse and human islets in vitro with pro-inflammatory cytokines $(29,267)$. To determine the functional impact of miR-29 upregulation on $\beta$-cells, MIN6 cells and mouse islets were transfected with miRNA mimics. This resulted in a rise in apoptosis caused by a direct interaction of the miRNAs with the 3’UTR of Mcl1. Masking miR-29 binding site on Mcl1 with a protector oligonucleotide prevented $\beta$-cell death induced by miR-29 or pro-inflammatory cytokines. Moreover, overexpression of miR29a/b/c reduced insulin secretion in response to glucose. This was paralleled by a decrease in the level of ONECUT2 and a concomitant rise in Granuphilin, a secretory granule protein potently inhibiting exocytosis (267). The role of miR-29 was also investigated in mice in which the two genomic clusters producing this miRNA family were independently knockdown: mir-29a/b-1 locus (KO mir-29a/b) or mir-29b-2/c locus (KO mir-29b/c) (59). Of note, miR-29 family is not solely expressed in $\beta$-cells but is also highly abundant in liver. Indeed, both KO mir-29a/b-1 and KO mir29b/c animals showed increased insulin sensitivity of peripheral tissues and insulin signaling in liver. However, KO mir-29b/c animals displayed normal fasting blood glucose and insulin levels, 
and did not show any glucose intolerance, despite a mild reduction of insulin levels in response to an IPGTT. In contrast, mice deficient for mir-29a/b-1 were hyperglycemic and glucose intolerant, displayed reduced fasting insulinemia and blunted insulin levels following an IPGTT. Ex vivo, insulin content and release in response to glucose in the islets of KO mir-29a/b was normal but basal insulin secretion was markedly affected. Onecut2 and Granuphilin were not changed in KO animals. However, Mct1, Stx1a and Vamp3 were modulated and increased expression of Sxt1a in islets might explain the reduced insulin exocytosis (59). These results are difficult to reconcile with those obtained in vitro upon overexpression of miR-29 family members (267). However, since insulin sensitivity was also affected in whole body $\mathrm{KO}$ animals, generation of transgenic mice with a $\beta$-cell specific ablation or overexpression of miR-29 family members will be required to fully understand the role of miR-29 in the regulation of insulin exocytosis under normal and diabetic conditions.

The upregulation of three other miRNAs, miR-21a-5p, miR-34a-5p and miR-146a-5p, observed in islets of pre-diabetic NOD mice could be mimicked by incubating human islets with IL-1 $\beta$ (266). Interestingly, miR-146a-5p expression was found to be controlled by NFkB, a wellknown mediator of cytokine-induced $\beta$-cell death. As expected, blockade of miR-146a-5p in MIN6 cells prevented apoptosis and c-Jun expression induced by IL-1 $1 \beta$. At the opposite, overexpression of this miRNA favored apoptosis (266). Increased levels of miR-34a-5p cells also promoted apoptosis and affected insulin expression, content and secretion in response to glucose. While miR$34 \mathrm{a}$ was previously reported to activate p53 and to decrease $\beta$-cell survival (194), the effect of miR-34a on insulin release was mediated, at least in part, by reduction of VAMP2 and of the GTPase Rab3a, two proteins involved in insulin exocytosis (266). Finally, overexpression of miR21 blunted glucose-induced insulin release with a concomitant decrease in the expression of regulators of insulin secretion, including VAMP2, RAB3 and PCLO $(29,266)$. Furthermore, some reports observed that miR-21 induction promotes $\beta$-cell apoptosis by directly targeting the antiapoptotic gene Bcl2 $(16,291)$. Nevertheless, miR-21 involvement in $\beta$-cell death is complex and controversial since other studies failed to observe an impact on $\beta$-cell viability upon miR-21 overexpression (266). MiR-21 was even suggested to potentially mediate the protective effect of $\mathrm{NF}-\kappa \mathrm{B}$ in mouse $\beta$-cells. Indeed, NF- $\mathrm{kB}$ prevents insulin-secreting cell death and activates miR-21 promoter (269). Moreover, inhibition of miR-21 up-regulates the expression, at both mRNA and protein levels, of the tumor suppressor PDCD4 in $\beta$-TC-6 cell line, and consistently promotes 
MIN6 cell apoptosis (29, 266, 269). Further investigations are still required to clarify miR-21 implication on $\beta$-cell death in T1D setting.

Several other miRNAs were dysregulated in response to pro-inflammatory cytokines in both human and mouse islets (29, 97, 98, 266). Among them, miR-23a-3p, miR-23b-3p, miR-1495p, miR-204 and miR-211-5p were downregulated in human islets and EndoC- $\beta \mathrm{H} 1$ cells treated with IL-1 $\beta$ and IFN $\gamma(97,98)$. These miRNAs could be part of the mechanisms by which cytokines induce $\beta$-cell death since decrease in their levels in human $\beta$-cells favor apoptosis and the expression of the pro-apoptotic genes PUMA and DP5 belonging to Bcl-2 family $(97,98)$. Moreover, co-depletion of miR-211-5p and miR-204 in human EndoC- $\beta \mathrm{H} 1$ cells induced expression of ER stress markers including CHOP, ATF3, ATF4 and EIF2A, in a PERK-dependent manner. Interestingly, miR-204 and miR-211-5p were reported to directly target, respectively, PERK in $\beta$-cells (338) and Chop in fibroblast NIH-3T3 cells (44).

Beside miRNA changes induced by pro-inflammatory conditions, $\beta$-cell dysfunction and death might also been caused by miRNA transfer from exosomes produced by T cells (see Section titled “Extracellular non-coding RNAs”).

\section{LncRNAs}

To investigate a possible involvement of lncRNAs in T1D development, Motterle et al. performed a global profiling of annotated lncRNAs in MIN6 cells exposed to pro-inflammatory cytokines and identified more than 650 dysregulated long non-coding transcripts (225). Of them, four lncRNAs (lncRNA-1 gm5970, lncRNA-2 AI451557, lncRNA-3 BC002288, lncRNA-4 gm16675) were selected for further analysis and their upregulation was confirmed in mouse islets treated with a mix of IFN $\gamma, \mathrm{TNF} \alpha$ and IL-1 $\beta$. Interestingly, the expression of lncRNA-1 -2 and -3 was also increased in islets of pre-diabetic female NOD mice during insulitis but not in immunodeficient control NOD SCID mice that do not develop diabetes (225), suggesting the involvement of the autoimmune reaction in the induction of these lncRNAs. Looking at their functions, these four lncRNAs were found to favor apoptosis in both MIN6 and mouse $\beta$-cells without affecting insulin secretion and content. Mechanistically, overexpression of lncRNA-1 gm5970 promoted cell death by inducing $\mathrm{NF \kappa B}$ translocation to the nucleus (225). This first study highlight the possible involvement of lncRNAs in $\beta$-cell death during the immune cell invasion of the pancreatic islets, but further studies are needed to fully understand the role of lncRNAs in T1D development. 


\section{Other non-coding RNAs}

Global profiling for piRNAs, snoRNAs, tRFs, and circRNAs remains to be performed in islets of T1D animal models in order to elucidate the involvement of these classes of ncRNAs in the development of this disease. So far, only the circRNA circARHGAP12 has been reported to be altered in the islets of pre-diabetic NOD mice. However, decreasing its level in MIN6 cells did not affect insulin secretion, proliferation, nor apoptosis (300).

\section{Type 2 Diabetes}

T2D develops when pancreatic $\beta$-cells are unable to release enough insulin to compensate for the diminished sensitivity of peripheral tissues. The main factors predisposing to T2D are excessive caloric intake and sedentary lifestyle combined with genetic susceptibility. In rodents, several models exist to study the etiology of this disease. $O b / o b$ and $d b / d b$ mice, lacking leptin and the leptin receptor, respectively, display massive obesity and hyperinsulinemia with or without chronic hyperglycemia according to the genetic background $(150,187)$. These models are extreme and reflect only the condition of a fraction of T2D patients that are overtly obese. Therefore, dietinduced obesity (DIO) is considered more representative of T2D development in human. In this model, mice are fed on a HFD for 2-3 months leading to progressive weight gain, hyperglycemia and hyperinsulinemia (248). Interestingly, the ability to compensate for insulin resistance differs in each individual mouse and provides a good opportunity to study the mechanisms leading to compensation or failure of $\beta$-cells (248). Goto-Kakizaki (GK) rats are a model of spontaneous T2D development. These rats are non-obese but have a defect in insulin release in response to glucose leading to chronic hyperglycemia (253).

The possibility to obtain human islets for research from pre-diabetic and T2D donors increased considerably in recent years, thanks to improvements in pancreatic acquisition, isolation methods and delivery systems. The access at these precious biological samples provided tremendously helpful information about the molecular mechanisms involved in $\beta$-cell dysfunction associated with obesogenic environment or diabetes duration in human, giving hope for the use of these data in the development of future therapeutic strategies to prevent diabetes. The analysis of the miRNA profile of islets obtained from human donors with and without T2D revealed that only a fraction of the miRNAs displaying expression changes in the islets of diabetes animal models are also dysregulated in the islets of T2D individuals. In contrast, the analysis of islet samples of 
healthy and diabetic patients led to the identification of new sets of diabetes-associated miRNAs previously not detected in animal models. As discussed elsewhere (104), these apparently discrepant findings can be explained by multiple factors and will probably apply to other classes of ncRNAs. In fact, the experiments carried out in rodents permit to avoid confounding effects such as genetic variability, differences linked to diet, T2D treatment, life style, age, gender and others. Thus, some of the changes observed in the islets of diabetes animal models may be difficult to reproduce in small human cohorts in which the influence of all these confounding factors cannot be avoided. In addition, at least part of the differences in ncRNAs expression detected in diabetes animal models are likely to be the consequence of chronically elevated blood glucose levels, a condition that is prevented in properly treated T2D patients. On the other hand, some of the differences in ncRNA expression associated with T2D in human islets may reflect an unfavorable genetic background predisposing to diabetes development or be the consequence of pharmacological treatments. Therefore, confirmed by additional studies involving larger human cohorts permitting to avoid potential confounding effects, these limitations should be taken into account when interpreting the results described below. A better reporting of the characteristics of human islets used in the different studies and of the diabetic donor information (when available) which are now becoming mandatory for publication in most journals $(249,250)$ will probably help to obtain more reproducible data.

miRNAs

Numerous studies conducted in islets isolated from T2D animal models reported changes in miRNA expression occurring during disease progression. Many of these studies have already been described in previous sections and have been extensively discussed in several other reviews (103, $104,169,209,239,329)$. In this section, we will focus exclusively on data collected from islets of human T2D donors or from transgenic and knock-out animal models in which miRNAs levels were modulated in attempt to prevent or reverse T2D in vivo.

To identify dysregulated miRNAs in human islets of T2D donors, two studies performed global miRNA profiling by small RNA-seq and RT-qPCR-based array. These studies reported elevated expression of miR-187-5p, miR-187-3p, miR-224 and miR-589 in islets of T2D donors, while miR-7, miR-369, miR-487a, miR-655 and miR-656 were reduced compared to islets from non-diabetic donors $(138,189)$. Moreover, Kameswaran et al. observed repression in islets from 
T2D donors of a cluster of miRNAs generated from the imprinted DLK1-MEG3 locus located on chromosome 14q32. Under diabetic conditions, $\beta$-cells were proposed to be sensitized to apoptosis, through the direct regulation of the pro-apoptotic genes IAPP and TP53INP1, via miR-376a and miR-432, two miRNAs generated from the DLK1-MEG3 locus (138). Locke et al. further investigated the role of miR-187-3p in the control of $\beta$-cell functions (189). Elevated miR-187-3p expression negatively correlated with glucose-stimulated insulin secretion in islets from normoglycemic donors. Consistently, overexpression of miR-187 in rat islets and INS-1 cells resulted in impaired insulin secretion. Moreover, miR-187 was found to inhibit insulin release by directly repressing the level of the homeodomain-interacting protein kinase-3 (Hipk3), a known regulator of insulin secretion, which is reduced in islets from individuals with T2D (189).

As described above, miR-7 is down-regulated in islets of obese mouse models (HFD and $o b / o b$ ) that maintain normoglycemia through compensatory insulin secretion, but is up-regulated in islets of $d b / d b$ mice which develop hyperglycemia and display reduced circulating insulin levels due to $\beta$-cell dysfunction. Moreover, this miRNA is reduced in GK rats, a non-obese model of T2D (69, 172). Consistently, Latreille et al. noticed reduced miR-7a levels in human islets transplanted in HFD mice and therefore exposed to an obesogenic environment (172). However, 10 weeks after transplantation miR-7a levels rose significantly, demonstrating the anti-correlation of miR-7a expression with the diabetogenic state of the mice. The authors observed lower levels of miR-7a in obese and nondiabetic subjects, but surprisingly miR-7a expression was also low in islets of moderate T2D human samples. This result was explained by the fact that this cohort includes patients undergoing a transitory phase of the disease, with $\beta$-cells still able to compensate for increased insulin needs in response to insulin resistance. Altogether, these observations indicate that miR-7 expression negatively correlates with $\beta$-cell compensation and preservation of the secretory function. Furthermore, transgenic mice overexpressing mir-7a-2 selectively in $\beta$-cells $(\operatorname{Tg} 7 \mathrm{a} 2)$ developed diabetes due to impaired insulin secretion and $\beta$-cell dedifferentiation (172) as discussed in the Section titled "Involvement of miRNAs in the control of $\beta$-cell functions".

Besides profiling, other miRNAs of interest were measured by qPCR and reported to be expressed at different levels in islets of T2D donors. While Kameswaran et al. did not observe a differences in miR-184 levels in their cohort (138), Tattikota et al. reported a reduction of miR-184 in the islets of T2D human subjects consistent with the observations in different animal models of obesity and diabetes $(231,306)$. Indeed, miR-184 appears to positively contribute to compensatory 
$\beta$-cell mass expansion under conditions of obesity in rodents (see Section titled " $\beta$-cell mass expansion during obesity and gestation”) (231, 305).

Other reports investigated the role of miR-130a-3p, miR-130b-3p, and miR-152-3p and miR-335, initially found to be increased in the islets of diabetic GK rats (69) and, more recently discovered to be dysregulated in islets from glucose intolerant (274) or hyperglycemic donors (238). Elevated miR-335 levels correlated with altered insulin secretion from islets of human prediabetic donors. Overexpression of miR-335 blunted glucose-induced insulin secretion of human EndoC- $\beta \mathrm{H} 1$ cells and of a rat $\beta$-cell line by altering insulin-granule exocytosis (274). Overexpression of miR-130a-3p, miR-130b-3p, and miR-152-3p individually resulted in decreased ATP content and cytosolic ATP/ADP ratios in INS-1 832/13 cells. By altering intracellular ATP dynamics, overexpression of these miRNAs also impaired glucose-stimulated insulin secretion and insulin biosynthesis. These miRNAs likely negatively regulate ATP-dependent insulin processes by reducing the mRNA and protein levels of pyruvate dehydrogenase E1 alpha (PDHA1) and GCK, both limiting factors for ATP production (238).

The expression of miR-124a raises during mouse embryonic pancreatic development (20) and is elevated in human pancreatic islets of T2D donors (282). In insulin-secreting MIN6 cells, miR-124a was shown to directly regulate the expression of genes involved in insulin granule exocytosis (Mtpn) or in glucose sensing (Foxa2). Moreover, in MIN6 cells miR-124 was found to negatively regulate insulin biosynthesis and insulin release by inhibiting Foxa2 levels, which in turn resulted in diminished of Pdx1, Kir6.2 and Sur1, and by modulating the levels of other regulators of insulin exocytosis such as SNAP25, Rab3A, synapsin-1A, Rab27A and Noc2 (20, 193, 282).

Dysregulation of miRNA expression in human islets may also be linked to maturity-onset diabetes of the young (MODY). A mild rise of miR-802 levels in the islets of diabetic $d b / d b$ mice and a more striking elevation of miR-802 expression in the liver of obese human individuals and DIO and $d b / d b$ mouse models have been associated with changes in insulin sensitivity and $H f n 1 b$ expression. Moreover, transgenic mice overexpressing mir-802 were glucose intolerant and insulin resistant (154). Despite, the mode of action of miR-802 in $\beta$-cells has not yet been elucidated, this miRNA may potentially contribute to $\beta$-cell failure associated with obesity and insulin resistance by repressing Hnf1b, the MODY type 5 gene (144). Two other MODY genes, Hnf1a and Neurod1, are direct target of miR-24 and mediate its contribution to loss of $\beta$-cell function (359). So far, the 
expression of miR-24 has not been investigated in islets of diabetic donors, but it is increased in islets of pre-diabetic and diabetic $d b / d b$ mice. Furthermore, knockdown of miR-24 rescued $\beta$-cell dysfunction observed in islets from DIO mice (359), suggesting that this miRNA may be important for proper islet function.

piRNAs

piRNA expression was also analyzed in pancreatic islets under diabetic conditions. A total of 347 differentially expressed piRNAs were identified between normoglycemic Wistar rats and GK rats, non-obese T2D rats characterized by impaired glucose-stimulated insulin secretion, suggesting a possible contribution of piRNAs to $\beta$-cell dysfunction. Indeed, increasing the levels of DQ732700 and DQ746748, two piRNAs enriched in the islets of diabetic GK rats, impaired glucose-stimulated insulin secretion in the islet cells of Wistar rats. Furthermore, putative targets of DQ732700 and DQ746748 were computationally analyzed and shown to be enriched for genes involved in insulin secretion (113). Altogether, these findings suggest that piRNAs may potentially contribute to the development of $\beta$-cell dysfunction in T2D by regulating gene expression in a miRNA like manner. However, the exact molecular mechanisms by which piRNAs regulate insulin secretion remain unknown. Additional studies are required to pinpoint the precise contribution of piRNAs in the acquisition of specific properties of $\beta$-cells.

\section{tRNA-derived fragments}

The reported roles of tRFs in various cellular processes and the correlation between sperm tRFs and metabolic dysfunction, necessitated the analysis of tRFs in pancreatic $\beta$-cells. While the abundance and the function of tRFs in pancreatic islets remain largely elusive, hypomethylation of glutamine tRNA was recently shown to destine the tRNA for fragmentation in human $\beta$-cells (50). Glutamine tRFs generated via this process were shown to enhance apoptotic pathways, which provided the initial evidence of tRF function in $\beta$-cells.

As modification state of tRNAs determines the production of tRFs (41, 198), analyzing tRF function in $\beta$-cells may shed a light on the role of tRNA modifying enzymes that are dysregulated during diabetes. Loss-of-function mutations in TRMT10A, a tRNA methyltransferase, are a monogenic cause of early onset T2D (119). While the increased rate of $\beta$-cell apoptosis is known in the absence of TRMT10A, the underlying molecular link between the enzyme and apoptosis was 
not understood. With the use of high-performance liquid chromatography coupled to tandem mass spectrometry (LC-MS), it was shown that tRNA methylation of guanine $\left(\mathrm{M}_{1} \mathrm{G}\right)$ is significantly reduced in TRMT10A-deficient patients (50). Using primer extension assays, TRMT10A was confirmed to methylate glutamine and initiator methionine tRNAs at G9 position. Furthermore, in TRMT10A deficient cells specific fragmentation of the glutamine tRNA including the hypomethylated 5' region was observed by Northern Blotting and qPCR. Interestingly, mimicking the levels of this glutamine tRF-5, induced apoptosis in the TRMT10A-competent EndoC-H1 human $\beta$-cell line. Reversely, inhibiting glutamine tRF-5 in TRMT10A-deficient EndoC-H1 cells reduced apoptosis, suggesting that the apoptotic phenotype observed in TRMT10A-deficient patients may result from the activity of glutamine tRF-5.

This report, in combination with the aforementioned association of tRFs with cytochrome c (41, 273), suggests that tRFs may be novel regulators of $\beta$-cell apoptosis. Further studies in models associated with $\beta$-cell death, such as T1D may help pinpoint the role of tRFs in $\beta$-cells.

LncRNAs

Various environmental and genetic factors contribute to the susceptibility of an individual to T2D. Interestingly, a large number of T2D-associated common variants that were identified in genomewide association studies map to noncoding genomic regions (245). Some of these risk alleles in human islets were found to correlate with the expression of lncRNAs $(73,153,322)$. The levels of several others lncRNAs were reported to be dysregulated in human islet samples diagnosed with T2D or impaired glucose tolerance (IGT) compared to non-diabetic donors $(8,73,221)$. Of them, HI-lnc71/PLUTO and MEG3 were found to be downregulated $(8,138)$ (see previous Section titled "IncRNAs in the control of $\beta$-cell functions").

Motterle and colleagues investigated the functional impact on $\beta$-cell function and survival of lncRNAs dysregulated in T2D mouse models (226). High-throughput RNA-sequencing with de novo annotation of islets from diet-induced obese (DIO) mice led to the identification of two $\beta$ cell-enriched and intergenic lncRNA, $\beta$ linc2 (XLOC_010971) and ßlinc3 (XLOC_013310), whose expression levels were correlating with body weight gain and glycaemia levels. Interestingly, altered expression of $\beta L I N C 3$ human orthologue was also observed in the islets of T2D donors compared to non-diabetic controls, and was negatively correlated with the BMI of the patients. Of note, the human ortholog of $\beta$ linc 2 could not be identified in this particular study. Both $\beta$ linc 2 and 
Blinc 3 were also found to be upregulated and downregulated, respectively, in islets of overtly obese and diabetic leptin-deficient $d b / d b$ mice, and in control islets exposed in vitro to elevated concentrations of glucose or of the saturated fatty acid palmitate. Ex vivo incubation of human islets with palmitate reduced also the level of $\beta L I N C 3$. The dysregulation of these lncRNAs could be part of the mechanisms leading to $\beta$-cell damage in T2D since altered expression of $\beta$ linc 2 and $\beta$ linc 3 in both MIN6 cells and mouse islets favored $\beta$-cell apoptosis.

The lncRNA GAS5 was also reported to be downregulated in islets of $\mathrm{db} / \mathrm{db}$ mice (131) and in serum samples of T2D donors when compared to non-diabetic control subjects (34). GAS5 (growth arrest-specific transcript 5) is a non-coding tumor suppressor gene whose expression is decreased in diverse cancers (129). GAS5 gene encodes in its exons a spliced long non-coding RNA, named lncRNA GAS5, and expresses from its intronic sequences multiple snoRNAs that are involved in the biosynthesis of ribosomal RNA (295). Deregulation of GAS5 expression in cancer cells affects apoptosis, proliferation, invasion and metastasis of cancer cells (Reviewed in (129)). GAS5 could also be of interest in the field of diabetes.

Downregulation of IncRNA Gas5 in mouse islets or MIN6 cells led to reduce expression of the Ins2 gene and the transcription factor $P d x 1$, NeuroD1 and MafA and an altered insulin secretion in response to glucose (131). Inhibition of lncRNA Gas5 did not impact cell survival but induced cell cycle G1 arrest. Interestingly, genes related to cell cycle (cyclinD1.3 and cyclinE1.2), and insulin secretion (Glut2) were found to be downregulated following GAS5 silencing (131). $\operatorname{circRNAs}$

CircRNA dysregulation has also been observed in the islets of rodent models of T2D. Indeed, ciRS7/Cdr1as level is decreased in $o b / o b$ and $d b / d b$ mouse islets, while that of circHIPK3 is diminished in the islets of $d b / d b$ mice. Interestingly, the islet expression of Hipk3, the parent gene of circHIPK3, is also decreased in $o b / o b$ and $d b / d b$ mice (300) and in humans with T2D (189). Hence, it is likely that islet circHIPK3 dysregulation also occurs in T2D patients, and that altered levels of both functional circRNAs contribute to $\beta$-cell failure in this disease. Unbiased analyses of circRNA expression in islets of different rodent models and of human donors are however required to fully explore the role of these ncRNAs in diabetes. 


\section{$\underline{\text { Extracellular non-coding RNAs and islet cells }}$}

NcRNAs exert a broad array of functions inside the $\beta$-cells but can also be secreted to send signals to other cells. The ncRNAs released from the cells are packaged in vesicle-like structures, such as exosomes and microvesicles $(118,294)$, form complexes with ribonucleoproteins $(14,220,313$, 325) or are transported by high-density lipoproteins (HDL) (320). For instance, miR-375 was recently reported to be released by $\beta$-cells and trapped by HDL (283). Once secreted, the ncRNAs travel in the bloodstream and in other body fluids and some of them are delivered to recipient cells, eventually resulting in gene expression changes (262, 316). NcRNA composition in biological fluids reflects ongoing processes and has been suggested to provide information about disease state, progression, prognosis and response to therapy (222). Thus, circulating ncRNAs represent promising biomarkers to predict and follow the progression of many diseases, including T1D and T2D (17, 289).

\section{Extracellular Vesicles}

The release of extracellular vesicles (EVs) is a highly conserved process used by different organisms for intercellular communication (55, 263, 279). EVs are very heterogeneous and differ in size and intracellular origin, making their classification and characterization a matter of debate $(127,210)$. In general, EVs are called microvesicles when they are generated by the blebbing of the plasma membrane and are larger than $200 \mathrm{~nm}$, while smaller EVs (less than $200 \mathrm{~nm}$ ) formed by the fusion of multivesicular bodies (MVBs) with the plasma membrane are called exosomes or small extracellular vesicles (sEV) $(156,260,318)$. Study of sEV composition revealed that they carry a cargo of diverse biomolecules, including proteins, lipids and nucleic acids, and that their content can vary between cells and conditions $(61,127,155,171)$. Importantly, sEV transport selected pools of miRNAs and other ncRNAs, such as tRFs, that can be transferred in active form to target cells, resulting in changes in the functional properties of the receiving cells $(47,286,290$, 316). While ncRNAs released in the circulation can be carried by different types of vesicles, most studies investigating cell-to-cell ncRNA transfer were performed with EV smaller than 200nm isolated by differential centrifugation. Therefore, in the present review will exclusively focus on this type of vesicles. 
Non-coding RNAs delivered to islet cells

During the initial phases of T1D, immune cells infiltrating the islets of Langerhans were reported to release exosomes that shuttle a specific set of miRNAs to $\beta$-cells (100). These miRNAs (miR142-3p/-5p and miR-155) induce the expression of cytokines and chemokines within the $\beta$-cells and promote apoptosis of these insulin-secreting cells, without affecting the survival of glucagonsecreting cells. Injection of a viral construct producing a transcript capable of binding and sequestering the miRNAs transferred inside the $\beta$-cells decreased by $50 \%$ diabetes incidence in NOD mice (100) (Fig. 8A). In addition to miRNAs, the exosomes released by T lymphocytes carry a variety of other RNA molecules that are likely to be transferred to $\beta$-cells during the autoimmune reaction. In fact, activated $\mathrm{T}$ lymphocytes were very recently reported to produce sEV selectively enriched for tRFs (43) suggesting that besides miRNAs, other non-coding RNAs might also be transferred to $\beta$-cells.

sEV may also carry signals to $\beta$-cells under conditions associated with T2D. Indeed, exosome-like vesicles (ELVs) secreted by skeletal muscle of HFD-fed mice were shown to transfer specific miRNAs to islet cells and to induce $\beta$-cell proliferation (126). A similar effect was obtained with hepatocyte-derived EVs from HFD-fed mice, where $\beta$-cell proliferation was mediated by miR7218-5p carried by these vesicles (85). These discoveries suggest the existence of a sEV-mediated crosstalk between skeletal muscle, liver and $\beta$-cells playing an important role in compensatory islet hyperplasia under conditions of insulin resistance $(85,126)$. (Fig. 8B). More studies point to a contribution of ncRNA cellular exchange through sEV in metabolic homeostasis (reviewed in (102, 116, 222)). Indeed, administration of plasma exosomes isolated from obese mice induces insulin resistance and glucose intolerance in lean mice $(35,36)$. A similar metabolic effect was observed with exosomes, carrying miR-155, released by adipose tissue macrophages from obese mice (342). Moreover, exosomes produced by brown adipose tissue were found to transfer to the liver a specific set of miRNAs (including miR-99b that targets FGF21) resulting in improved glucose tolerance (309). It is therefore tempting to speculate that ncRNAs derived from adipose tissue and macrophages may also modulate $\beta$-cell metabolism and/or inflammation (116). A complex signaling network between key metabolic organs, including liver, pancreas, adipose tissue and skeletal muscles, is essential to regulate glucose and lipid metabolism and to achieve metabolic homeostasis and energy balance. Dysregulation in this organ crosstalk can lead to obesity and T2D. 
As described above, accumulating evidence support the importance of extracellular ncRNAs as mediators of this crosstalk, complementing the well-known role of hormones and metabolites.

Transfer of non-coding RNA released by islet cells

Pancreatic islets and different $\beta$-cell lines have been reported to release extracellular vesicles (77, 101, 176). MiRNAs are horizontally transferred between murine $\beta$-cells in vitro through exosomes (101). Moreover, exposure of MIN6 $\beta$-cells to pro-inflammatory cytokines, affect the composition of exosomal miRNAs (exo-miR) and induce apoptosis in the recipient $\beta$-cells (101). Islet cell exosomes can also actively contribute to the crosstalk with immune cells and stimulate their activation during T1D pathogenesis (Fig. 8A). Day's group was the first to show that insulinomareleased exosomes can activate autoreactive Th1 cells (288) and marginal zone (MZ)-like B cells (23) in pre-diabetic NOD mice. In vivo experiments revealed that immunization with these exosomes accelerates insulitis development in non-obese diabetes-resistant (NOR) mice (288). In a follow up study, they demonstrated that exosomes released by islet mesenchymal stem cells (iMSCs) are able to activate autoreactive B and T cells in NOD mice and increase their IFN- $\gamma$ production (259) (Fig. 8A). More recently, Rutman and colleagues demonstrated that human islet exosomes are internalized by monocytes and B cells, induce T-helper cytokine production and T/ B-cell proliferation (272). However, the cargo of these exosomes was not analyzed. Thus, the potential role of ncRNAs in the observed outcomes remains to be demonstrated.

Exosomal miRNA transfer may also favor islet vascularization and engraftment following transplantation in T1D patients. Indeed, Figliolini and colleagues reported that human islets release sEV containing miR-27b, miR-126, miR-130 and miR-196 and capable of promoting migration, proliferation and survival of islet endothelial cells (IEC) and to induce the expression of proangiogenic and anti-apoptotic factors (77). Interestingly, endothelial progenitor cells (EPC) were also found to secrete sEV favoring insulin release and $\beta$-cell survival of human islet cells (32). In vivo, sEV from EPC enhanced the vascularization of human islets xenotransplanted in SCID mice. However, sEV collected from EPC deficient for the miRNA processing enzyme Dicer1 exerted reduced proliferative and angiogenic effects on IEC, suggesting that miRNAs are important players in this vascularization process resulting from the crosstalk between islet and endothelial cells (32). 
The use of non-coding RNAs released by $\beta$-cells as biomarkers

Since they are stable, resistant to long term storage conditions and can be readily detected in different body fluids, circulating miRNAs have been suggested to represent a novel class of biomarkers capable of predicting the appearance and/or the clinical progression of different forms of diabetes (reviewed in $(222,281)$ ). However, to have clinical significance, biomarkers need to be disease-specific, highly reproducible and sensitive. Despite all efforts made by the scientific community, a specific and unambiguous miRNA signature predicting T1D or T2D development or outcomes is not yet available. In the present review, we describe the most promising strategies and we highlight the remaining challenges for the clinical implementation of circulating ncRNAs as diabetes biomarkers. For an exhaustive list of the studies that addressed this topic, we refer the reader to recent reviews $(222,281)$.

Since miR-375 is highly enriched in pancreatic islet cells, measurements of circulating levels of this miRNA stand out as a very attractive opportunity to monitor $\beta$-cell damage. Indeed, elevated levels of miR-375 were detected in blood samples of streptozotocin-treated mice and NOD mice following $\beta$-cell death at diabetes onset (68). However, analysis performed in $\beta$-cell specific mir-375 KO mice demonstrated that less than 1\% of plasma miR-375 originates from the insulinsecreting cells (173). Thus, the contribution of $\beta$-cells to the total pool of circulating miRNAs is likely to be marginal. In sera of children newly diagnosed with T1D, miR-375 was reported to be increased (166), not changed (67) or even decreased (204). In one study, plasma miR-375 levels were found to be predictive of residual $\beta$-cell function measured by C-peptide released after a meal (275). On the contrary, increased levels of plasma miR-375 following islet transplantation correlated with lower islet yield and poor transplant outcomes $(265,277)$. Taken together, these results highlight the potential lack of reproducibility among studies when measuring global circulating levels of ncRNAs.

Specific analysis of ncRNA content of sEV in plasma or serum samples may be an interesting alternative to global profiling. sEV are released by regulated processes and their cargo varies depending on physiological and pathophysiological conditions. Indeed, human islets exposed to pro-inflammatory cytokines and/or hypoxia released a miRNA cargo that differs from control conditions (278). Interestingly, some of these sEV miRNAs were detected solely in the plasma of streptozotocin-treated mice transplanted with human islets and in the blood of recently 
transplanted patients, suggesting a potential use as diagnostic biomarkers of $\beta$-cell stress after islet transplantation.

To circumvent the limited contribution of $\beta$-cells to total circulating RNA molecules, Vallabhajosyula and colleagues have recently described a method to specifically isolate isletderived exosomes in the context of islet transplantation, based on differences between donor HLA and recipient HLA, in both xenotransplantation (human/ mouse) and allotransplantation (human/ human) (317). Exosomes released by transplanted islets could be purified from recipient blood samples and characterized by proteomic and miRNA profiling. Interestingly, the amount of exosomes originating from transplanted islets and their RNA and proteomic signatures changed during rejection, underlying their potential utilization to monitor graft outcome (317). This strategy is very promising and the identification of additional markers specifically present at the surface of exosomes released by $\beta$-cells would enable their purification from blood samples and would open the door to the discovery of new miRNAs as specific $\beta$-cell biomarkers.

Alternatively, other ncRNAs could potentially be used as biomarkers. For example, the expression of lncRNAs is known to be more tissue- and stage-specific compared to coding genes and miRNAs $(56,58)$. Thus, they may better mirror $\beta$-cell dysfunction and failure during diabetes development (270). Other types of ncRNAs, including tRFs or circRNAs, will also have to be considered (334, 352).

\section{The therapeutic potential of ncRNAs}

As highlighted in the previous sections, there is growing evidence that different classes of ncRNAs are directly involved in the control of islet function and in diabetes development. Indeed, experimental strategies permitting to manipulate the level of selected ncRNAs in animal models can successfully prevent or treat the disease or its complications (reviewed in $(169,261)$ ). Thus, ncRNAs hold a strong therapeutic potential and are attractive targets for the design of new pharmaceutical principles for diabetes treatment. However, translating the findings obtained in animal models to the clinics is a major challenge that faces several important obstacles. Strategies permitting to efficiently modulate the level of ncRNAs are already available. However, these strategies have major drawbacks and their use in humans cannot yet be envisaged. One of the approaches available to control the activity of ncRNAs takes advantage of sense or antisense oligonucleotide derivatives that mimic or block the selected ncRNA (271, 319). Although these 
molecules can be modified to increase their stability and promote their transfer inside the tissues, the main obstacle for the usage of these molecules is that they cannot be specifically targeted to selected islet cells. Thus, this approach is likely to result in unacceptable side effects. An alternative strategy allowing to circumvent this problem is based on the use of viral constructs driven by cellspecific promoters. These constructs can be designed to either overexpress the ncRNA (199) or to produce transcripts capable of interfering with the activity of the selected ncRNA (63). Although these strategies have already been successfully applied to modulate the activity of miRNAs in rodent islet cells $(100,123,228)$, the use of viral constructs that chronically modulate the level of ncRNAs to treat diabetes in humans would raise major safety concerns.

There is no doubts that ncRNAs hold a great potential for the treatment of diabetes but the tools presently available to modulate the activity of these non-coding transcripts are not appropriate for therapeutic usage in human. New approaches allowing an efficient delivery of molecules, including RNA derivatives, to specific target cells are currently intensively investigated. Thus, there is hope that in the near future we will dispose of better approaches to efficiently and safely deliver molecules capable of correcting the activity of selected ncRNAs to islet cells. This would be instrumental to open the way to the design of therapeutic tools aiming at treating diabetes by restoring proper ncRNA function.

\section{Conclusion}

The discovery that a large fraction of the mammalian genomes is transcribed and generates a plethora of ncRNAs with regulatory functions opened a new era in the elucidation of the mechanisms underlying the development of most human diseases, including diabetes mellitus. Fifteen years of intense investigations permitted to obtain an exhaustive picture of the miRNAs expressed in $\alpha$ - and $\beta$-cells and to identify changes in the miRNA profile occurring in association with obesity, inflammation and diabetes. The involvement of these small ncRNAs in all aspects of islet biology is now well established and there are no doubts that dysregulation of important miRNAs can contribute to the development of different forms of diabetes. Strategies to correct the level of dysregulated miRNAs are emerging and may soon permit the design of new therapeutic principles to prevent or treat diabetes. The presence of miRNAs in plasma and other body fluids prompted many groups to assess the value of these circulating ncRNAs as biomarkers of $\beta$-cell function and/or loss. However, because of the heterogeneous origin of the circulating miRNAs, 
measurements of the total pool of blood miRNAs appear to be inappropriate to detect specific changes occurring in $\beta$-cells. In the future, approaches permitting the isolation of miRNAs selectively released by $\beta$-cells will probably permit to overcome this obstacle.

It has now become clear that, beside miRNAs, islet cells and, in particular $\beta$-cells, express a large number of other non-coding transcripts, including piRNAs, tRFs, snoRNAs, lncRNAs and circRNAs. These classes of ncRNAs are less well characterized than miRNAs. However, there is already evidence indicating that these newly discovered transcripts play important roles in the differentiation and function of islet cells and that they can be dysregulated under conditions associated with diabetes development. We are still learning how these ncRNAs are generated and how they mediate their activities inside the cells. Moreover, we are only beginning to understand the potential interactions existing between these different classes of ncRNAs. Answering these questions will provide a more complete view of the complex regulatory networks governing islet cell functions under normal and disease conditions. The coming years promise to unveil new secrets about the fascinating RNA world hidden inside the cells, hopefully providing new ground to elucidate the causes of diabetes mellitus and to design better treatments for diabetic patients.

\section{Acknowledgement}

The authors are supported by grants of the Swiss National Science Foundation 310030-188447, from European Foundation for the Study of Diabetes and from Société Francophone du Diabète. Figure 8 has been realized using Servier Medical Art. 


\section{References}

1. An integrated encyclopedia of DNA elements in the human genome. Nature 489: 57-74, 2012.

2. Ackermann AM, Wang Z, Schug J, Naji A, and Kaestner KH. Integration of ATACseq and RNA-seq identifies human alpha cell and beta cell signature genes. Mol Metab 5: 233-244, 2016.

3. Agarwal V, Bell GW, Nam JW, and Bartel DP. Predicting effective microRNA target sites in mammalian mRNAs. Elife 4: 2015.

4. Aguayo-Mazzucato C, Andle J, Lee TB, Jr., Midha A, Talemal L, Chipashvili V, Hollister-Lock J, van Deursen J, Weir G, and Bonner-Weir S. Acceleration of beta Cell Aging Determines Diabetes and Senolysis Improves Disease Outcomes. Cell Metab 30: 129-142 e124, 2019.

5. Aguayo-Mazzucato C, Koh A, El Khattabi I, Li WC, Toschi E, Jermendy A, Juhl K, Mao K, Weir GC, Sharma A, and Bonner-Weir S. Mafa expression enhances glucoseresponsive insulin secretion in neonatal rat beta cells. Diabetologia 54: 583-593, 2011.

6. Aguayo-Mazzucato C, Sanchez-Soto C, Godinez-Puig V, Gutierrez-Ospina G, and Hiriart M. Restructuring of pancreatic islets and insulin secretion in a postnatal critical window. PLOS ONE 1: e35, 2006.

7. Ahren B. Glucagon--Early breakthroughs and recent discoveries. Peptides 67: 74-81, 2015. 8. Akerman I, Tu Z, Beucher A, Rolando DMY, Sauty-Colace C, Benazra M, Nakic N, Yang J, Wang H, Pasquali L, Moran I, Garcia-Hurtado J, Castro N, Gonzalez-Franco R, Stewart AF, Bonner C, Piemonti L, Berney T, Groop L, Kerr-Conte J, Pattou F, Argmann C, Schadt E, Ravassard P, and Ferrer J. Human Pancreatic beta Cell lncRNAs Control CellSpecific Regulatory Networks. Cell Metab 25: 400-411, 2017.

9. Alejandro EU, Gregg B, Wallen T, Kumusoglu D, Meister D, Chen A, Merrins MJ, Satin LS, Liu M, Arvan P, and Bernal-Mizrachi E. Maternal diet-induced microRNAs and mTOR underlie beta cell dysfunction in offspring. J Clin Invest 2014.

10. Ameres SL, and Zamore PD. Diversifying microRNA sequence and function. Nature reviews 14: 475-488, 2013.

11. Angulo MA, Butler MG, and Cataletto ME. Prader-Willi syndrome: a review of clinical, genetic, and endocrine findings. J Endocrinol Invest 38: 1249-1263, 2015.

12. Araujo EP, Amaral ME, Souza CT, Bordin S, Ferreira F, Saad MJ, Boschero AC, Magalhaes EC, and Velloso LA. Blockade of IRS1 in isolated rat pancreatic islets improves glucose-induced insulin secretion. FEBS Lett 531: 437-442, 2002.

13. Arnes L, Akerman I, Balderes DA, Ferrer J, and Sussel L. betalinc1 encodes a long noncoding RNA that regulates islet beta-cell formation and function. Genes Dev 30: 502-507, 2016. 14. Arroyo JD, Chevillet JR, Kroh EM, Ruf IK, Pritchard CC, Gibson DF, Mitchell PS, Bennett CF, Pogosova-Agadjanyan EL, Stirewalt DL, Tait JF, and Tewari M. Argonaute2 complexes carry a population of circulating microRNAs independent of vesicles in human plasma. Proc Natl Acad Sci U S A 108: 5003-5008, 2011.

15. Atkinson MA, Eisenbarth GS, and Michels AW. Type 1 diabetes. Lancet 383: 69-82, 2014.

16. Backe MB, Novotny GW, Christensen DP, Grunnet LG, and Mandrup-Poulsen T. Altering beta-cell number through stable alteration of miR-21 and miR-34a expression. Islets 6: 2014. 
17. Backes C, Meese E, and Keller A. Specific miRNA Disease Biomarkers in Blood, Serum and Plasma: Challenges and Prospects. Mol Diagn Ther 20: 509-518, 2016.

18. Baird JD, and Farquhar JW. Insulin-secreting capacity in newborn infants of normal and diabetic women. Lancet 1: 71-74, 1962.

19. Barbagallo D, Piro S, Condorelli AG, Mascali LG, Urbano F, Parrinello N, Monello A, Statello L, Ragusa M, Rabuazzo AM, Di Pietro C, Purrello F, and Purrello M. miR-2963p, miR-298-5p and their downstream networks are causally involved in the higher resistance of mammalian pancreatic alpha cells to cytokine-induced apoptosis as compared to beta cells. BMC Genomics 14: 62, 2013.

20. Baroukh N, Ravier MA, Loder MK, Hill EV, Bounacer A, Scharfmann R, Rutter GA, and Van Obberghen E. MicroRNA-124a regulates Foxa2 expression and intracellular signaling in pancreatic beta-cell lines. J Biol Chem 282: 19575-19588, 2007.

21. Bartel DP. Metazoan MicroRNAs. Cell 173: 20-51, 2018.

22. Bartel DP. MicroRNAs: target recognition and regulatory functions. Cell 136: 215-233, 2009.

23. Bashratyan R, Sheng H, Regn D, Rahman MJ, and Dai YD. Insulinoma-released exosomes activate autoreactive marginal zone-like B cells that expand endogenously in prediabetic NOD mice. Eur J Immunol 43: 2588-2597, 2013.

24. Belgardt BF, Ahmed K, Spranger M, Latreille M, Denzler R, Kondratiuk N, von Meyenn F, Villena FN, Herrmanns K, Bosco D, Kerr-Conte J, Pattou F, Rulicke T, and Stoffel M. The microRNA-200 family regulates pancreatic beta cell survival in type 2 diabetes. Nat Med 21: 619-627, 2015.

25. Benner C, van der Meulen T, Caceres E, Tigyi K, Donaldson CJ, and Huising MO. The transcriptional landscape of mouse beta cells compared to human beta cells reveals notable species differences in long non-coding RNA and protein-coding gene expression. BMC Genomics 15: 620, 2014.

26. Betel D, Sheridan R, Marks DS, and Sander C. Computational analysis of mouse piRNA sequence and biogenesis. PLoS Comput Biol 3: e222, 2007.

27. Bijkerk R, Esguerra JLS, Ellenbroek JH, Au YW, Hanegraaf MAJ, de Koning EJ, Eliasson L, and van Zonneveld AJ. In Vivo Silencing of MicroRNA-132 Reduces Blood Glucose and Improves Insulin Secretion. Nucleic Acid Ther 29: 67-72, 2019.

28. Bratkovic T, Bozic J, and Rogelj B. Functional diversity of small nucleolar RNAs. Nucleic Acids Res 2019.

29. Bravo-Egana V, Rosero S, Klein D, Jiang Z, Vargas N, Tsinoremas N, Doni M, Podetta M, Ricordi C, Molano RD, Pileggi A, and Pastori RL. Inflammation-Mediated Regulation of MicroRNA Expression in Transplanted Pancreatic Islets. J Transplant 2012: 723614, 2012.

30. Burnett LC, Hubner G, LeDuc CA, Morabito MV, Carli JFM, and Leibel RL. Loss of the imprinted, non-coding Snord116 gene cluster in the interval deleted in the Prader Willi syndrome results in murine neuronal and endocrine pancreatic developmental phenotypes. Hum Mol Genet 26: 4606-4616, 2017.

31. Burnett LC, LeDuc CA, Sulsona CR, Paull D, Rausch R, Eddiry S, Carli JF, Morabito MV, Skowronski AA, Hubner G, Zimmer M, Wang L, Day R, Levy B, Fennoy I, Dubern B, Poitou C, Clement K, Butler MG, Rosenbaum M, Salles JP, Tauber M, Driscoll DJ, Egli D, and Leibel RL. Deficiency in prohormone convertase PC1 impairs prohormone processing in Prader-Willi syndrome. J Clin Invest 127: 293-305, 2017.

32. Cantaluppi V, Biancone L, Figliolini F, Beltramo S, Medica D, Deregibus MC, Galimi F, Romagnoli R, Salizzoni M, Tetta C, Segoloni GP, and Camussi G. Microvesicles derived 
from endothelial progenitor cells enhance neoangiogenesis of human pancreatic islets. Cell Transplant 21: 1305-1320, 2012.

33. Carrieri C, Cimatti L, Biagioli M, Beugnet A, Zucchelli S, Fedele S, Pesce E, Ferrer I, Collavin L, Santoro C, Forrest AR, Carninci P, Biffo S, Stupka E, and Gustincich S. Long non-coding antisense RNA controls Uchl1 translation through an embedded SINEB2 repeat. Nature 491: 454-457, 2012.

34. Carter G, Miladinovic B, Patel AA, Deland L, Mastorides S, and Patel NA. Circulating long noncoding RNA GAS5 levels are correlated to prevalence of type 2 diabetes mellitus. $B B A$ Clin 4: 102-107, 2015.

35. Castano C, Kalko S, Novials A, and Parrizas M. Obesity-associated exosomal miRNAs modulate glucose and lipid metabolism in mice. Proc Natl Acad Sci U S A 115: 12158-12163, 2018.

36. Castano C, Novials A, and Parrizas M. Exosomes and diabetes. Diabetes Metab Res Rev e3107, 2018.

37. Cech TR, and Steitz JA. The noncoding RNA revolution-trashing old rules to forge new ones. Cell 157: 77-94, 2014.

38. Cesana M, Cacchiarelli D, Legnini I, Santini T, Sthandier O, Chinappi M, Tramontano A, and Bozzoni I. A long noncoding RNA controls muscle differentiation by functioning as a competing endogenous RNA. Cell 147: 358-369, 2011.

39. Chen H, Gu X, Liu Y, Wang J, Wirt SE, Bottino R, Schorle H, Sage J, and Kim SK. PDGF signalling controls age-dependent proliferation in pancreatic beta-cells. Nature 478: 349355, 2011.

40. Chen Q, Yan M, Cao Z, Li X, Zhang Y, Shi J, Feng GH, Peng H, Zhang X, Zhang Y, Qian J, Duan E, Zhai Q, and Zhou Q. Sperm tsRNAs contribute to intergenerational inheritance of an acquired metabolic disorder. Science 351: 397-400, 2016.

41. Chen Z, Qi M, Shen B, Luo G, Wu Y, Li J, Lu Z, Zheng Z, Dai Q, and Wang H. Transfer RNA demethylase ALKBH3 promotes cancer progression via induction of tRNA-derived small RNAs. Nucleic Acids Res 47: 2533-2545, 2019.

42. Cheng J, Metge F, and Dieterich C. Specific identification and quantification of circular RNAs from sequencing data. Bioinformatics 32: 1094-1096, 2016.

43. Chiou NT, Kageyama R, and Ansel KM. Selective Export into Extracellular Vesicles and Function of tRNA Fragments during T Cell Activation. Cell Rep 25: 3356-3370 e3354, 2018.

44. Chitnis NS, Pytel D, Bobrovnikova-Marjon E, Pant D, Zheng H, Maas NL, Frederick B, Kushner JA, Chodosh LA, Koumenis C, Fuchs SY, and Diehl JA. miR-211 is a prosurvival microRNA that regulates chop expression in a PERK-dependent manner. Mol Cell 48: 353-364, 2012.

45. Cho JH, Chen L, Kim MH, Chow RH, Hille B, and Koh DS. Characteristics and functions of \{alpha\}-amino-3-hydroxy-5-methyl-4-isoxazolepropionate receptors expressed in mouse pancreatic \{alpha\}-cells. Endocrinology 151: 1541-1550, 2010.

46. Cho YS, Chen CH, Hu C, Long J, Ong RT, Sim X, Takeuchi F, Wu Y, Go MJ, Yamauchi T, Chang YC, Kwak SH, Ma RC, Yamamoto K, Adair LS, Aung T, Cai Q, Chang LC, Chen YT, Gao Y, Hu FB, Kim HL, Kim S, Kim YJ, Lee JJ, Lee NR, Li Y, Liu JJ, Lu W, Nakamura J, Nakashima E, Ng DP, Tay WT, Tsai FJ, Wong TY, Yokota M, Zheng W, Zhang R, Wang C, So WY, Ohnaka K, Ikegami H, Hara K, Cho YM, Cho NH, Chang TJ, Bao Y, Hedman AK, Morris AP, McCarthy MI, Consortium D, Mu TC, Takayanagi R, Park KS, Jia W, Chuang LM, Chan JC, Maeda S, Kadowaki T, Lee JY, Wu JY, Teo YY, Tai ES, Shu 
XO, Mohlke KL, Kato N, Han BG, and Seielstad M. Meta-analysis of genome-wide association studies identifies eight new loci for type 2 diabetes in east Asians. Nature genetics 44: 67-72, 2011. 47. Conine CC, Sun F, Song L, Rivera-Perez JA, and Rando OJ. Small RNAs Gained during Epididymal Transit of Sperm Are Essential for Embryonic Development in Mice. Developmental cell 46: 470-480 e473, 2018.

48. Conrad E, Stein R, and Hunter CS. Revealing transcription factors during human pancreatic beta cell development. Trends Endocrinol Metab 25: 407-414, 2014.

49. Correa-Medina M, Bravo-Egana V, Rosero S, Ricordi C, Edlund H, Diez J, and Pastori RL. MicroRNA miR-7 is preferentially expressed in endocrine cells of the developing and adult human pancreas. Gene Expr Patterns 9: 193-199, 2009.

50. Cosentino C, Toivonen S, Diaz Villamil E, Atta M, Ravanat JL, Demine S, Schiavo AA, Pachera N, Deglasse JP, Jonas JC, Balboa D, Otonkoski T, Pearson ER, Marchetti P, Eizirik DL, Cnop M, and Igoillo-Esteve M. Pancreatic beta-cell tRNA hypomethylation and fragmentation link TRMT10A deficiency with diabetes. Nucleic Acids Res 46: 10302-10318, 2018. 51. Cozen AE, Quartley E, Holmes AD, Hrabeta-Robinson E, Phizicky EM, and Lowe TM. ARM-seq: AlkB-facilitated RNA methylation sequencing reveals a complex landscape of modified tRNA fragments. Nat Methods 12: 879-884, 2015.

52. Cunha DA, Igoillo-Esteve M, Gurzov EN, Germano CM, Naamane N, Marhfour I, Fukaya M, Vanderwinden JM, Gysemans C, Mathieu C, Marselli L, Marchetti P, Harding HP, Ron D, Eizirik DL, and Cnop M. Death protein 5 and p53-upregulated modulator of apoptosis mediate the endoplasmic reticulum stress-mitochondrial dialog triggering lipotoxic rodent and human beta-cell apoptosis. Diabetes 61: 2763-2775, 2012.

53. da Rocha ST, Edwards CA, Ito M, Ogata T, and Ferguson-Smith AC. Genomic imprinting at the mammalian Dlk1-Dio3 domain. Trends Genet 24: 306-316, 2008.

54. De Tata V. Age-related impairment of pancreatic Beta-cell function: pathophysiological and cellular mechanisms. Front Endocrinol (Lausanne) 5: 138, 2014.

55. Deatherage BL, and Cookson BT. Membrane vesicle release in bacteria, eukaryotes, and archaea: a conserved yet underappreciated aspect of microbial life. Infect Immun 80: 1948-1957, 2012.

56. Derrien T, Johnson R, Bussotti G, Tanzer A, Djebali S, Tilgner H, Guernec G, Martin D, Merkel A, Knowles DG, Lagarde J, Veeravalli L, Ruan X, Ruan Y, Lassmann T, Carninci P, Brown JB, Lipovich L, Gonzalez JM, Thomas M, Davis CA, Shiekhattar R, Gingeras TR, Hubbard TJ, Notredame C, Harrow J, and Guigo R. The GENCODE v7 catalog of human long noncoding RNAs: analysis of their gene structure, evolution, and expression. Genome Res 22: 1775-1789, 2012.

57. Dibble CC, and Cantley LC. Regulation of mTORC1 by PI3K signaling. Trends in cell biology 25: 545-555, 2015.

58. Djebali S, Davis CA, Merkel A, Dobin A, Lassmann T, Mortazavi A, Tanzer A, Lagarde J, Lin W, Schlesinger F, Xue C, Marinov GK, Khatun J, Williams BA, Zaleski C, Rozowsky J, Roder M, Kokocinski F, Abdelhamid RF, Alioto T, Antoshechkin I, Baer MT, Bar NS, Batut P, Bell K, Bell I, Chakrabortty S, Chen X, Chrast J, Curado J, Derrien T, Drenkow J, Dumais E, Dumais J, Duttagupta R, Falconnet E, Fastuca M, Fejes-Toth K, Ferreira P, Foissac S, Fullwood MJ, Gao H, Gonzalez D, Gordon A, Gunawardena H, Howald C, Jha S, Johnson R, Kapranov P, King B, Kingswood C, Luo OJ, Park E, Persaud K, Preall JB, Ribeca P, Risk B, Robyr D, Sammeth M, Schaffer L, See LH, Shahab A, Skancke J, Suzuki AM, Takahashi H, Tilgner H, Trout D, Walters N, Wang H, Wrobel J, Yu Y, Ruan X, Hayashizaki Y, Harrow J, Gerstein M, Hubbard T, Reymond A, Antonarakis SE, 
Hannon G, Giddings MC, Ruan Y, Wold B, Carninci P, Guigo R, and Gingeras TR. Landscape of transcription in human cells. Nature 489: 101-108, 2012.

59. Dooley J, Garcia-Perez JE, Sreenivasan J, Schlenner SM, Vangoitsenhoven R, Papadopoulou AS, Tian L, Schonefeldt S, Serneels L, Deroose C, Staats KA, Van der Schueren B, De Strooper B, McGuinness OP, Mathieu C, and Liston A. The microRNA-29 Family Dictates the Balance Between Homeostatic and Pathological Glucose Handling in Diabetes and Obesity. Diabetes 65: 53-61, 2016.

60. Dumortier O, Hinault C, Gautier N, Patouraux S, Casamento V, and Van Obberghen E. Maternal protein restriction leads to pancreatic failure in offspring: role of misexpressed microRNA-375. Diabetes 63: 3416-3427, 2014.

61. Durcin M, Fleury A, Taillebois E, Hilairet G, Krupova Z, Henry C, Truchet S, Trotzmuller M, Kofeler H, Mabilleau G, Hue O, Andriantsitohaina R, Martin P, and Le Lay S. Characterisation of adipocyte-derived extracellular vesicle subtypes identifies distinct protein and lipid signatures for large and small extracellular vesicles. J Extracell Vesicles 6: 1305677, 2017.

62. Dusaulcy R, Handgraaf S, Visentin F, Vesin C, Philippe J, and Gosmain Y. miR-132$3 p$ is a positive regulator of alpha-cell mass and is downregulated in obese hyperglycemic mice. Mol Metab 22: 84-95, 2019.

63. Ebert MS, Neilson JR, and Sharp PA. MicroRNA sponges: competitive inhibitors of small RNAs in mammalian cells. Nat Methods 4: 721-726, 2007.

64. Eizirik DL, Colli ML, and Ortis F. The role of inflammation in insulitis and beta-cell loss in type 1 diabetes. Nat Rev Endocrinol 5: 219-226, 2009.

65. El Ouaamari A, Baroukh N, Martens GA, Lebrun P, Pipeleers D, and van Obberghen E. miR-375 targets 3'-phosphoinositide-dependent protein kinase-1 and regulates glucose-induced biological responses in pancreatic beta-cells. Diabetes 57: 2708-2717, 2008.

66. Enright AJ, John B, Gaul U, Tuschl T, Sander C, and Marks DS. MicroRNA targets in Drosophila. Genome Biol 5: R1, 2003.

67. Erener S, Marwaha A, Tan R, Panagiotopoulos C, and Kieffer TJ. Profiling of circulating microRNAs in children with recent onset of type 1 diabetes. JCI Insight 2: e89656, 2017.

68. Erener S, Mojibian M, Fox JK, Denroche HC, and Kieffer TJ. Circulating miR-375 as a biomarker of beta-cell death and diabetes in mice. Endocrinology 154: 603-608, 2013.

69. Esguerra JL, Bolmeson C, Cilio CM, and Eliasson L. Differential Glucose-Regulation of MicroRNAs in Pancreatic Islets of Non-Obese Type 2 Diabetes Model Goto-Kakizaki Rat. PLoS One 6: e18613, 2011.

70. Esguerra JL, and Eliasson L. Functional implications of long non-coding RNAs in the pancreatic islets of Langerhans. Front Genet 5: 209, 2014.

71. Esguerra JL, Mollet IG, Salunkhe VA, Wendt A, and Eliasson L. Regulation of Pancreatic Beta Cell Stimulus-Secretion Coupling by microRNAs. Genes (Basel) 5: 1018-1031, 2014.

72. Esguerra JLS, Nagao M, Ofori JK, Wendt A, and Eliasson L. MicroRNAs in islet hormone secretion. Diabetes Obes Metab 20 Suppl 2: 11-19, 2018.

73. Fadista J, Vikman P, Laakso EO, Mollet IG, Esguerra JL, Taneera J, Storm P, Osmark P, Ladenvall C, Prasad RB, Hansson KB, Finotello F, Uvebrant K, Ofori JK, Di Camillo B, Krus U, Cilio CM, Hansson O, Eliasson L, Rosengren AH, Renstrom E, Wollheim CB, and Groop L. Global genomic and transcriptomic analysis of human pancreatic islets reveals novel genes influencing glucose metabolism. Proc Natl Acad Sci U S A 111: 13924-13929, 2014. 
74. Faghihi MA, Modarresi F, Khalil AM, Wood DE, Sahagan BG, Morgan TE, Finch CE, St Laurent G, 3rd, Kenny PJ, and Wahlestedt C. Expression of a noncoding RNA is elevated in Alzheimer's disease and drives rapid feed-forward regulation of beta-secretase. Nat Med 14: 723-730, 2008.

75. Fajas L, Annicotte JS, Miard S, Sarruf D, Watanabe M, and Auwerx J. Impaired pancreatic growth, beta cell mass, and beta cell function in E2F1 (-/- )mice. J Clin Invest 113: 1288-1295, 2004.

76. Fernandez-Twinn DS, Hjort L, Novakovic B, Ozanne SE, and Saffery R. Intrauterine programming of obesity and type 2 diabetes. Diabetologia 62: 1789-1801, 2019.

77. Figliolini F, Cantaluppi V, De Lena M, Beltramo S, Romagnoli R, Salizzoni M, Melzi R, Nano R, Piemonti L, Tetta C, Biancone L, and Camussi G. Isolation, characterization and potential role in beta cell-endothelium cross-talk of extracellular vesicles released from human pancreatic islets. PLoS One 9: e102521, 2014.

78. Filios SR, and Shalev A. beta-Cell MicroRNAs: Small but Powerful. Diabetes 64: 36313644, 2015.

79. Filios SR, Xu G, Chen J, Hong K, Jing G, and Shalev A. MicroRNA-200 Is Induced by Thioredoxin-interacting Protein and Regulates Zeb1 Protein Signaling and Beta Cell Apoptosis. $J$ Biol Chem 289: 36275-36283, 2014.

80. Francis N, Moore M, Rutter GA, and Burns C. The role of microRNAs in the pancreatic differentiation of pluripotent stem cells. Microrna 3: 54-63, 2014.

81. Friedlander MR, Chen W, Adamidi C, Maaskola J, Einspanier R, Knespel S, and Rajewsky N. Discovering microRNAs from deep sequencing data using miRDeep. Nat Biotechnol 26: 407-415, 2008.

82. Friedlander MR, Mackowiak SD, Li N, Chen W, and Rajewsky N. miRDeep2 accurately identifies known and hundreds of novel microRNA genes in seven animal clades. Nucleic Acids Res 40: 37-52, 2012.

83. Friedman RC, Farh KK, Burge CB, and Bartel DP. Most mammalian mRNAs are conserved targets of microRNAs. Genome Res 19: 92-105, 2009.

84. Frost RJ, and Olson EN. Control of glucose homeostasis and insulin sensitivity by the Let-7 family of microRNAs. Proc Natl Acad Sci U S A 108: 21075-21080, 2011.

85. Fu Q, Li Y, Jiang H, Shen Z, Gao R, He Y, Liu Y, Xu K, and Yang T. Hepatocytes derived extracellular vesicles from high-fat diet induced obese mice modulate genes expression and proliferation of islet beta cells. Biochem Biophys Res Commun 516: 1159-1166, 2019.

86. Fu Q, and Wang PJ. Mammalian piRNAs: Biogenesis, function, and mysteries. Spermatogenesis 4: e27889, 2014.

87. Furman BL. Streptozotocin-Induced Diabetic Models in Mice and Rats. Curr Protoc Pharmacol 70: 547 41-20, 2015.

88. Gabory A, Ripoche MA, Le Digarcher A, Watrin F, Ziyyat A, Forne T, Jammes H, Ainscough JF, Surani MA, Journot L, and Dandolo L. H19 acts as a trans regulator of the imprinted gene network controlling growth in mice. Development 136: 3413-3421, 2009.

89. Gao Y, Zhang J, and Zhao F. Circular RNA identification based on multiple seed matching. Brief Bioinform 19: 803-810, 2018.

90. Gentilella R, Pechtner V, Corcos A, and Consoli A. Glucagon-like peptide-1 receptor agonists in type 2 diabetes treatment: are they all the same? Diabetes Metab Res Rev 35: e3070, 2019.

91. Gkirtzou K, Tsamardinos I, Tsakalides P, and Poirazi P. MatureBayes: a probabilistic algorithm for identifying the mature miRNA within novel precursors. PLoS One 5: e11843, 2010. 
92. Glazar P, Papavasileiou P, and Rajewsky N. circBase: a database for circular RNAs. RNA 20: 1666-1670, 2014.

93. Gong C, and Maquat LE. IncRNAs transactivate STAU1-mediated mRNA decay by duplexing with 3' UTRs via Alu elements. Nature 470: 284-288, 2011.

94. Goodarzi H, Liu X, Nguyen HC, Zhang S, Fish L, and Tavazoie SF. Endogenous tRNADerived Fragments Suppress Breast Cancer Progression via YBX1 Displacement. Cell 161: 790802, 2015.

95. Gou LT, Dai P, Yang JH, Xue Y, Hu YP, Zhou Y, Kang JY, Wang X, Li H, Hua MM, Zhao S, Hu SD, Wu LG, Shi HJ, Li Y, Fu XD, Qu LH, Wang ED, and Liu MF. Pachytene piRNAs instruct massive mRNA elimination during late spermiogenesis. Cell research 25: 266, 2015.

96. Grasso S, Messina A, Saporito N, and Reitano G. Serum-insulin response to glucose and aminoacids in the premature infant. Lancet 2: 755-756, 1968.

97. Grieco FA, Schiavo AA, Brozzi F, Juan-Mateu J, Bugliani M, Marchetti P, and Eizirik D. The microRNAs miR-211-5p and miR-204-5p modulate ER stress in human beta cells. $J$ Mol Endocrinol 2019.

98. Grieco FA, Sebastiani G, Juan-Mateu J, Villate O, Marroqui L, Ladriere L, Tugay K, Regazzi R, Bugliani M, Marchetti P, Dotta F, and Eizirik DL. MicroRNAs miR-23a-3p, miR23b-3p, and miR-149-5p Regulate the Expression of Proapoptotic BH3-Only Proteins DP5 and PUMA in Human Pancreatic beta-Cells. Diabetes 66: 100-112, 2017.

99. Guay C, Jacovetti C, Nesca V, Motterle A, Tugay K, and Regazzi R. Emerging roles of non-coding RNAs in pancreatic beta-cell function and dysfunction. Diabetes Obes Metab 14 Suppl 3: 12-21, 2012.

100. Guay C, Kruit JK, Rome S, Menoud V, Mulder NL, Jurdzinski A, Mancarella F, Sebastiani G, Donda A, Gonzalez BJ, Jandus C, Bouzakri K, Pinget M, Boitard C, Romero P, Dotta F, and Regazzi R. Lymphocyte-Derived Exosomal MicroRNAs Promote Pancreatic beta Cell Death and May Contribute to Type 1 Diabetes Development. Cell Metab 29: 348-361 e346, 2019.

101. Guay C, Menoud V, Rome S, and Regazzi R. Horizontal transfer of exosomal microRNAs transduce apoptotic signals between pancreatic beta-cells. Cell Commun Signal 13: 17, 2015.

102. Guay C, and Regazzi R. Exosomes as new players in metabolic organ cross-talk. Diabetes Obes Metab 19 Suppl 1: 137-146, 2017.

103. Guay C, and Regazzi R. MicroRNAs and the functional beta cell mass: For better or worse. Diabetes Metab 41: 369-377, 2015.

104. Guay C, and Regazzi R. Role of islet microRNAs in diabetes: which model for which question? Diabetologia 58: 456-463, 2015.

105. Guttman M, Donaghey J, Carey BW, Garber M, Grenier JK, Munson G, Young G, Lucas AB, Ach R, Bruhn L, Yang X, Amit I, Meissner A, Regev A, Rinn JL, Root DE, and Lander ES. lincRNAs act in the circuitry controlling pluripotency and differentiation. Nature 477: 295-300, 2011.

106. Guttman M, and Rinn JL. Modular regulatory principles of large non-coding RNAs. Nature 482: 339-346, 2012.

107. Gyuris A, Navarrete-Perea J, Jo A, Cristea S, Zhou S, Fraser K, Wei Z, Krichevsky AM, Weissleder R, Lee H, Gygi SP, and Charest A. Physical and Molecular Landscapes of Mouse Glioma Extracellular Vesicles Define Heterogeneity. Cell reports 27: 3972-3987 e3976, 2019. 
108. Hacisuleyman E, Goff LA, Trapnell C, Williams A, Henao-Mejia J, Sun L, McClanahan P, Hendrickson DG, Sauvageau M, Kelley DR, Morse M, Engreitz J, Lander ES, Guttman M, Lodish HF, Flavell R, Raj A, and Rinn JL. Topological organization of multichromosomal regions by the long intergenic noncoding RNA Firre. Nat Struct Mol Biol 21: 198-206, 2014.

109. Hackenberg M, Rodriguez-Ezpeleta N, and Aransay AM. miRanalyzer: an update on the detection and analysis of microRNAs in high-throughput sequencing experiments. Nucleic Acids Res 39: W132-138, 2011.

110. Hackenberg M, Sturm M, Langenberger D, Falcon-Perez JM, and Aransay AM. miRanalyzer: a microRNA detection and analysis tool for next-generation sequencing experiments. Nucleic Acids Res 37: W68-76, 2009.

111. Hansen TB. Improved circRNA Identification by Combining Prediction Algorithms. Front Cell Dev Biol 6: 20, 2018.

112. Helwak A, Kudla G, Dudnakova T, and Tollervey D. Mapping the human miRNA interactome by CLASH reveals frequent noncanonical binding. Cell 153: 654-665, 2013.

113. Henaoui IS, Jacovetti C, Guerra Mollet I, Guay C, Sobel J, Eliasson L, and Regazzi R. PIWI-interacting RNAs as novel regulators of pancreatic beta cell function. Diabetologia 60: 1977-1986, 2017.

114. Holdt LM, Kohlmaier A, and Teupser D. Molecular roles and function of circular RNAs in eukaryotic cells. Cell Mol Life Sci 75: 1071-1098, 2018.

115. Hong K, Xu G, Grayson TB, and Shalev A. Cytokines Regulate beta-Cell Thioredoxininteracting Protein (TXNIP) via Distinct Mechanisms and Pathways. J Biol Chem 291: 8428-8439, 2016.

116. Huang-Doran I, Zhang CY, and Vidal-Puig A. Extracellular Vesicles: Novel Mediators of Cell Communication In Metabolic Disease. Trends Endocrinol Metab 28: 3-18, 2017.

117. Huang TH, Fan B, Rothschild MF, Hu ZL, Li K, and Zhao SH. MiRFinder: an improved approach and software implementation for genome-wide fast microRNA precursor scans. BMC Bioinformatics 8: 341, 2007.

118. Hunter MP, Ismail N, Zhang X, Aguda BD, Lee EJ, Yu L, Xiao T, Schafer J, Lee ML, Schmittgen TD, Nana-Sinkam SP, Jarjoura D, and Marsh CB. Detection of microRNA expression in human peripheral blood microvesicles. PLoS One 3: e3694, 2008.

119. Igoillo-Esteve M, Genin A, Lambert N, Desir J, Pirson I, Abdulkarim B, Simonis N, Drielsma A, Marselli L, Marchetti P, Vanderhaeghen P, Eizirik DL, Wuyts W, Julier C, Chakera AJ, Ellard S, Hattersley AT, Abramowicz M, and Cnop M. tRNA methyltransferase homolog gene TRMT10A mutation in young onset diabetes and primary microcephaly in humans. PLoS Genet 9: e1003888, 2013.

120. Ivanov P. Emerging Roles of tRNA-derived Fragments in Viral Infections: The Case of Respiratory Syncytial Virus. Molecular therapy : the journal of the American Society of Gene Therapy 23: 1557-1558, 2015.

121. Ivanov P, Emara MM, Villen J, Gygi SP, and Anderson P. Angiogenin-induced tRNA fragments inhibit translation initiation. Molecular cell 43: 613-623, 2011.

122. Jacovetti C, Abderrahmani A, Parnaud G, Jonas JC, Peyot ML, Cornu M, Laybutt R, Meugnier E, Rome S, Thorens B, Prentki M, Bosco D, and Regazzi R. MicroRNAs contribute to compensatory beta cell expansion during pregnancy and obesity. J Clin Invest 122: 3541-3551, 2012. 
123. Jacovetti C, Jimenez V, Ayuso E, Laybutt R, Peyot ML, Prentki M, Bosch F, and Regazzi R. Contribution of Intronic miR-338-3p and Its Hosting Gene AATK to Compensatory beta-Cell Mass Expansion. Mol Endocrinol 29: 693-702, 2015.

124. Jacovetti C, Matkovich SJ, Rodriguez-Trejo A, Guay C, and Regazzi R. Postnatal betacell maturation is associated with islet-specific microRNA changes induced by nutrient shifts at weaning. Nat Commun 6: 8084, 2015.

125. Jacovetti C, Rodriguez-Trejo A, Guay C, Sobel J, Gattesco S, Petrenko V, Saini C, Dibner C, and Regazzi R. MicroRNAs modulate core-clock gene expression in pancreatic islets during early postnatal life in rats. Diabetologia 60: 2011-2020, 2017.

126. Jalabert A, Vial G, Guay C, Wiklander OP, Nordin JZ, Aswad H, Forterre A, Meugnier E, Pesenti S, Regazzi R, Danty-Berger E, Ducreux S, Vidal H, El-Andaloussi S, Rieusset $\mathbf{J}$, and Rome S. Exosome-like vesicles released from lipid-induced insulin-resistant muscles modulate gene expression and proliferation of beta recipient cells in mice. Diabetologia 59: 1049-1058, 2016.

127. Jeppesen DK, Fenix AM, Franklin JL, Higginbotham JN, Zhang Q, Zimmerman LJ, Liebler DC, Ping J, Liu Q, Evans R, Fissell WH, Patton JG, Rome LH, Burnette DT, and Coffey RJ. Reassessment of Exosome Composition. Cell 177: 428-445 e418, 2019.

128. Jha A, and Shankar R. miReader: Discovering Novel miRNAs in Species without Sequenced Genome. PLoS One 8: e66857, 2013.

129. Ji J, Dai X, Yeung SJ, and He X. The role of long non-coding RNA GAS5 in cancers. Cancer Manag Res 11: 2729-2737, 2019.

130. Jimenez-Palomares M, Lopez-Acosta JF, Villa-Perez P, Moreno-Amador JL, MunozBarrera J, Fernandez-Luis S, Heras-Pozas B, Perdomo G, Bernal-Mizrachi E, and CozarCastellano I. Cyclin C stimulates beta-cell proliferation in rat and human pancreatic beta-cells. American journal of physiology Endocrinology and metabolism 308: E450-459, 2015.

131. Jin F, Wang N, Zhu Y, You L, Wang L, De W, and Tang W. Downregulation of Long Noncoding RNA Gas5 Affects Cell Cycle and Insulin Secretion in Mouse Pancreatic beta Cells. Cell Physiol Biochem 43: 2062-2073, 2017.

132. Jo S, Chen J, Xu G, Grayson TB, Thielen LA, and Shalev A. miR-204 Controls Glucagon-Like Peptide 1 Receptor Expression and Agonist Function. Diabetes 67: 256-264, 2018. 133. Joglekar MV, Joglekar VM, and Hardikar AA. Expression of islet-specific microRNAs during human pancreatic development. Gene Expr Patterns 9: 109-113, 2009.

134. Jonsson J, Carlsson L, Edlund T, and Edlund $\mathbf{H}$. Insulin-promoter-factor 1 is required for pancreas development in mice. Nature 371: 606-609, 1994.

135. Kadri S, Hinman V, and Benos PV. HHMMiR: efficient de novo prediction of microRNAs using hierarchical hidden Markov models. BMC Bioinformatics 10 Suppl 1: S35, 2009.

136. Kahn SE, Cooper ME, and Del Prato S. Pathophysiology and treatment of type 2 diabetes: perspectives on the past, present, and future. Lancet 383: 1068-1083, 2014.

137. Kalis M, Bolmeson C, Esguerra JL, Gupta S, Edlund A, Tormo-Badia N, Speidel D, Holmberg D, Mayans S, Khoo NK, Wendt A, Eliasson L, and Cilio CM. Beta-cell specific deletion of dicer1 leads to defective insulin secretion and diabetes mellitus. PLoS One 6: e29166, 2011.

138. Kameswaran V, Bramswig NC, McKenna LB, Penn M, Schug J, Hand NJ, Chen Y, Choi I, Vourekas A, Won KJ, Liu C, Vivek K, Naji A, Friedman JR, and Kaestner KH. Epigenetic regulation of the DLK1-MEG3 microRNA cluster in human type 2 diabetic islets. Cell Metab 19: 135-145, 2014. 
139. Kameswaran V, and Kaestner KH. The Missing lnc(RNA) between the pancreatic betacell and diabetes. Front Genet 5: 200, 2014.

140. Kanji MS, Martin MG, and Bhushan A. Dicer1 is required to repress neuronal fate during endocrine cell maturation. Diabetes 62: 1602-1611, 2013.

141. Kapranov P, Cheng J, Dike S, Nix DA, Duttagupta R, Willingham AT, Stadler PF, Hertel J, Hackermuller J, Hofacker IL, Bell I, Cheung E, Drenkow J, Dumais E, Patel S, Helt G, Ganesh M, Ghosh S, Piccolboni A, Sementchenko V, Tammana H, and Gingeras TR. RNA maps reveal new RNA classes and a possible function for pervasive transcription. Science 316: 1484-1488, 2007.

142. Karaiskos S, and Grigoriev A. Dynamics of tRNA fragments and their targets in aging mammalian brain. F1000Research 5: 2016.

143. Kaspi H, Pasvolsky R, and Hornstein E. Could microRNAs contribute to the maintenance of beta cell identity? Trends Endocrinol Metab 25: 285-292, 2014.

144. Kato T, Tanaka D, Muro S, Jambaljav B, Mori E, Yonemitsu S, Oki S, and Inagaki N. A Novel p.L145Q Mutation in the HNF1B Gene in a Case of Maturity-onset Diabetes of the Young Type 5 (MODY5). Intern Med 57: 2035-2039, 2018.

145. Kaur S, Mirza AH, and Pociot F. Cell Type-Selective Expression of Circular RNAs in Human Pancreatic Islets. Noncoding RNA 4: 2018.

146. Kaviani M, Azarpira N, Karimi MH, and Al-Abdullah I. The role of microRNAs in islet beta-cell development. Cell Biol Int 40: 1248-1255, 2016.

147. Kertesz M, Iovino N, Unnerstall U, Gaul U, and Segal E. The role of site accessibility in microRNA target recognition. Nat Genet 39: 1278-1284, 2007.

148. Khalil AM, Guttman M, Huarte M, Garber M, Raj A, Rivea Morales D, Thomas K, Presser A, Bernstein BE, van Oudenaarden A, Regev A, Lander ES, and Rinn JL. Many human large intergenic noncoding RNAs associate with chromatin-modifying complexes and affect gene expression. Proc Natl Acad Sci U S A 106: 11667-11672, 2009.

149. Kim HK, Fuchs G, Wang S, Wei W, Zhang Y, Park H, Roy-Chaudhuri B, Li P, Xu J, Chu K, Zhang F, Chua MS, So S, Zhang QC, Sarnow P, and Kay MA. A transfer-RNA-derived small RNA regulates ribosome biogenesis. Nature 552: 57-62, 2017.

150. Kjorholt C, Akerfeldt MC, Biden TJ, and Laybutt DR. Chronic hyperglycemia, independent of plasma lipid levels, is sufficient for the loss of beta-cell differentiation and secretory function in the $\mathrm{db} / \mathrm{db}$ mouse model of diabetes. Diabetes 54: 2755-2763, 2005.

151. Klein D, Misawa R, Bravo-Egana V, Vargas N, Rosero S, Piroso J, Ichii H, Umland O, Zhijie J, Tsinoremas N, Ricordi C, Inverardi L, Dominguez-Bendala J, and Pastori RL. MicroRNA expression in alpha and beta cells of human pancreatic islets. PLoS One 8: e55064, 2013.

152. Kloosterman WP, Lagendijk AK, Ketting RF, Moulton JD, and Plasterk RH. Targeted inhibition of miRNA maturation with morpholinos reveals a role for miR-375 in pancreatic islet development. PLoS Biol 5: e203, 2007.

153. Kong Y, Sharma RB, Ly S, Stamateris RE, Jesdale WM, and Alonso LC. CDKN2A/B T2D Genome-Wide Association Study Risk SNPs Impact Locus Gene Expression and Proliferation in Human Islets. Diabetes 67: 872-884, 2018.

154. Kornfeld JW, Baitzel C, Konner AC, Nicholls HT, Vogt MC, Herrmanns K, Scheja L, Haumaitre C, Wolf AM, Knippschild U, Seibler J, Cereghini S, Heeren J, Stoffel M, and Bruning JC. Obesity-induced overexpression of miR-802 impairs glucose metabolism through silencing of Hnf1b. Nature 494: 111-115, 2013. 
155. Kowal J, Arras G, Colombo M, Jouve M, Morath JP, Primdal-Bengtson B, Dingli F, Loew D, Tkach M, and Thery C. Proteomic comparison defines novel markers to characterize heterogeneous populations of extracellular vesicle subtypes. Proc Natl Acad Sci U S A 113: E968977, 2016.

156. Kowal J, Tkach M, and Thery C. Biogenesis and secretion of exosomes. Curr Opin Cell Biol 29: 116-125, 2014.

157. Kozomara A, Birgaoanu M, and Griffiths-Jones S. miRBase: from microRNA sequences to function. Nucleic Acids Res 47: D155-D162, 2019.

158. Kredo-Russo S, Mandelbaum AD, Ness A, Alon I, Lennox KA, Behlke MA, and Hornstein E. Pancreas-enriched miRNA refines endocrine cell differentiation. Development 139: 3021-3031, 2012.

159. Kredo-Russo S, Ness A, Mandelbaum AD, Walker MD, and Hornstein E. Regulation of pancreatic microRNA-7 expression. Exp Diabetes Res 2012: 695214, 2012.

160. Kristensen LS, Andersen MS, Stagsted LVW, Ebbesen KK, Hansen TB, and Kjems J. The biogenesis, biology and characterization of circular RNAs. Nat Rev Genet 2019.

161. Kruger J, and Rehmsmeier M. RNAhybrid: microRNA target prediction easy, fast and flexible. Nucleic Acids Res 34: W451-454, 2006.

162. Ku GM, Kim H, Vaughn IW, Hangauer MJ, Myung Oh C, German MS, and McManus MT. Research resource: RNA-Seq reveals unique features of the pancreatic beta-cell transcriptome. Mol Endocrinol 26: 1783-1792, 2012.

163. Kumar P, Kuscu C, and Dutta A. Biogenesis and Function of Transfer RNA-Related Fragments (tRFs). Trends in biochemical sciences 41: 679-689, 2016.

164. Kuscu C, Kumar P, Kiran M, Su Z, Malik A, and Dutta A. tRNA fragments (tRFs) guide Ago to regulate gene expression post-transcriptionally in a Dicer-independent manner. Rna 24: 1093-1105, 2018.

165. Lai EC, Tomancak P, Williams RW, and Rubin GM. Computational identification of Drosophila microRNA genes. Genome Biol 4: R42, 2003.

166. Lakhter AJ, Pratt RE, Moore RE, Doucette KK, Maier BF, DiMeglio LA, and Sims EK. Beta cell extracellular vesicle miR-21-5p cargo is increased in response to inflammatory cytokines and serves as a biomarker of type 1 diabetes. Diabetologia 61: 1124-1134, 2018.

167. Lalaouna D, Carrier MC, Semsey S, Brouard JS, Wang J, Wade JT, and Masse E. A 3' external transcribed spacer in a tRNA transcript acts as a sponge for small RNAs to prevent transcriptional noise. Mol Cell 58: 393-405, 2015.

168. Lall S, Grun D, Krek A, Chen K, Wang YL, Dewey CN, Sood P, Colombo T, Bray N, Macmenamin P, Kao HL, Gunsalus KC, Pachter L, Piano F, and Rajewsky N. A genomewide map of conserved microRNA targets in C. elegans. Curr Biol 16: 460-471, 2006.

169. LaPierre MP, and Stoffel M. MicroRNAs as stress regulators in pancreatic beta cells and diabetes. Mol Metab 6: 1010-1023, 2017.

170. Lasda E, and Parker R. Circular RNAs: diversity of form and function. RNA 20: 18291842, 2014.

171. Lasser C, Shelke GV, Yeri A, Kim DK, Crescitelli R, Raimondo S, Sjostrand M, Gho YS, Van Keuren Jensen K, and Lotvall J. Two distinct extracellular RNA signatures released by a single cell type identified by microarray and next-generation sequencing. RNA Biol 14: 58-72, 2017.

172. Latreille M, Hausser J, Stutzer I, Zhang Q, Hastoy B, Gargani S, Kerr-Conte J, Pattou F, Zavolan M, Esguerra JL, Eliasson L, Rulicke T, Rorsman P, and Stoffel M. MicroRNA-7a regulates pancreatic beta cell function. J Clin Invest 124: 2722-2735, 2014. 
173. Latreille M, Herrmanns K, Renwick N, Tuschl T, Malecki MT, McCarthy MI, Owen KR, Rulicke T, and Stoffel M. miR-375 gene dosage in pancreatic beta-cells: implications for regulation of beta-cell mass and biomarker development. J Mol Med (Berl) 93: 1159-1169, 2015.

174. Lecerf C, Le Bourhis X, and Adriaenssens E. The long non-coding RNA H19: an active player with multiple facets to sustain the hallmarks of cancer. Cell Mol Life Sci 2019.

175. Lee EJ, Banerjee S, Zhou H, Jammalamadaka A, Arcila M, Manjunath BS, and Kosik KS. Identification of piRNAs in the central nervous system. RNA 17: 1090-1099, 2011.

176. Lee HS, Jeong J, and Lee KJ. Characterization of vesicles secreted from insulinoma NIT1 cells. J Proteome Res 8: 2851-2862, 2009.

177. Lee J, Harris AN, Holley CL, Mahadevan J, Pyles KD, Lavagnino Z, Scherrer DE, Fujiwara H, Sidhu R, Zhang J, Huang SC, Piston DW, Remedi MS, Urano F, Ory DS, and Schaffer JE. Rpl13a small nucleolar RNAs regulate systemic glucose metabolism. J Clin Invest 126: 4616-4625, 2016.

178. Lee RC, Feinbaum RL, and Ambros V. The C. elegans heterochronic gene lin-4 encodes small RNAs with antisense complementarity to lin-14. Cell 75: 843-854, 1993.

179. Lemaire K, Thorrez L, and Schuit F. Disallowed and Allowed Gene Expression: Two Faces of Mature Islet Beta Cells. Annu Rev Nutr 36: 45-71, 2016.

180. Lerner AG, Upton JP, Praveen PV, Ghosh R, Nakagawa Y, Igbaria A, Shen S, Nguyen V, Backes BJ, Heiman M, Heintz N, Greengard P, Hui S, Tang Q, Trusina A, Oakes SA, and Papa FR. IRE1alpha induces thioredoxin-interacting protein to activate the NLRP3 inflammasome and promote programmed cell death under irremediable ER stress. Cell Metab 16: 250-264, 2012. 181. Li D, Luo L, Zhang W, Liu F, and Luo F. A genetic algorithm-based weighted ensemble method for predicting transposon-derived piRNAs. BMC Bioinformatics 17: 329, 2016.

182. Li J, and Liu C. Coding or Noncoding, the Converging Concepts of RNAs. Front Genet 10: 496, 2019.

183. Li W, Notani D, and Rosenfeld MG. Enhancers as non-coding RNA transcription units: recent insights and future perspectives. Nat Rev Genet 17: 207-223, 2016.

184. Li Y, Luo T, Wang L, Wu J, and Guo S. MicroRNA-19a-3p enhances the proliferation and insulin secretion, while it inhibits the apoptosis of pancreatic beta cells via the inhibition of SOCS3. Int J Mol Med 38: 1515-1524, 2016.

185. Liang D, Zhang Y, Han J, Wang W, Liu Y, Li J, and Jiang X. Embryonic stem cellderived pancreatic endoderm transplant with MCT1-suppressing miR-495 attenuates type II diabetes in mice. Endocr J 62: 907-920, 2015.

186. Lim LP, Lau NC, Weinstein EG, Abdelhakim A, Yekta S, Rhoades MW, Burge CB, and Bartel DP. The microRNAs of Caenorhabditis elegans. Genes Dev 17: 991-1008, 2003.

187. Lindstrom P. The physiology of obese-hyperglycemic mice [ob/ob mice]. ScientificWorldJournal 7: 666-685, 2007.

188. Liu B, Yang F, and Chou KC. 2L-piRNA: A Two-Layer Ensemble Classifier for Identifying Piwi-Interacting RNAs and Their Function. Mol Ther Nucleic Acids 7: 267-277, 2017. 189. Locke JM, da Silva Xavier G, Dawe HR, Rutter GA, and Harries LW. Increased expression of miR-187 in human islets from individuals with type 2 diabetes is associated with reduced glucose-stimulated insulin secretion. Diabetologia 57: 122-128, 2014.

190. Loher P, and Rigoutsos I. Interactive exploration of RNA22 microRNA target predictions. Bioinformatics 28: 3322-3323, 2012.

191. Loher P, Telonis AG, and Rigoutsos I. MINTmap: fast and exhaustive profiling of nuclear and mitochondrial tRNA fragments from short RNA-seq data. Sci Rep 7: 41184, 2017. 
192. Lopez-Beas J, Capilla-Gonzalez V, Aguilera Y, Mellado N, Lachaud CC, Martin F, Smani T, Soria B, and Hmadcha A. miR-7 Modulates hESC Differentiation into InsulinProducing Beta-like Cells and Contributes to Cell Maturation. Mol Ther Nucleic Acids 12: 463477, 2018.

193. Lovis P, Gattesco S, and Regazzi R. Regulation of the expression of components of the exocytotic machinery of insulin-secreting cells by microRNAs. Biol Chem 389: 305-312, 2008.

194. Lovis P, Roggli E, Laybutt DR, Gattesco S, Yang JY, Widmann C, Abderrahmani A, and Regazzi R. Alterations in microRNA expression contribute to fatty acid-induced pancreatic beta-cell dysfunction. Diabetes 57: 2728-2736, 2008.

195. Lu Y, Fei XQ, Yang SF, Xu BK, and Li YY. Glucose-induced microRNA-17 promotes pancreatic beta cell proliferation through down-regulation of Menin. Eur Rev Med Pharmacol Sci 19: 624-629, 2015.

196. Luo L, Li D, Zhang W, Tu S, Zhu X, and Tian G. Accurate Prediction of TransposonDerived piRNAs by Integrating Various Sequential and Physicochemical Features. PLoS One 11: e0153268, 2016.

197. Lynn FC, Skewes-Cox P, Kosaka Y, McManus MT, Harfe BD, and German MS. MicroRNA expression is required for pancreatic islet cell genesis in the mouse. Diabetes 56: 29382945, 2007.

198. Lyons SM, Fay MM, and Ivanov P. The role of RNA modifications in the regulation of tRNA cleavage. FEBS letters 592: 2828-2844, 2018.

199. Mak KY, Rajapaksha IG, Angus PW, and Herath CB. The Adeno-associated Virus - A Safe and Promising Vehicle for Liverspecific Gene Therapy of Inherited and Non-inherited Disorders. Curr Gene Ther 17: 4-16, 2017.

200. Malm HA, Mollet IG, Berggreen C, Orho-Melander M, Esguerra JL, Goransson O, and Eliasson L. Transcriptional regulation of the miR-212/miR-132 cluster in insulin-secreting beta-cells by cAMP-regulated transcriptional co-activator 1 and salt-inducible kinases. Mol Cell Endocrinol 424: 23-33, 2016.

201. Malone CD, Brennecke J, Dus M, Stark A, McCombie WR, Sachidanandam R, and Hannon GJ. Specialized piRNA pathways act in germline and somatic tissues of the Drosophila ovary. Cell 137: 522-535, 2009.

202. Mandelbaum AD, Kredo-Russo S, Aronowitz D, Myers N, Yanowski E, Klochendler A, Swisa A, Dor Y, and Hornstein E. miR-17-92 and miR-106b-25 clusters regulate beta cell mitotic checkpoint and insulin secretion in mice. Diabetologia 62: 1653-1666, 2019.

203. Mandelbaum AD, Melkman-Zehavi T, Oren R, Kredo-Russo S, Nir T, Dor Y, and Hornstein E. Dysregulation of Dicer1 in beta cells impairs islet architecture and glucose metabolism. Exp Diabetes Res 2012: 470302, 2012.

204. Marchand L, Jalabert A, Meugnier E, Van den Hende K, Fabien N, Nicolino M, Madec AM, Thivolet C, and Rome S. miRNA-375 a Sensor of Glucotoxicity Is Altered in the Serum of Children with Newly Diagnosed Type 1 Diabetes. J Diabetes Res 2016: 1869082, 2016. 205. Martianov I, Ramadass A, Serra Barros A, Chow N, and Akoulitchev A. Repression of the human dihydrofolate reductase gene by a non-coding interfering transcript. Nature 445: 666670, 2007.

206. Martin-Gronert MS, and Ozanne SE. Metabolic programming of insulin action and secretion. Diabetes Obes Metab 14 Suppl 3: 29-39, 2012.

207. Martinez-Sanchez A, Nguyen-Tu MS, Cebola I, Yavari A, Marchetti P, Piemonti L, de Koning E, Shapiro AMJ, Johnson P, Sakamoto K, Smith DM, Leclerc I, Ashrafian H, 
Ferrer J, and Rutter GA. MiR-184 expression is regulated by AMPK in pancreatic islets. FASEB J 32: 2587-2600, 2018.

208. Martinez-Sanchez A, Nguyen-Tu MS, and Rutter GA. DICER Inactivation Identifies Pancreatic beta-Cell "Disallowed" Genes Targeted by MicroRNAs. Mol Endocrinol 29: 10671079, 2015.

209. Martinez-Sanchez A, Rutter GA, and Latreille M. MiRNAs in beta-Cell Development, Identity, and Disease. Front Genet 7: 226, 2016.

210. Mathieu M, Martin-Jaular L, Lavieu G, and Thery C. Specificities of secretion and uptake of exosomes and other extracellular vesicles for cell-to-cell communication. Nat Cell Biol 21: 9-17, 2019.

211. Maute RL, Schneider C, Sumazin P, Holmes A, Califano A, Basso K, and DallaFavera R. tRNA-derived microRNA modulates proliferation and the DNA damage response and is down-regulated in B cell lymphoma. Proc Natl Acad Sci U S A 110: 1404-1409, 2013.

212. McKenzie MD, Jamieson E, Jansen ES, Scott CL, Huang DC, Bouillet P, Allison J, Kay TW, Strasser A, and Thomas HE. Glucose induces pancreatic islet cell apoptosis that requires the BH3-only proteins Bim and Puma and multi-BH domain protein Bax. Diabetes 59: 644-652, 2010.

213. Meier JJ, Butler AE, Saisho Y, Monchamp T, Galasso R, Bhushan A, Rizza RA, and Butler PC. Beta-cell replication is the primary mechanism subserving the postnatal expansion of beta-cell mass in humans. Diabetes 57: 1584-1594, 2008.

214. Melkman-Zehavi T, Oren R, Kredo-Russo S, Shapira T, Mandelbaum AD, Rivkin N, Nir T, Lennox KA, Behlke MA, Dor Y, and Hornstein E. miRNAs control insulin content in pancreatic beta-cells via downregulation of transcriptional repressors. Embo J 30: 835-845, 2011. 215. Memczak S, Jens M, Elefsinioti A, Torti F, Krueger J, Rybak A, Maier L, Mackowiak SD, Gregersen LH, Munschauer M, Loewer A, Ziebold U, Landthaler M, Kocks C, le Noble $\mathbf{F}$, and Rajewsky N. Circular RNAs are a large class of animal RNAs with regulatory potency. Nature 495: 333-338, 2013.

216. Mercer TR, Dinger ME, and Mattick JS. Long non-coding RNAs: insights into functions. Nat Rev Genet 10: 155-159, 2009.

217. Michel CI, Holley CL, Scruggs BS, Sidhu R, Brookheart RT, Listenberger LL, Behlke MA, Ory DS, and Schaffer JE. Small nucleolar RNAs U32a, U33, and U35a are critical mediators of metabolic stress. Cell Metab 14: 33-44, 2011.

218. Miyoshi N, Wagatsuma H, Wakana S, Shiroishi T, Nomura M, Aisaka K, Kohda T, Surani MA, Kaneko-Ishino T, and Ishino F. Identification of an imprinted gene, Meg3/Gtl2 and its human homologue MEG3, first mapped on mouse distal chromosome 12 and human chromosome 14q. Genes Cells 5: 211-220, 2000.

219. Mohan R, Mao Y, Zhang S, Zhang YW, Xu CR, Gradwohl G, and Tang X. Differentially Expressed MicroRNA-483 Confers Distinct Functions in Pancreatic beta- and alphaCells. J Biol Chem 290: 19955-19966, 2015.

220. Montani F, and Bianchi F. Circulating Cancer Biomarkers: The Macro-revolution of the Micro-RNA. EBioMedicine 5: 4-6, 2016.

221. Moran I, Akerman I, van de Bunt M, Xie R, Benazra M, Nammo T, Arnes L, Nakic N, Garcia-Hurtado J, Rodriguez-Segui S, Pasquali L, Sauty-Colace C, Beucher A, Scharfmann R, van Arensbergen J, Johnson PR, Berry A, Lee C, Harkins T, Gmyr V, Pattou F, Kerr-Conte J, Piemonti L, Berney T, Hanley N, Gloyn AL, Sussel L, Langman L, Brayman KL, Sander M, McCarthy MI, Ravassard P, and Ferrer J. Human beta cell transcriptome 
analysis uncovers lncRNAs that are tissue-specific, dynamically regulated, and abnormally expressed in type 2 diabetes. Cell Metab 16: 435-448, 2012.

222. Mori MA, Ludwig RG, Garcia-Martin R, Brandao BB, and Kahn CR. Extracellular miRNAs: From Biomarkers to Mediators of Physiology and Disease. Cell Metab 2019.

223. Morita S, Horii T, Kimura M, and Hatada I. MiR-184 regulates insulin secretion through repression of Slc25a22. PeerJ 1: e162, 2013.

224. Morris KV, and Mattick JS. The rise of regulatory RNA. Nat Rev Genet 15: 423-437, 2014.

225. Motterle A, Gattesco S, Caille D, Meda P, and Regazzi R. Involvement of long noncoding RNAs in beta cell failure at the onset of type 1 diabetes in NOD mice. Diabetologia 58: 1827-1835, 2015.

226. Motterle A, Gattesco S, Peyot ML, Esguerra JLS, Gomez-Ruiz A, Laybutt DR, Gilon P, Burdet F, Ibberson M, Eliasson L, Prentki M, and Regazzi R. Identification of islet-enriched long non-coding RNAs contributing to beta-cell failure in type 2 diabetes. Mol Metab 6: 14071418, 2017.

227. Motterle A, Sanchez-Parra C, and Regazzi R. Role of long non-coding RNAs in the determination of beta-cell identity. Diabetes Obes Metab 18 Suppl 1: 41-50, 2016.

228. Mulder NL, Havinga R, Kluiver J, Groen AK, and Kruit JK. AAV8-mediated gene transfer of microRNA-132 improves beta cell function in mice fed a high-fat diet. $J$ Endocrinol 240: 123-132, 2019.

229. Mziaut H, Henniger G, Ganss K, Hempel S, Wolk S, McChord J, Chowdhury K, Ravassard P, Knoch K-P, Krautz C, Weitz J, Grützmann R, Pilarsky C, Solimena M, and Kersting S. MiR-132 controls pancreatic beta cell proliferation and survival through Pten/Akt/Foxo3 signaling. Molecular Metabolism 31: 150-162, 2020.

230. Nam JW, Kim J, Kim SK, and Zhang BT. ProMiR II: a web server for the probabilistic prediction of clustered, nonclustered, conserved and nonconserved microRNAs. Nucleic Acids Res 34: W455-458, 2006.

231. Nesca V, Guay C, Jacovetti C, Menoud V, Peyot ML, Laybutt DR, Prentki M, and Regazzi R. Identification of particular groups of microRNAs that positively or negatively impact on beta cell function in obese models of type 2 diabetes. Diabetologia 56: 2203-2212, 2013.

232. Newman MA, and Hammond SM. Lin-28: an early embryonic sentinel that blocks Let-7 biogenesis. Int J Biochem Cell Biol 42: 1330-1333, 2010.

233. Ng KW, Anderson C, Marshall EA, Minatel BC, Enfield KS, Saprunoff HL, Lam WL, and Martinez VD. Piwi-interacting RNAs in cancer: emerging functions and clinical utility. Mol Cancer 15: 5, 2016.

234. Nieto M, Hevia P, Garcia E, Klein D, Alvarez-Cubela S, Bravo-Egana V, Rosero S, Damaris Molano R, Vargas N, Ricordi C, Pileggi A, Diez J, Dominguez-Bendala J, and Pastori RL. Antisense miR-7 impairs insulin expression in developing pancreas and in cultured pancreatic buds. Cell Transplant 21: 1761-1774, 2012.

235. Nishibu T, Hayashida Y, Tani S, Kurono S, Kojima-Kita K, Ukekawa R, Kurokawa T, Kuramochi-Miyagawa S, Nakano T, Inoue K, and Honda S. Identification of MIWIassociated Poly(A) RNAs by immunoprecipitation with an anti-MIWI monoclonal antibody. Biosci Trends 6: 248-261, 2012.

236. Nolan CJ, Damm P, and Prentki M. Type 2 diabetes across generations: from pathophysiology to prevention and management. Lancet 378: 169-181, 2011. 
237. Offield MF, Jetton TL, Labosky PA, Ray M, Stein RW, Magnuson MA, Hogan BL, and Wright CV. PDX-1 is required for pancreatic outgrowth and differentiation of the rostral duodenum. Development 122: 983-995, 1996.

238. Ofori JK, Salunkhe VA, Bagge A, Vishnu N, Nagao M, Mulder H, Wollheim CB, Eliasson L, and Esguerra JL. Elevated miR-130a/miR130b/miR-152 expression reduces intracellular ATP levels in the pancreatic beta cell. Sci Rep 7: 44986, 2017.

239. Osmai M, Osmai Y, Bang-Berthelsen CH, Pallesen EM, Vestergaard AL, Novotny GW, Pociot F, and Mandrup-Poulsen T. MicroRNAs as regulators of beta-cell function and dysfunction. Diabetes Metab Res Rev 32: 334-349, 2016.

240. Oulas A, Boutla A, Gkirtzou K, Reczko M, Kalantidis K, and Poirazi P. Prediction of novel microRNA genes in cancer-associated genomic regions--a combined computational and experimental approach. Nucleic Acids Res 37: 3276-3287, 2009.

241. Oulas A, and Poirazi P. Utilization of SSCprofiler to predict a new miRNA gene. Methods Mol Biol 676: 243-252, 2011.

242. Ozata DM, Gainetdinov I, Zoch A, O'Carroll D, and Zamore PD. PIWI-interacting RNAs: small RNAs with big functions. Nature reviews Genetics 20: 89-108, 2019.

243. Pan T. Modifications and functional genomics of human transfer RNA. Cell Res 28: 395404, 2018.

244. Pandey RR, Homolka D, Olotu O, Sachidanandam R, Kotaja N, and Pillai RS. Exonuclease Domain-Containing 1 Enhances MIWI2 piRNA Biogenesis via Its Interaction with TDRD12. Cell Rep 24: 3423-3432 e3424, 2018.

245. Pasquali L, Gaulton KJ, Rodriguez-Segui SA, Mularoni L, Miguel-Escalada I, Akerman I, Tena JJ, Moran I, Gomez-Marin C, van de Bunt M, Ponsa-Cobas J, Castro N, Nammo T, Cebola I, Garcia-Hurtado J, Maestro MA, Pattou F, Piemonti L, Berney T, Gloyn AL, Ravassard P, Skarmeta JLG, Muller F, McCarthy MI, and Ferrer J. Pancreatic islet enhancer clusters enriched in type 2 diabetes risk-associated variants. Nat Genet 46: 136-143, 2014. 246. Pearson JA, Wong FS, and Wen L. The importance of the Non Obese Diabetic (NOD) mouse model in autoimmune diabetes. J Autoimmun 66: 76-88, 2016.

247. Petry CJ. Gestational diabetes: risk factors and recent advances in its genetics and treatment. Br J Nutr 104: 775-787, 2010.

248. Peyot ML, Pepin E, Lamontagne J, Latour MG, Zarrouki B, Lussier R, Pineda M, Jetton TL, Madiraju SR, Joly E, and Prentki M. Beta-cell failure in diet-induced obese mice stratified according to body weight gain: secretory dysfunction and altered islet lipid metabolism without steatosis or reduced beta-cell mass. Diabetes 59: 2178-2187, 2010.

249. Poitout V, Satin LS, Kahn SE, Stoffers DA, Marchetti P, Gannon M, Verchere CB, Herold KC, Myers MG, Jr., and Marshall SM. A call for improved reporting of human islet characteristics in research articles. Diabetologia 62: 209-211, 2019.

250. Poitout V, Satin LS, Kahn SE, Stoffers DA, Marchetti P, Gannon M, Verchere CB, Herold KC, Myers MG, Jr., and Marshall SM. A Call for Improved Reporting of Human Islet Characteristics in Research Articles. Diabetes 68: 239-240, 2019.

251. Poliseno L, Salmena L, Zhang J, Carver B, Haveman WJ, and Pandolfi PP. A codingindependent function of gene and pseudogene mRNAs regulates tumour biology. Nature 465: 1033-1038, 2010.

252. Ponting CP, Oliver PL, and Reik W. Evolution and functions of long noncoding RNAs. Cell 136: 629-641, 2009. 
253. Portha B, Lacraz G, Kergoat M, Homo-Delarche F, Giroix MH, Bailbe D, Gangnerau MN, Dolz M, Tourrel-Cuzin C, and Movassat J. The GK rat beta-cell: a prototype for the diseased human beta-cell in type 2 diabetes? Mol Cell Endocrinol 297: 73-85, 2009.

254. Poy MN, Eliasson L, Krutzfeldt J, Kuwajima S, Ma X, Macdonald PE, Pfeffer S, Tuschl T, Rajewsky N, Rorsman P, and Stoffel M. A pancreatic islet-specific microRNA regulates insulin secretion. Nature 432: 226-230, 2004.

255. Poy MN, Hausser J, Trajkovski M, Braun M, Collins S, Rorsman P, Zavolan M, and Stoffel M. miR-375 maintains normal pancreatic alpha- and beta-cell mass. Proc Natl Acad Sci $U$ S A 106: 5813-5818, 2009.

256. Pullen TJ, da Silva Xavier G, Kelsey G, and Rutter GA. miR-29a and miR-29b contribute to pancreatic beta-cell-specific silencing of monocarboxylate transporter 1 (Mct1). Mol Cell Biol 31: 3182-3194, 2011.

257. Pullen TJ, and Rutter GA. Roles of lncRNAs in pancreatic beta cell identity and diabetes susceptibility. Front Genet 5: 193, 2014.

258. Pullen TJ, Sylow L, Sun G, Halestrap AP, Richter EA, and Rutter GA. Overexpression of monocarboxylate transporter-1 (SLC16A1) in mouse pancreatic beta-cells leads to relative hyperinsulinism during exercise. Diabetes 61: 1719-1725, 2012.

259. Rahman MJ, Regn D, Bashratyan R, and Dai YD. Exosomes released by islet-derived mesenchymal stem cells trigger autoimmune responses in NOD mice. Diabetes 63: 1008-1020, 2014.

260. Raposo G, and Stoorvogel W. Extracellular vesicles: exosomes, microvesicles, and friends. J Cell Biol 200: 373-383, 2013.

261. Regazzi R. MicroRNAs as therapeutic targets for the treatment of diabetes mellitus and its complications. Expert Opin Ther Targets 22: 153-160, 2018.

262. Ridder K, Keller S, Dams M, Rupp AK, Schlaudraff J, Del Turco D, Starmann J, Macas J, Karpova D, Devraj K, Depboylu C, Landfried B, Arnold B, Plate KH, Hoglinger G, Sultmann H, Altevogt P, and Momma S. Extracellular vesicle-mediated transfer of genetic information between the hematopoietic system and the brain in response to inflammation. PLoS Biol 12: e1001874, 2014.

263. Robinson DG, Ding Y, and Jiang L. Unconventional protein secretion in plants: a critical assessment. Protoplasma 253: 31-43, 2016.

264. Rodriguez-Comas J, Moreno-Asso A, Moreno-Vedia J, Martin M, Castano C, MarzaFlorensa A, Bofill-De Ros X, Mir-Coll J, Montane J, Fillat C, Gasa R, Novials A, and Servitja JM. Stress-Induced MicroRNA-708 Impairs beta-Cell Function and Growth. Diabetes 2017.

265. Roels S, Costa OR, Tersey SA, Stange G, De Smet D, Balti EV, Gillard P, Keymeulen B, Ling Z, Pipeleers DG, Gorus FK, Mirmira RG, and Martens GA. Combined Analysis of GAD65, miR-375, and Unmethylated Insulin DNA Following Islet Transplantation in Patients With T1D. J Clin Endocrinol Metab 104: 451-460, 2019.

266. Roggli E, Britan A, Gattesco S, Lin-Marq N, Abderrahmani A, Meda P, and Regazzi $\mathbf{R}$. Involvement of microRNAs in the cytotoxic effects exerted by proinflammatory cytokines on pancreatic beta-cells. Diabetes 59: 978-986, 2010.

267. Roggli E, Gattesco S, Caille D, Briet C, Boitard C, Meda P, and Regazzi R. Changes in microRNA expression contribute to pancreatic beta-cell dysfunction in prediabetic NOD mice. Diabetes 61: 1742-1751, 2012.

268. Ross RJ, Weiner MM, and Lin H. PIWI proteins and PIWI-interacting RNAs in the soma. Nature 505: 353-359, 2014. 
269. Ruan Q, Wang T, Kameswaran V, Wei Q, Johnson DS, Matschinsky F, Shi W, and Chen YH. The microRNA-21-PDCD4 axis prevents type 1 diabetes by blocking pancreatic beta cell death. Proc Natl Acad Sci U S A 108: 12030-12035, 2011.

270. Ruan Y, Lin N, Ma Q, Chen R, Zhang Z, Wen W, Chen H, and Sun J. Circulating LncRNAs Analysis in Patients with Type 2 Diabetes Reveals Novel Genes Influencing Glucose Metabolism and Islet beta-Cell Function. Cell Physiol Biochem 46: 335-350, 2018.

271. Rupaimoole R, and Slack FJ. MicroRNA therapeutics: towards a new era for the management of cancer and other diseases. Nat Rev Drug Discov 16: 203-222, 2017.

272. Rutman AK, Negi S, Gasparrini M, Hasilo CP, Tchervenkov J, and Paraskevas S. Immune Response to Extracellular Vesicles From Human Islets of Langerhans in Patients With Type 1 Diabetes. Endocrinology 159: 3834-3847, 2018.

273. Saikia M, Jobava R, Parisien M, Putnam A, Krokowski D, Gao XH, Guan BJ, Yuan Y, Jankowsky E, Feng Z, Hu GF, Pusztai-Carey M, Gorla M, Sepuri NB, Pan T, and Hatzoglou M. Angiogenin-cleaved tRNA halves interact with cytochrome c, protecting cells from apoptosis during osmotic stress. Mol Cell Biol 34: 2450-2463, 2014.

274. Salunkhe VA, Ofori JK, Gandasi NR, Salo SA, Hansson S, Andersson ME, Wendt A, Barg S, Esguerra JLS, and Eliasson L. MiR-335 overexpression impairs insulin secretion through defective priming of insulin vesicles. Physiol Rep 5: 2017.

275. Samandari N, Mirza AH, Nielsen LB, Kaur S, Hougaard P, Fredheim S, Mortensen HB, and Pociot F. Circulating microRNA levels predict residual beta cell function and glycaemic control in children with type 1 diabetes mellitus. Diabetologia 60: 354-363, 2017.

276. Sanchez-Parra C, Jacovetti C, Dumortier O, Lee K, Peyot ML, Guay C, Prentki M, Laybutt DR, Van Obberghen E, and Regazzi R. Contribution of the Long Noncoding RNA H19 to beta-Cell Mass Expansion in Neonatal and Adult Rodents. Diabetes 67: 2254-2267, 2018.

277. Saravanan PB, Kanak MA, Chang CA, Darden C, Yoshimatsu G, Lawrence MC, and Naziruddin B. Islet damage during isolation as assessed by miRNAs and the correlation of miRNA levels with posttransplantation outcome in islet autotransplantation. Am J Transplant 18: 982-989, 2018.

278. Saravanan PB, Vasu S, Yoshimatsu G, Darden CM, Wang X, Gu J, Lawrence MC, and Naziruddin B. Differential expression and release of exosomal miRNAs by human islets under inflammatory and hypoxic stress. Diabetologia 62: 1901-1914, 2019.

279. Schorey JS, Cheng Y, Singh PP, and Smith VL. Exosomes and other extracellular vesicles in host-pathogen interactions. EMBO Rep 16: 24-43, 2015.

280. Schorn AJ, Gutbrod MJ, LeBlanc C, and Martienssen R. LTR-Retrotransposon Control by tRNA-Derived Small RNAs. Cell 170: 61-71 e11, 2017.

281. Sebastiani G, Nigi L, Grieco GE, Mancarella F, Ventriglia G, and Dotta F. Circulating microRNAs and diabetes mellitus: a novel tool for disease prediction, diagnosis, and staging? $J$ Endocrinol Invest 40: 591-610, 2017.

282. Sebastiani G, Po A, Miele E, Ventriglia G, Ceccarelli E, Bugliani M, Marselli L, Marchetti P, Gulino A, Ferretti E, and Dotta F. MicroRNA-124a is hyperexpressed in type 2 diabetic human pancreatic islets and negatively regulates insulin secretion. Acta Diabetol 52: 523530, 2015.

283. Sedgeman LR, Beysen C, Ramirez Solano MA, Michell DL, Sheng Q, Zhao S, Turner S, Linton MF, and Vickers KC. Beta cell secretion of miR-375 to HDL is inversely associated with insulin secretion. Sci Rep 9: 3803, 2019.

284. Selbach M, Schwanhausser B, Thierfelder N, Fang Z, Khanin R, and Rajewsky N. Widespread changes in protein synthesis induced by microRNAs. Nature 455: 58-63, 2008. 
285. Shang J, Li J, Keller MP, Hohmeier HE, Wang Y, Feng Y, Zhou HH, Shen X, Rabaglia M, Soni M, Attie AD, Newgard CB, Thornberry NA, Howard AD, and Zhou YP. Induction of miR-132 and miR-212 Expression by Glucagon-Like Peptide 1 (GLP-1) in Rodent and Human Pancreatic beta-Cells. Mol Endocrinol 29: 1243-1253, 2015.

286. Sharma U, Sun F, Conine CC, Reichholf B, Kukreja S, Herzog VA, Ameres SL, and Rando OJ. Small RNAs Are Trafficked from the Epididymis to Developing Mammalian Sperm. Dev Cell 46: 481-494 e486, 2018.

287. Shen EZ, Chen H, Ozturk AR, Tu S, Shirayama M, Tang W, Ding YH, Dai SY, Weng Z, and Mello CC. Identification of piRNA Binding Sites Reveals the Argonaute Regulatory Landscape of the C. elegans Germline. Cell 172: 937-951 e918, 2018.

288. Sheng H, Hassanali S, Nugent C, Wen L, Hamilton-Williams E, Dias P, and Dai YD. Insulinoma-released exosomes or microparticles are immunostimulatory and can activate autoreactive T cells spontaneously developed in nonobese diabetic mice. J Immunol 187: 15911600, 2011.

289. Shi Q, and Yang X. Circulating MicroRNA and Long Noncoding RNA as Biomarkers of Cardiovascular Diseases. J Cell Physiol 231: 751-755, 2016.

290. Simons M, and Raposo G. Exosomes--vesicular carriers for intercellular communication. Curr Opin Cell Biol 21: 575-581, 2009.

291. Sims EK, Lakhter AJ, Anderson-Baucum E, Kono T, Tong X, and Evans-Molina C. MicroRNA 21 targets BCL2 mRNA to increase apoptosis in rat and human beta cells. Diabetologia 60: 1057-1065, 2017.

292. Singer RA, and Sussel L. Islet Long Noncoding RNAs: A Playbook for Discovery and Characterization. Diabetes 67: 1461-1470, 2018.

293. Sisino G, Zhou AX, Dahr N, Sabirsh A, Soundarapandian MM, Perera R, LarssonLekholm E, Magnone MC, Althage M, and Tyrberg B. Long noncoding RNAs are dynamically regulated during beta-cell mass expansion in mouse pregnancy and control beta-cell proliferation in vitro. PLoS One 12: e0182371, 2017.

294. Skog J, Wurdinger T, van Rijn S, Meijer DH, Gainche L, Sena-Esteves M, Curry WT, Jr., Carter BS, Krichevsky AM, and Breakefield XO. Glioblastoma microvesicles transport RNA and proteins that promote tumour growth and provide diagnostic biomarkers. Nat Cell Biol 10: 1470-1476, 2008.

295. Smith CM, and Steitz JA. Classification of gas5 as a multi-small-nucleolar-RNA (snoRNA) host gene and a member of the 5'-terminal oligopyrimidine gene family reveals common features of snoRNA host genes. Mol Cell Biol 18: 6897-6909, 1998.

296. Smith MA, and Mattick JS. Structural and Functional Annotation of Long Noncoding RNAs. Methods Mol Biol 1526: 65-85, 2017.

297. Song X, Zhang N, Han P, Moon BS, Lai RK, Wang K, and Lu W. Circular RNA profile in gliomas revealed by identification tool UROBORUS. Nucleic Acids Res 44: e87, 2016.

298. Soni MS, Rabaglia ME, Bhatnagar S, Shang J, Ilkayeva O, Mynatt R, Zhou YP, Schadt EE, Thornberry NA, Muoio DM, Keller MP, and Attie AD. Downregulation of carnitine acyl-carnitine translocase by miRNAs 132 and 212 amplifies glucose-stimulated insulin secretion. Diabetes 63: 3805-3814, 2014.

299. St Laurent G, Wahlestedt C, and Kapranov P. The Landscape of long noncoding RNA classification. Trends Genet 31: 239-251, 2015.

300. Stoll L, Sobel J, Rodriguez-Trejo A, Guay C, Lee K, Veno MT, Kjems J, Laybutt DR, and Regazzi R. Circular RNAs as novel regulators of beta-cell functions in normal and disease conditions. Mol Metab 9: 69-83, 2018. 
301. Stolovich-Rain M, Enk J, Vikesa J, Nielsen FC, Saada A, Glaser B, and Dor Y. Weaning triggers a maturation step of pancreatic beta cells. Dev Cell 32: 535-545, 2015.

302. Sun C, Fu Z, Wang S, Li J, Li Y, Zhang Y, Yang F, Chu J, Wu H, Huang X, Li W, and Yin Y. Roles of tRNA-derived fragments in human cancers. Cancer letters 414: 16-25, 2018. 303. Szabo L, Morey R, Palpant NJ, Wang PL, Afari N, Jiang C, Parast MM, Murry CE, Laurent LC, and Salzman J. Statistically based splicing detection reveals neural enrichment and tissue-specific induction of circular RNA during human fetal development. Genome Biol 16: 126, 2015.

304. Talchai C, Xuan S, Lin HV, Sussel L, and Accili D. Pancreatic beta cell dedifferentiation as a mechanism of diabetic beta cell failure. Cell 150: 1223-1234, 2012.

305. Tattikota SG, Rathjen T, Hausser J, Khedkar A, Kabra UD, Pandey V, Sury M, Wessels HH, Mollet IG, Eliasson L, Selbach M, Zinzen RP, Zavolan M, Kadener S, Tschop MH, Jastroch M, Friedlander MR, and Poy MN. miR-184 Regulates Pancreatic beta-Cell Function According to Glucose Metabolism. J Biol Chem 290: 20284-20294, 2015.

306. Tattikota SG, Rathjen T, McAnulty SJ, Wessels HH, Akerman I, van de Bunt M, Hausser J, Esguerra JL, Musahl A, Pandey AK, You X, Chen W, Herrera PL, Johnson PR, O'Carroll D, Eliasson L, Zavolan M, Gloyn AL, Ferrer J, Shalom-Feuerstein R, Aberdam D, and Poy MN. Argonaute2 mediates compensatory expansion of the pancreatic beta cell. Cell Metab 19: 122-134, 2014.

307. Terai G, Komori T, Asai K, and Kin T. miRRim: a novel system to find conserved miRNAs with high sensitivity and specificity. RNA 13: 2081-2090, 2007.

308. Terauchi Y, Takamoto I, Kubota N, Matsui J, Suzuki R, Komeda K, Hara A, Toyoda Y, Miwa I, Aizawa S, Tsutsumi S, Tsubamoto Y, Hashimoto S, Eto K, Nakamura A, Noda M, Tobe K, Aburatani H, Nagai R, and Kadowaki T. Glucokinase and IRS-2 are required for compensatory beta cell hyperplasia in response to high-fat diet-induced insulin resistance. $J$ Clin Invest 117: 246-257, 2007.

309. Thomou T, Mori MA, Dreyfuss JM, Konishi M, Sakaguchi M, Wolfrum C, Rao TN, Winnay JN, Garcia-Martin R, Grinspoon SK, Gorden P, and Kahn CR. Adipose-derived circulating miRNAs regulate gene expression in other tissues. Nature 542: 450-455, 2017.

310. Towns WL, and Begley TJ. Transfer RNA methytransferases and their corresponding modifications in budding yeast and humans: activities, predications, and potential roles in human health. DNA Cell Biol 31: 434-454, 2012.

311. Tripathi V, Ellis JD, Shen Z, Song DY, Pan Q, Watt AT, Freier SM, Bennett CF, Sharma A, Bubulya PA, Blencowe BJ, Prasanth SG, and Prasanth KV. The nuclear-retained noncoding RNA MALAT1 regulates alternative splicing by modulating SR splicing factor phosphorylation. Mol Cell 39: 925-938, 2010.

312. Tugay K, Guay C, Marques AC, Allagnat F, Locke JM, Harries LW, Rutter GA, and Regazzi R. Role of microRNAs in the age-associated decline of pancreatic beta cell function in rat islets. Diabetologia 59: 161-169, 2016.

313. Turchinovich A, Weiz L, Langheinz A, and Burwinkel B. Characterization of extracellular circulating microRNA. Nucleic Acids Res 39: 7223-7233, 2011.

314. Unger RH, and Orci L. The essential role of glucagon in the pathogenesis of diabetes mellitus. Lancet 1: 14-16, 1975.

315. Upton JP, Wang L, Han D, Wang ES, Huskey NE, Lim L, Truitt M, McManus MT, Ruggero D, Goga A, Papa FR, and Oakes SA. IRE1alpha cleaves select microRNAs during ER stress to derepress translation of proapoptotic Caspase-2. Science 338: 818-822, 2012. 
316. Valadi H, Ekstrom K, Bossios A, Sjostrand M, Lee JJ, and Lotvall JO. Exosomemediated transfer of mRNAs and microRNAs is a novel mechanism of genetic exchange between cells. Nat Cell Biol 9: 654-659, 2007.

317. Vallabhajosyula P, Korutla L, Habertheuer A, Yu M, Rostami S, Yuan CX, Reddy S, Liu C, Korutla V, Koeberlein B, Trofe-Clark J, Rickels MR, and Naji A. Tissue-specific exosome biomarkers for noninvasively monitoring immunologic rejection of transplanted tissue. $J$ Clin Invest 127: 1375-1391, 2017.

318. van Niel G, D'Angelo G, and Raposo G. Shedding light on the cell biology of extracellular vesicles. Nat Rev Mol Cell Biol 19: 213-228, 2018.

319. van Rooij E, and Kauppinen S. Development of microRNA therapeutics is coming of age. EMBO Mol Med 6: 851-864, 2014.

320. Vickers KC, Palmisano BT, Shoucri BM, Shamburek RD, and Remaley AT. MicroRNAs are transported in plasma and delivered to recipient cells by high-density lipoproteins. Nat Cell Biol 13: 423-433, 2011.

321. Vinod M, Patankar JV, Sachdev V, Frank S, Graier WF, Kratky D, and Kostner GM. MiR-206 is expressed in pancreatic islets and regulates glucokinase activity. Am J Physiol Endocrinol Metab 311: E175-E185, 2016.

322. Voight BF, Scott LJ, Steinthorsdottir V, Morris AP, Dina C, Welch RP, Zeggini E, Huth C, Aulchenko YS, Thorleifsson G, McCulloch LJ, Ferreira T, Grallert H, Amin N, Wu G, Willer CJ, Raychaudhuri S, McCarroll SA, Langenberg C, Hofmann OM, Dupuis J, Qi L, Segre AV, van Hoek M, Navarro P, Ardlie K, Balkau B, Benediktsson R, Bennett AJ, Blagieva R, Boerwinkle E, Bonnycastle LL, Bengtsson Bostrom K, Bravenboer B, Bumpstead S, Burtt NP, Charpentier G, Chines PS, Cornelis M, Couper DJ, Crawford G, Doney AS, Elliott KS, Elliott AL, Erdos MR, Fox CS, Franklin CS, Ganser M, Gieger C, Grarup N, Green T, Griffin S, Groves CJ, Guiducci C, Hadjadj S, Hassanali N, Herder C, Isomaa B, Jackson AU, Johnson PR, Jorgensen T, Kao WH, Klopp N, Kong A, Kraft P, Kuusisto J, Lauritzen T, Li M, Lieverse A, Lindgren CM, Lyssenko V, Marre M, Meitinger T, Midthjell K, Morken MA, Narisu N, Nilsson P, Owen KR, Payne F, Perry JR, Petersen AK, Platou C, Proenca C, Prokopenko I, Rathmann W, Rayner NW, Robertson NR, Rocheleau G, Roden M, Sampson MJ, Saxena R, Shields BM, Shrader P, Sigurdsson G, Sparso T, Strassburger K, Stringham HM, Sun Q, Swift AJ, Thorand B, Tichet J, Tuomi T, van Dam RM, van Haeften TW, van Herpt T, van Vliet-Ostaptchouk JV, Walters GB, Weedon MN, Wijmenga C, Witteman J, Bergman RN, Cauchi S, Collins FS, Gloyn AL, Gyllensten U, Hansen T, Hide WA, Hitman GA, Hofman A, Hunter DJ, Hveem K, Laakso M, Mohlke KL, Morris AD, Palmer CN, Pramstaller PP, Rudan I, Sijbrands E, Stein LD, Tuomilehto J, Uitterlinden A, Walker M, Wareham NJ, Watanabe RM, Abecasis GR, Boehm BO, Campbell H, Daly MJ, Hattersley AT, Hu FB, Meigs JB, Pankow JS, Pedersen O, Wichmann HE, Barroso I, Florez JC, Frayling TM, Groop L, Sladek R, Thorsteinsdottir U, Wilson JF, Illig T, Froguel P, van Duijn CM, Stefansson K, Altshuler D, Boehnke M, McCarthy MI, investigators M, and Consortium G. Twelve type 2 diabetes susceptibility loci identified through large-scale association analysis. Nat Genet 42: 579-589, 2010.

323. Wang K, Liang C, Liu J, Xiao H, Huang S, Xu J, and Li F. Prediction of piRNAs using transposon interaction and a support vector machine. BMC Bioinformatics 15: 419, 2014.

324. Wang K, Singh D, Zeng Z, Coleman SJ, Huang Y, Savich GL, He X, Mieczkowski P, Grimm SA, Perou CM, MacLeod JN, Chiang DY, Prins JF, and Liu J. MapSplice: accurate mapping of RNA-seq reads for splice junction discovery. Nucleic Acids Res 38: e178, 2010. 
325. Wang K, Zhang S, Weber J, Baxter D, and Galas DJ. Export of microRNAs and microRNA-protective protein by mammalian cells. Nucleic Acids Res 38: 7248-7259, 2010.

326. Wang N, Zhu Y, Xie M, Wang L, Jin F, Li Y, Yuan Q, and De W. Long Noncoding RNA Meg3 Regulates Mafa Expression in Mouse Beta Cells by Inactivating Rad21, Smc3 or Sin3alpha. Cell Physiol Biochem 45: 2031-2043, 2018.

327. Wang P, Fiaschi-Taesch NM, Vasavada RC, Scott DK, Garcia-Ocana A, and Stewart AF. Diabetes mellitus--advances and challenges in human beta-cell proliferation. Nat Rev Endocrinol 11: 201-212, 2015.

328. Wenda JM, Homolka D, Yang Z, Spinelli P, Sachidanandam R, Pandey RR, and Pillai RS. Distinct Roles of RNA Helicases MVH and TDRD9 in PIWI Slicing-Triggered Mammalian piRNA Biogenesis and Function. Dev Cell 41: 623-637 e629, 2017.

329. Wendt A, Esguerra JL, and Eliasson L. Islet microRNAs in health and type-2 diabetes. Curr Opin Pharmacol 43: 46-52, 2018.

330. Wessels HH, Lebedeva S, Hirsekorn A, Wurmus R, Akalin A, Mukherjee N, and Ohler U. Global identification of functional microRNA-mRNA interactions in Drosophila. Nat Commun 10: 1626, 2019.

331. Westholm JO, Miura P, Olson S, Shenker S, Joseph B, Sanfilippo P, Celniker SE, Graveley BR, and Lai EC. Genome-wide analysis of drosophila circular RNAs reveals their structural and sequence properties and age-dependent neural accumulation. Cell Rep 9: 1966-1980, 2014.

332. Wightman B, Ha I, and Ruvkun G. Posttranscriptional regulation of the heterochronic gene lin-14 by lin-4 mediates temporal pattern formation in C. elegans. Cell 75: 855-862, 1993.

333. Wong WKM, Sorensen AE, Joglekar MV, Hardikar AA, and Dalgaard LT. NonCoding RNA in Pancreas and beta-Cell Development. Noncoding RNA 4: 2018.

334. Wu H, Wu S, Zhu Y, Ye M, Shen J, Liu Y, Zhang Y, and Bu S. Hsa_circRNA_0054633 is highly expressed in gestational diabetes mellitus and closely related to glycosylation index. Clin Epigenetics 11: 22, 2019.

335. Wu M, and Shen J. From Super-Enhancer Non-coding RNA to Immune Checkpoint: Frameworks to Functions. Front Oncol 9: 1307, 2019.

336. Wu WS, Brown JS, Chen TT, Chu YH, Huang WC, Tu S, and Lee HC. piRTarBase: a database of piRNA targeting sites and their roles in gene regulation. Nucleic Acids Res 47: D181D187, 2019.

337. Wu WS, Huang WC, Brown JS, Zhang D, Song X, Chen H, Tu S, Weng Z, and Lee HC. pirScan: a webserver to predict piRNA targeting sites and to avoid transgene silencing in $\mathrm{C}$. elegans. Nucleic Acids Res 46: W43-W48, 2018.

338. Xu G, Chen J, Jing G, Grayson TB, and Shalev A. miR-204 Targets PERK and Regulates UPR Signaling and beta-Cell Apoptosis. Mol Endocrinol 30: 917-924, 2016.

339. Xu G, Chen J, Jing G, and Shalev A. Thioredoxin-interacting protein regulates insulin transcription through microRNA-204. Nat Med 19: 1141-1146, 2013.

340. Xu H, Guo S, Li W, and Yu P. The circular RNA Cdr1as, via miR-7 and its targets, regulates insulin transcription and secretion in islet cells. Sci Rep 5: 12453, 2015.

341. Xu X, Chen J, Hu L, Liang M, Wang X, Feng S, Shen J, and Luan X. Liraglutide regulates the viability of pancreatic alpha-cells and pancreatic beta-cells through cAMP-PKA signal pathway. Life Sci 195: 87-94, 2018.

342. Ying W, Riopel M, Bandyopadhyay G, Dong Y, Birmingham A, Seo JB, Ofrecio JM, Wollam J, Hernandez-Carretero A, Fu W, Li P, and Olefsky JM. Adipose Tissue Macrophage- 
Derived Exosomal miRNAs Can Modulate In Vivo and In Vitro Insulin Sensitivity. Cell 171: 372384 e312, 2017.

343. You L, Wang N, Yin D, Wang L, Jin F, Zhu Y, Yuan Q, and De W. Downregulation of Long Noncoding RNA Meg3 Affects Insulin Synthesis and Secretion in Mouse Pancreatic Beta Cells. Journal of cellular physiology 231: 852-862, 2016.

344. You X, Vlatkovic I, Babic A, Will T, Epstein I, Tushev G, Akbalik G, Wang M, Glock C, Quedenau C, Wang X, Hou J, Liu H, Sun W, Sambandan S, Chen T, Schuman EM, and Chen W. Neural circular RNAs are derived from synaptic genes and regulated by development and plasticity. Nat Neurosci 18: 603-610, 2015.

345. Yousef M, Nebozhyn M, Shatkay H, Kanterakis S, Showe LC, and Showe MK. Combining multi-species genomic data for microRNA identification using a Naive Bayes classifier. Bioinformatics 22: 1325-1334, 2006.

346. Zemel S, Bartolomei MS, and Tilghman SM. Physical linkage of two mammalian imprinted genes, H19 and insulin-like growth factor 2. Nat Genet 2: 61-65, 1992.

347. Zhang D, Tu S, Stubna M, Wu WS, Huang WC, Weng Z, and Lee HC. The piRNA targeting rules and the resistance to piRNA silencing in endogenous genes. Science 359: 587-592, 2018.

348. Zhang H, Liu R, Deng T, Wang X, Lang H, Qu Y, Duan J, Huang D, Ying G, and Ba Y. The microRNA-124-iGluR2/3 pathway regulates glucagon release from alpha cells. Oncotarget 7: 24734-24743, 2016.

349. Zhang XO, Dong R, Zhang Y, Zhang JL, Luo Z, Zhang J, Chen LL, and Yang L. Diverse alternative back-splicing and alternative splicing landscape of circular RNAs. Genome Res 26: 1277-1287, 2016.

350. Zhang Y, Wang $\mathbf{X}$, and Kang L. A k-mer scheme to predict piRNAs and characterize locust piRNAs. Bioinformatics 27: 771-776, 2011.

351. Zhao E, Keller MP, Rabaglia ME, Oler AT, Stapleton DS, Schueler KL, Neto EC, Moon JY, Wang P, Wang IM, Lum PY, Ivanovska I, Cleary M, Greenawalt D, Tsang J, Choi YJ, Kleinhanz R, Shang J, Zhou YP, Howard AD, Zhang BB, Kendziorski C, Thornberry NA, Yandell BS, Schadt EE, and Attie AD. Obesity and genetics regulate microRNAs in islets, liver, and adipose of diabetic mice. Mamm Genome 20: 476-485, 2009.

352. Zhao Z, Li X, Jian D, Hao P, Rao L, and Li M. Hsa_circ_0054633 in peripheral blood can be used as a diagnostic biomarker of pre-diabetes and type 2 diabetes mellitus. Acta Diabetol 54: 237-245, 2017.

353. Zheng G, Qin Y, Clark WC, Dai Q, Yi C, He C, Lambowitz AM, and Pan T. Efficient and quantitative high-throughput tRNA sequencing. Nat Methods 12: 835-837, 2015.

354. Zheng LL, Xu WL, Liu S, Sun WJ, Li JH, Wu J, Yang JH, and Qu LH. tRF2Cancer: A web server to detect tRNA-derived small RNA fragments (tRFs) and their expression in multiple cancers. Nucleic Acids Res 44: W185-193, 2016.

355. Zhou Y, Zhang X, and Klibanski A. MEG3 noncoding RNA: a tumor suppressor. J Mol Endocrinol 48: R45-53, 2012.

356. Zhu H, Shah S, Shyh-Chang N, Shinoda G, Einhorn WS, Viswanathan SR, Takeuchi A, Grasemann C, Rinn JL, Lopez MF, Hirschhorn JN, Palmert MR, and Daley GQ. Lin28a transgenic mice manifest size and puberty phenotypes identified in human genetic association studies. Nat Genet 42: 626-630, 2010.

357. Zhu H, Shyh-Chang N, Segre AV, Shinoda G, Shah SP, Einhorn WS, Takeuchi A, Engreitz JM, Hagan JP, Kharas MG, Urbach A, Thornton JE, Triboulet R, Gregory RI, 
Altshuler D, and Daley GQ. The Lin28/let-7 axis regulates glucose metabolism. Cell 147: 81-94, 2011.

358. Zhu M, Wei Y, Geissler C, Abschlag K, Corbalan Campos J, Hristov M, Mollmann J, Lehrke M, Karshovska E, and Schober A. Hyperlipidemia-Induced MicroRNA-155-5p Improves beta-Cell Function by Targeting Mafb. Diabetes 66: 3072-3084, 2017.

359. Zhu Y, You W, Wang H, Li Y, Qiao N, Shi Y, Zhang C, Bleich D, and Han X. MicroRNA-24/MODY gene regulatory pathway mediates pancreatic beta-cell dysfunction. Diabetes 62: 3194-3206, 2013. 


\section{Figure legends}

Fig. 1 Regulation of $\boldsymbol{\beta}$-cell mass over lifetime. The functional $\beta$-cell mass is regulated by different processes over the course of a lifetime. During embryonic development and the neonatal period, expansion of the $\beta$-cells is critical for the acquisition and the maintenance of a fully functional $\beta$-cell mass. Adverse conditions limiting $\beta$-mass expansion during these critical periods predispose individuals to diabetes later in life. Pancreatic $\beta$-cells can be the target of an autoimmune attack. Immune cells infiltrate the islets and selectively kill the $\beta$-cells, leading to a near complete loss of insulin-secreting cells and the appearance of Type 1 diabetes. Throughout life, several mechanisms favor the expansion of the functional $\beta$-cell mass during pregnancy or in obese individuals to compensate for insulin resistance of peripheral tissues. Type 2 diabetes develops if the functional $\beta$-cell mass fails to adapt to cover the increased insulin needs. Lastly, ageing and $\beta$ cell senescence can reduce the capacity to compensate for insulin resistance.

Fig. 2 | Relative amounts of RNA transcripts in human and mouse cells. Pie chart representing the proportion of different RNA classes compared to the total number of annotated genes in A) Human (60’603 genes) or B) Mouse (55’487 genes). Data obtained from Gencode 31. (Abv: lncRNAs = long-non coding RNAs, miRNAs = microRNAs, snoRNAs = small nucleolar RNAs, snRNAs $=$ small nuclear RNAs, ncRNAs $=$ non-coding RNAs $)$.

Fig. 3 | Classification of RNAs. RNA molecules can be divided in two categories depending on their ability to code (coding RNA) or not (non-coding RNA) for proteins. Non-coding RNA transcripts are classified based on their function (rRNA = ribosomal RNA, tRNA = transfer RNA) or on their length (shorter or longer than 200 nucleotides). The short RNA families include snoRNAs (small nucleolar RNAs), snRNAs (small nuclear RNAs), siRNAs (small interfering RNAs), miRNAs (microRNAs) and piRNAs (PIWI-interacting RNAs). The long non-coding RNA family is further subdivided based on the shape of the RNA molecules: linear long-non coding RNA (lncRNA) or circular RNA (circRNA). Of note, tRNA molecules can be cleaved to generate fragments (tRF) that share some properties with other short ncRNAs. 
Fig. 4 | Generation and classification of tRFs. Endonucleic cleavage of mature tRNAs generates a diverse range of tRFs. Various endonucleases including Dicer generate short tRFs (12-20 nucleotides) at either arms of the tRNAs. Alternatively, Angiogenin cleaves tRNAs at the anticodon loop, generating tRNA halves (32-50 nucleotides, also known as tiRNAs). A double cleavage along the length of tRNAs can generate internal tRNA fragments (16 nucleotides or longer, also known as i-tRFs).

Fig. 5 | Classification of IncRNAs based on their genomic proximity to protein-coding genes. A) Long intergenic non-coding RNAs (lincRNAs) are located in intergenic regions. They are situated at more than $1 \mathrm{~kb}$ distance from the nearest protein-coding genes. B) The other classes of long non-coding RNAs (lncRNAs) are located in the vicinity of protein-coding genes and are named based on how their exons are positioned on the genome with respect to the exons of the mRNA and on the direction of transcription: overlapping, intronic, cis-antisens or bidirectional.

Fig. 6 | Examples of mode of action of IncRNAs in $\boldsymbol{\beta}$-cells. A) The lncRNA PLUTO acts on 3D chromatin organization to favor the transcription of $P D X 1$ by bringing in close proximity the $P D X 1$ promoter with its enhancer cluster. B) The lncRNA Meg3 inhibits EZH2-mediated methylation of Rad21, Smc3 and Sin3 $\alpha$ promoters, triggering the expression of these transcription factors and, therefore, resulting in the inhibition of MafA expression. C) The lncRNA H19 sequesters let-7 members to prevent the repression of target genes of these miRNAs, leading to activation the PI3K/AKT pathway. (Abv: lncRNA = long non-coding RNA, miRNA = microRNA, PI3K = phosphatidylinositol 3-kinase)

Fig. 7 Formation of circular RNAs in eukaryotic cells. Eukaryotic circular RNAs can be generated from introns (grey) and/or exons (colored) of pre-mRNAs. Circular intronic RNAs (left) arise from introns circularized at the 5' and branchpoint (bp) nucleotides by a 2' -5' junction during linear splicing. These branched circular introns have a linear 3' tail and are known as lariats. Intron lariats can be debranched and rapidly degraded or escape debranching, lose their tail, and turn into stable circular intronic RNAs. Instead, circular exonic and exonic-intronic RNAs (right) can 
contain one or more exons and/or introns and are produced by backsplicing of an upstream 3' splice site and a downstream 5' splice site circularized by a 3'-5' junction.

Figure 8 | Exosome cross-talk in the context of type 1 and type 2 diabetes. A) In the context of T1D, islet Mesenchymal Stem Cells (i-MSC) and $\beta$-cells secrete exosomes that activate T-cells and B-cells. Pancreatic islet-cells produce exosomes that can horizontally transfer genetic material to adjacent islet-cells and endothelial cells. Infiltrated T-cells transfer specific miRNAs via exosomes to $\beta$-cells. B) In the context of T2D, muscle and hepatic exosomes deliver miRNAs to pancreatic islet cells. Exosomes secreted from Adipose Tissue Macrophages (ATMs) transfer miRNAs to insulin target tissues. Adipose tissue release exosomes containing miRNAs to liver and skeletal muscle. A-B) Pancreatic islet exosomes and ncRNAs that are released in the blood stream represent potential biomarkers for T1D and T2D. 
Table 1: List of ncRNAs investigated in pancreatic $\beta$-cells*

\begin{tabular}{|c|c|c|c|}
\hline ncRNA & Animal/cell models & Expression/ functional effects / mechanism of action & References \\
\hline \multicolumn{4}{|l|}{ piRNA } \\
\hline DQ732700 and & Islets of GK rats & Increased levels of DQ732700 and DQ746748 & $(113)$ \\
\hline DQ746748 & Overexpression in rat islets & Reduction of GIIS & \\
\hline \multicolumn{4}{|l|}{ snoRNAs } \\
\hline \multirow[t]{4}{*}{ U32a, U33, U34, U35a } & Rpl13a-snoless mice & Increased GIIS in vivo and ex vivo & $(177)$ \\
\hline & & Enhanced glucose tolerance & \\
\hline & & $\begin{array}{l}\text { Remain normoglycemic in respose to STZ treatment, } \\
\text { or when crossed with Akita or NOD mice }\end{array}$ & \\
\hline & & Rpl13a-snoless islets are resistant to oxidative stress & \\
\hline \multirow[t]{5}{*}{ snoRNAs from Snord116 } & Snord $116^{\mathrm{p}-/ \mathrm{m}+}$ mice & Defect in proinsulin processing & $(31)$ \\
\hline & & Secretion of a higher proinsulin/C-peptide ratio & \\
\hline & & Reduction of mean islet size & $(30)$ \\
\hline & & Increased number of polyhormonal islet cells & \\
\hline & & Lower levels of $P d x 1, P a x 6$ and $N k x 6.1$ in adult islets & \\
\hline
\end{tabular}

\begin{tabular}{|c|c|c|c|}
\hline \multicolumn{4}{|l|}{ tRFs } \\
\hline \multirow[t]{2}{*}{ 5'-tRNA Gln } & Augmentation in EndoC- $\beta \mathrm{H} 1$ & Induces apoptosis & \multirow[t]{2}{*}{$(50)$} \\
\hline & Inhibition in EndoC- $\beta \mathrm{H} 1$ & Prevents apoptosis induced by TRMT10A deficiency & \\
\hline \multicolumn{4}{|l|}{ IncRNAs } \\
\hline \multirow[t]{2}{*}{ ßlinc2 (XLOC_010971) } & Islets of DIO and ob/ob mice & Increased levels of $\beta$ linc2 (vs normal diet and $+/+$, respectively) & \multirow[t]{2}{*}{$(226)$} \\
\hline & $\begin{array}{l}\text { Downregulation in mouse islets and } \\
\text { MIN6 cells }\end{array}$ & Favors $\beta$-cell apoptosis & \\
\hline
\end{tabular}


Blinc3 (XLOC_013310)

GAS5

H19

HI-LNC15 / ßlinc 1

HI-LNC25

HI-LNC78

Lnc03 (Gm16308)

lncRNA-1 gm5970
Islets of T2D donors and DIO mice (vs normal diet)

Islets of $\mathrm{db} / \mathrm{db}$ mice (vs $\mathrm{db} /+$ )

Downregulation in mouse islets and MIN6 cells

Islets of T2D donors and $\mathrm{db} / \mathrm{db}$ mice (vs C57BL/KsJ)

Inhibition of GAS5 in MIN6 cells and/or mouse islets

Islets of $\mathrm{db} / \mathrm{db}$, ob/ob and DIO mice Rat islet maturation

Islets from LP pups

Deregulation of H19 in adult and P10 rat islets

Downregulation in EndoC- $\beta \mathrm{H} 1$ Whole-body KO mice

Downregulation in EndoC- $\beta \mathrm{H} 1$

Downregulation in EndoC- $\beta \mathrm{H} 1$

Islets from pregnant mice

Downregulation of Lnc03 in mouse islets

Islets of 8 wks NOD mice (vs 4 wks, and compared to SCID)

Mouse islets/MIN6 exposed to cyt. mix

Upregulation of lncRNA-1 in MIN6 and mouse islets
Increased levels of $\beta$ linc 3

Decreased levels of $\beta$ linc3

Favors $\beta$-cell apoptosis

Decreased levels of GAS5

Reduction of GIIS, insulin content and Ins2, MafA and Pdx1

expression

Cell cycle arrest without impact on cell survival

Upregulation of H19 (vs db/+, +/+ and normal diet, resp.)

Decreased expression of H19 in adult vs P10 pups

Downregulation of H19 in P10 pups born from dams fed low-protein diet vs normal diet

Regulation of $\beta$-cell proliferation by sponging let-7 family members and favoring PI3K-AKT signaling pathway

Dysregulation of genes related to NKX2.2 regulatory network

Reduction in $\beta$-cell mass at birth

Glucose- and insulin-intolerant at adult age

Favors GLIS3 expression

Reduction of insulin content and GIIS

Upregulation of Lnc03 (vs non-pregnant)

Decreases $\beta$-cell proliferation induced by prolactin

Increased levels of lncRNA-1

Increased levels of lncRNA-1

Induces $\beta$-cell apoptosis and favors NFkB translocation to the nucleus 
lncRNA-2 AI451557

lncRNA-3 BC002288

MEG3

PLUTO (HI-LNC71)
Islets of 8 wks NOD mice (vs 4 wks, and compared to SCID)

Mouse islets/MIN6 exposed

to cyt. mix

Upregulation of lncRNA-1 in MIN6 and mouse islets

Islets of 8 wks NOD mice (vs 4 wks, and compared to SCID)

Mouse islets/MIN6 exposed to cyt. mix

Upregulation of lncRNA-1 in MIN6 and mouse islets

Mouse islets/MIN6 exposed to cyt. mix

Upregulation of lncRNA-1 in MIN6 and mouse islets

Islets of T2D donors

Islets of $\mathrm{db} / \mathrm{db}$ and NOD mice (compared to Balb/c)

Balb/c mice injected with siMeg3

Inhibition of Meg3 in MIN6/mouse islets

T2D and IGT donors

Downregulation in EndoC- $\beta \mathrm{H} 1$ and human islets

Downregulation in EndoC- $\beta \mathrm{H} 1$
Increased levels of IncRNA-2

Increased levels of lncRNA-2

Induces $\beta$-cell apoptosis

Increased levels of lncRNA-3

Increased levels of lncRNA-3

Induces $\beta$-cell apoptosis

Increased levels of lncRNA-4

Induces $\beta$-cell apoptosis

Downregulation of MEG3

Downregulation of MEG3

Impaired glucose tolerance

Reduction of serum insulin levels in response to IPGTT

Reduction of Ins2 expression and insulin secretion

Meg3 favors Rad21, Smc3 and Sin3a expression which repress MafA

Downregulation of PLUTO expression

Reduced PDX1 expression by affecting chromatin organization

Decreased insulin content and consequent impaired GIIS

\section{circRNAs}

circAFF1

Downregulation in rat islets

Induced apoptosis 
circARHGAP12

ciRS-7/Cdr1as

circHIPK3
Islets of 8 wks NOD mice (vs 4 wks, and compared to SCID)

Islets of ob/ob and $\mathrm{db} / \mathrm{db}$ mice

Downregulation in rat islets

Overexpression in MIN6

and mouse islets

Islets of $\mathrm{db} / \mathrm{db}$ mice

Downregulation in rat islets
Decreased levels of circARHGAP12

Decreased levels of ciRS-7/Cdr1as

Tendency to inhibit GIIS

Reduce $\beta$-cell proliferative capacity

Slight increase in GIIS

Higher insulin content

Upregulation of Myrip and Pax6 expression by sponging miR-7

Decreased levels of circHIPK3

Inhibition of GIIS

Reduction of $\beta$-cell proliferative capacity

Rise in the apoptotic rate

* For miRNAs, readers are referred to dedicated review $(72,78,169)$ 
Table 2: Summary of the bioinformatic tools developed for ncRNA identification and for target prediction

\begin{tabular}{|c|c|c|c|c|c|c|}
\hline Category & Tool & Type & $\begin{array}{c}\text { Last } \\
\text { update }\end{array}$ & Brief description & URL & Ref. \\
\hline \multirow[t]{12}{*}{$\begin{array}{c}\text { miRNA } \\
\text { identification }\end{array}$} & MiRscan & Web server & 2003 & $\begin{array}{l}\text { Based on RNA fold and evolutionarily } \\
\text { conserved miRNAs }\end{array}$ & http://hollywood.mit.edu/mirscan/ & $(186)$ \\
\hline & miRseeker & Method & 2003 & $\begin{array}{l}\text { Based on M-fold and evolutionarily conserved } \\
\text { miRNAs }\end{array}$ & - & $(165)$ \\
\hline & ProMir II & Web server & 2006 & $\begin{array}{l}\text { HMM-based tool; predicts conserved and non- } \\
\text { conserved miRNAs }\end{array}$ & - & $(230)$ \\
\hline & MiRRim & Method & 2007 & $\begin{array}{l}\text { HMM-based tool; high-performance } \\
\text { identification of those clustering with known } \\
\text { miRNAs }\end{array}$ & - & $(307)$ \\
\hline & HHMMiR & Software & 2009 & $\begin{array}{l}\text { Based on hierarchical HMM; predicts de novo } \\
\text { miRNA hairpins in the absence of evolutionary } \\
\text { conservation }\end{array}$ & $\begin{array}{l}\text { http://www.benoslab.pitt.edu/kadriA } \\
\underline{\text { PBC2009.html }}\end{array}$ & $(135)$ \\
\hline & SSCprofiler & Web server & 2009 & $\begin{array}{l}\text { Based on profile HMM; identifies novel } \\
\text { miRNAs located in cancer-associated genomic } \\
\text { regions }\end{array}$ & $\underline{\text { http://mirna.imbb.forth.gr/SSCprofile }}$ & $(240,241)$ \\
\hline & BayesmiRNAfind & Web server & 2006 & NBC-based program & - & $(345)$ \\
\hline & MatureBayes & $\begin{array}{l}\text { Web server with } \\
\text { script code }\end{array}$ & 2010 & NBC-based program & $\begin{array}{l}\text { http://mirna.imbb.forth.gr/MatureBay } \\
\text { es.html }\end{array}$ & $(91)$ \\
\hline & MiRFinder & Software & 2007 & $\begin{array}{l}\text { SVM-based tool; performs pair-wise genome } \\
\text { alignments between related species; fails to } \\
\text { detect species-specific pre-miRNAs }\end{array}$ & $\begin{array}{l}\overline{\text { https://www.bioinformatics.org/mirfi }} \\
\underline{\text { nder/ }}\end{array}$ & $(117)$ \\
\hline & $\begin{array}{l}\text { miRDeep/ } \\
\text { miRDeep2 }\end{array}$ & Software & 2012 & $\begin{array}{l}\text { Predicts known and novel miRNAs from NGS } \\
\text { data }\end{array}$ & $\begin{array}{l}\text { https://www.mdc-berlin.de/ } \\
\text { content/mirdeep2-documentation }\end{array}$ & $(81,82)$ \\
\hline & miRanalyzer & Web server & 2013 & $\begin{array}{l}\text { Predicts known and novel miRNAs from NGS } \\
\text { data }\end{array}$ & $\begin{array}{l}\text { https://bioinfo5.ugr.es/srnatoolbox/sr } \\
\underline{\text { nabench/ }}\end{array}$ & $(109,110)$ \\
\hline & miReader & Software & 2013 & $\begin{array}{l}\text { Identifies mature miRNAs directly from NGS } \\
\text { data without the need for genomic sequences }\end{array}$ & - & $(128)$ \\
\hline \multirow[t]{2}{*}{$\begin{array}{l}\text { miRNA target } \\
\text { prediction }\end{array}$} & TargetScan & $\begin{array}{l}\text { Web server with } \\
\text { script code }\end{array}$ & 2018 & $\begin{array}{l}\text { Uses the context++ model to predict the most } \\
\text { effective canonical targeting }\end{array}$ & http://www.targetscan.org/vert 72/ & (3) \\
\hline & miRanda & Software & 2010 & $\begin{array}{l}\text { Recognizes target sites using features like } \\
\text { sequence complementarity between mature } \\
\text { miRNA and the free energy of the duplex }\end{array}$ & $\begin{array}{l}\text { http://www.mirtoolsgallery.org/miRT } \\
\underline{\text { oolsGallery/node/1055 }}\end{array}$ & (66) \\
\hline
\end{tabular}




\begin{tabular}{|c|c|c|c|c|c|c|}
\hline & PITA & Software & 2008 & Takes in to account target site accessibility & $\underline{\text { https://genie.weizmann.ac.il/pubs/mir }}$ & $(147)$ \\
\hline & PicTar & Web server & 2007 & $\begin{array}{l}\text { Detects conserved sites across multiple species } \\
\text { using a pair-wise alignment algorithm }\end{array}$ & $\underline{\underline{\text { http}}: / / \text { pictar.mdc-berlin.de/ }}$ & $(168)$ \\
\hline & RNA22 & Web server & 2015 & $\begin{array}{l}\text { Pattern-based program to find miRNA binding } \\
\text { sites without cross-species sequence } \\
\text { conservation filtering }\end{array}$ & $\underline{\text { https://cm.jefferson.edu/rna22/ }}$ & (190) \\
\hline & RNAhybird & $\begin{array}{l}\text { Web server with } \\
\text { script code }\end{array}$ & 2006 & $\begin{array}{l}\text { Based on free energy of miRNA:mRNA } \\
\text { duplexes }\end{array}$ & $\begin{array}{l}\text { https://bibiserv.cebitec.uni- } \\
\text { bielefeld.de/rnahybrid }\end{array}$ & $(161)$ \\
\hline \multirow[t]{5}{*}{$\begin{array}{c}\text { piRNA } \\
\text { identification }\end{array}$} & piRNApredictor & Software & 2011 & $\begin{array}{l}\text { Based on a k-mer scheme to identify piRNA } \\
\text { sequences, relying on the training sets from non- } \\
\text { piRNA and piRNA sequences }\end{array}$ & - & $(350)$ \\
\hline & Piano & Software & 2014 & $\begin{array}{l}\text { Based on piRNA-transposon interaction } \\
\text { information }\end{array}$ & $\begin{array}{l}\text { http://www.insect- } \\
\text { genome.com/links/piano.php }\end{array}$ & (323) \\
\hline & Luo method & Software & 2016 & Transposon-derived piRNA prediction & $\begin{array}{l}\text { https://journals.plos.org/plosone/artic } \\
\text { le?id=10.1371/journal.pone. } 0153268\end{array}$ & (196) \\
\hline & Li method & Software & 2016 & $\begin{array}{l}\text { Based on a genetic algorithm weighted } \\
\text { ensemble method for predicting transposon- } \\
\text { derived piRNAs }\end{array}$ & $\begin{array}{l}\text { https://github.com/zw9977129/piRN } \\
\text { APredictor }\end{array}$ & $(181)$ \\
\hline & 2L-piRNA & Web server & 2017 & $\begin{array}{l}\text { Identifies whether a query RNA molecule is } \\
\text { piRNA and if it instructs target mRNA } \\
\text { deadenylation }\end{array}$ & $\begin{array}{l}\text { http://bioinformatics.hitsz.edu.cn/2L- } \\
\text { piRNA/ }\end{array}$ & (188) \\
\hline \multirow[t]{2}{*}{$\begin{array}{l}\text { piRNA target } \\
\text { prediction }\end{array}$} & pirScan & Web server & 2018 & $\begin{array}{l}\text { Identifies C. elegans piRNA-targeting sites } \\
\text { within a given mRNA or spliced DNA sequence }\end{array}$ & $\underline{\text { http://cosbi4.ee.ncku.edu.tw/pirScan/ }}$ & $(337)$ \\
\hline & piRTarBase & Web server & 2018 & $\begin{array}{l}\text { Integrative platform that identifies functional } \\
\text { piRNA target sites by taking in to account } \\
\text { multiple information }\end{array}$ & $\begin{array}{l}\text { http://cosbi6.ee.ncku.edu.tw/piRTarB } \\
\underline{\text { ase/ }}\end{array}$ & $(336)$ \\
\hline \multirow[t]{2}{*}{$\begin{array}{c}\text { tRNA } \\
\text { fragment } \\
\text { identification }\end{array}$} & MINTmap & Software & 2017 & $\begin{array}{l}\text { Based on a sequence-centric scheme for labeling } \\
\text { tRFs to calculate and report raw and normalized } \\
\text { abundances for the discovered tRFs }\end{array}$ & $\begin{array}{l}\text { https://github.com/TJU-CMC- } \\
\text { Org/MINTmap/ }\end{array}$ & $(191)$ \\
\hline & tRF2Cancer & Web server & 2016 & $\begin{array}{l}\text { Based on a binomial test to distinguish genuine } \\
\text { tRFs from degradation fragments }\end{array}$ & $\underline{\text { http://rna.sysu.edu.cn/tRFfinder/ }}$ & (354) \\
\hline \multirow[t]{4}{*}{$\begin{array}{c}\text { circRNA } \\
\text { identification }\end{array}$} & circRNA_finder & Software & 2018 & Based on STAR-mapped reads & $\begin{array}{l}\text { https://github.com/orzechoj/circRNA } \\
\text { finder }\end{array}$ & $\overline{(331)}$ \\
\hline & CIRCexplorer2 & Software & 2019 & Based on Tophat-mapped reads & $\begin{array}{l}\text { https://github.com/YangLab/CIRCex } \\
\text { plorer2 }\end{array}$ & (349) \\
\hline & CIRI2 & Software & 2017 & Based on BWA-mapped reads & $\begin{array}{l}\text { https://sourceforge.net/projects/ciri/fi } \\
\underline{\text { les/CIRI2/ }}\end{array}$ & (89) \\
\hline & find_circ & Software & 2017 & Based on Bowtie2-mapped reads & $\begin{array}{l}\text { https://github.com/marvin- } \\
\text { jens/find_circ }\end{array}$ & $(215)$ \\
\hline
\end{tabular}




\begin{tabular}{|c|c|c|c|c|c|}
\hline MapSplice & Software & 2016 & Based on Tophat-mapped reads & $\begin{array}{l}\underline{\text { http://www.netlab.uky.edu/p/bioinfo/ }} \\
\underline{\text { MapSplice2 }}\end{array}$ & $(324)$ \\
\hline ACFS & Software & 2017 & Based on BWA-mapped reads & https://github.com/arthuryxt/acfs & $(344)$ \\
\hline DCC & Software & 2019 & Based on STAR-mapped reads & https://github.com/dieterich-lab/DCC & $(42)$ \\
\hline KNIFE & Software & 2017 & Based on Bowtie2-mapped reads & https://github.com/lindaszabo/KNIFE & $(303)$ \\
\hline Uroborus & Software & 2018 & Based on Tophat-mapped reads & $\begin{array}{l}\text { https://github.com/WGLab/UROBO } \\
\text { RUS }\end{array}$ & $(297)$ \\
\hline
\end{tabular}




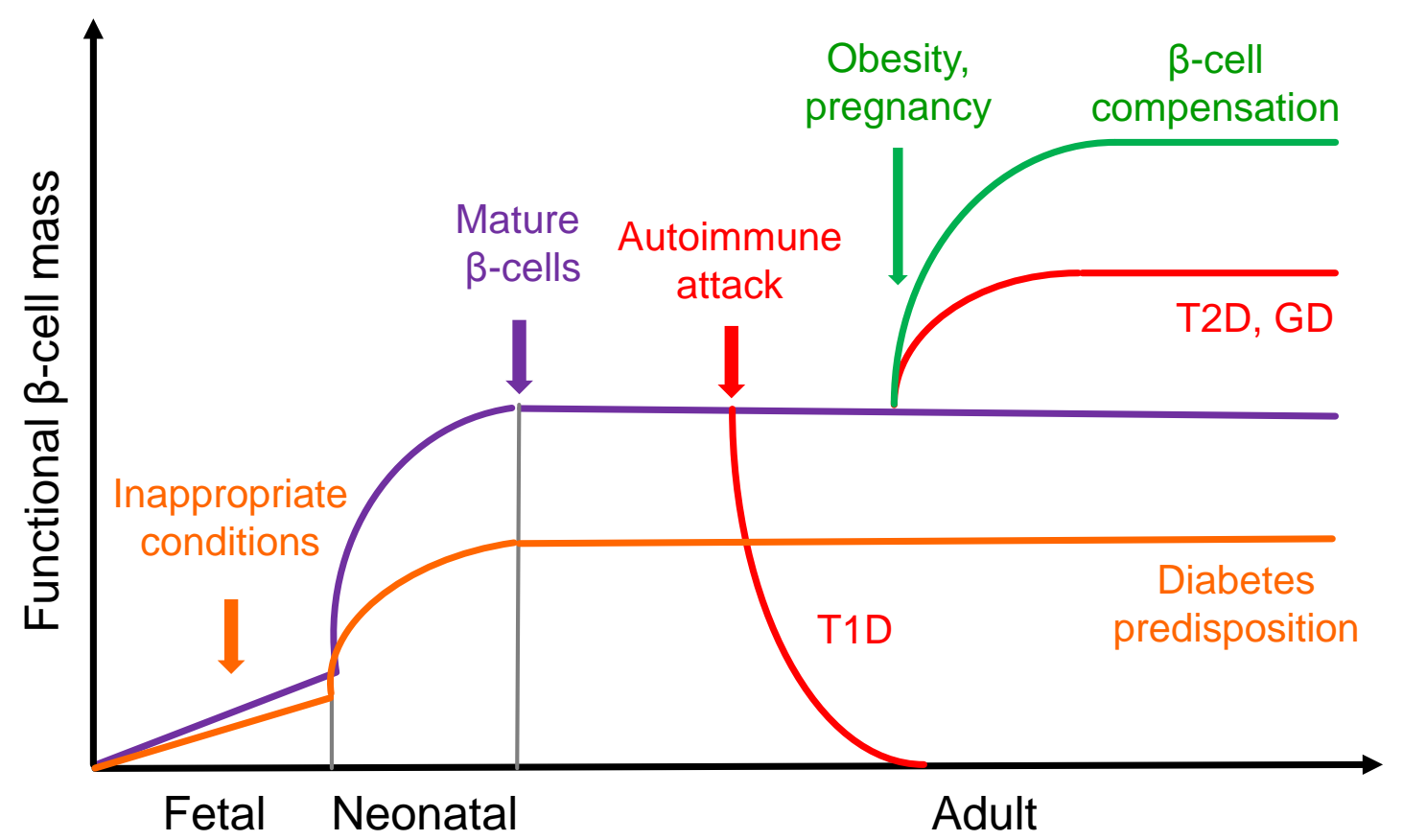

Figure 1 Guay et al. 
A
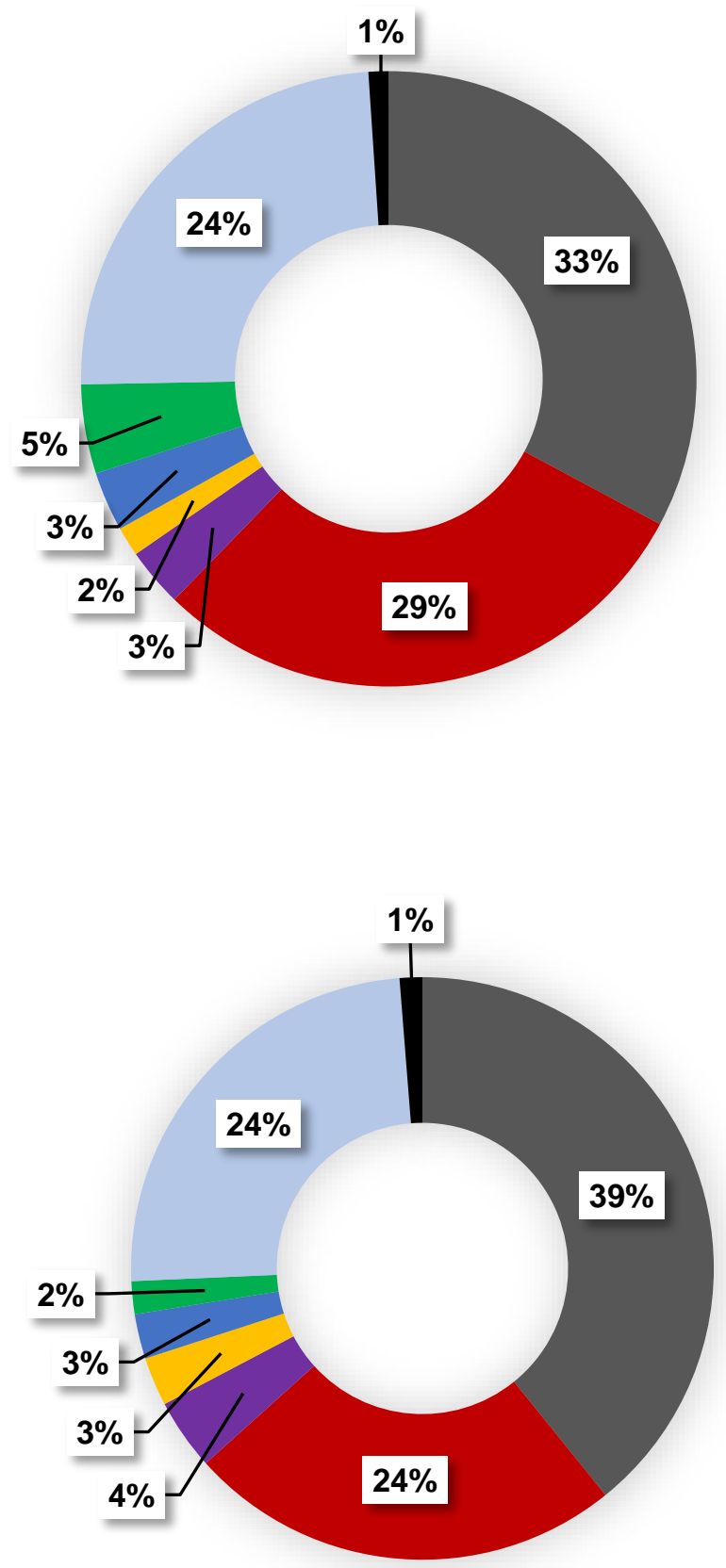

\section{B}

- Protein-coding genes

- IncRNAs

- miRNAs

m snoRNAs

- snRNAs

- Other small ncRNAs

- Pseudogenes

- Others

Figure 2 Guay et al.

- Protein-coding genes

- IncRNAs

- miRNAs

- snoRNAs

- snRNAs

- Others small ncRNAs

- Pseudogenes

- Others 


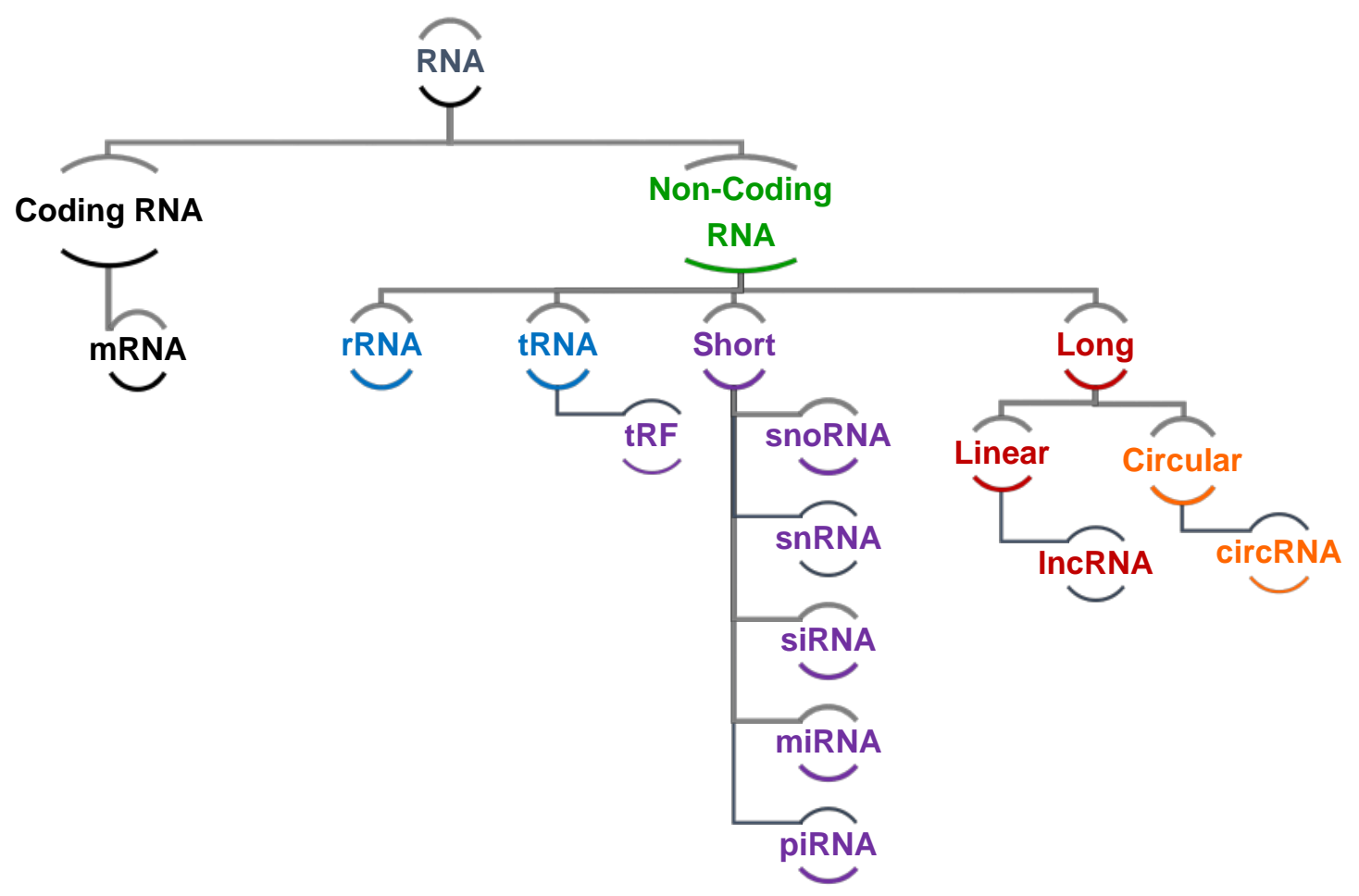

Figure 3 Guay et al. 


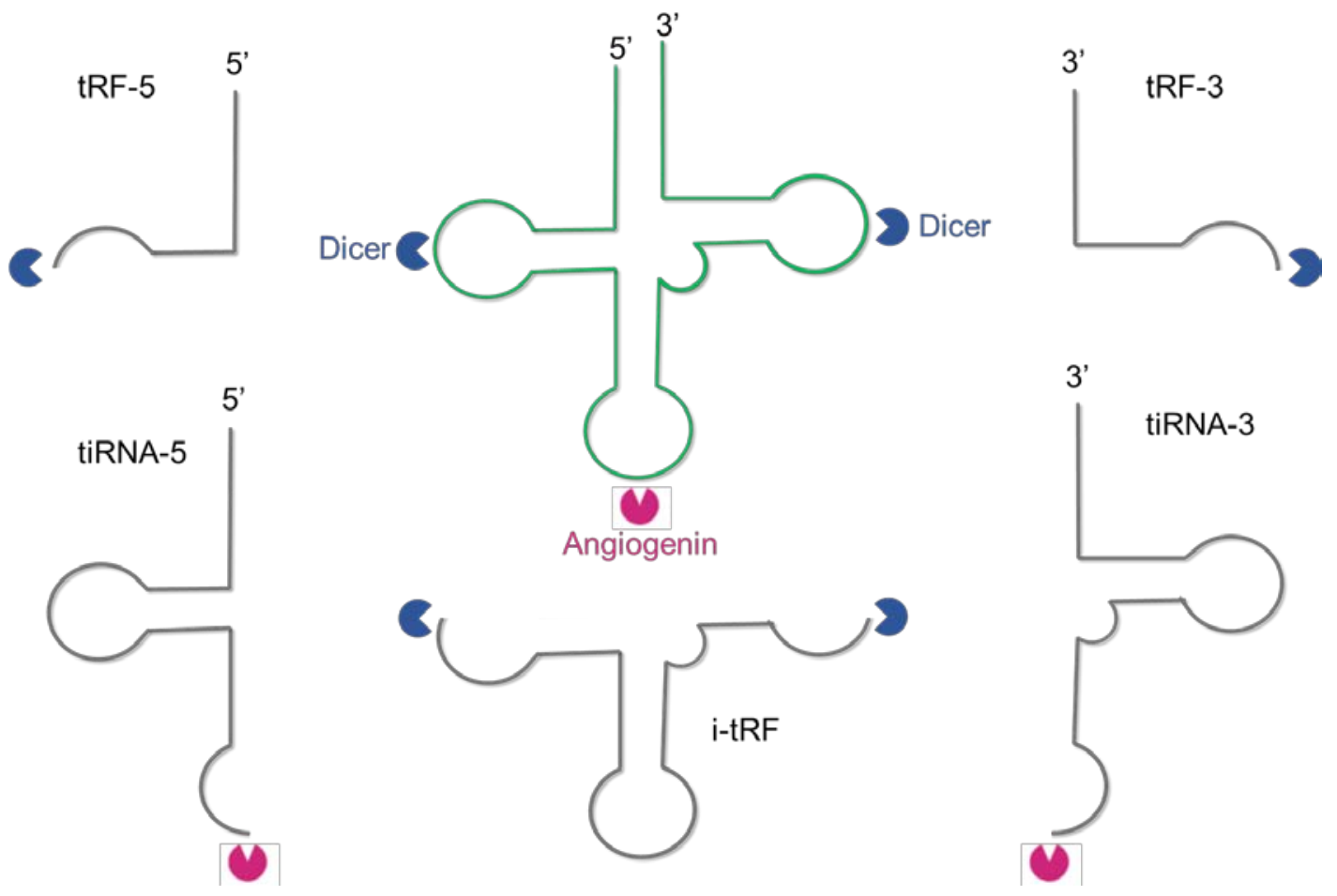

Figure 4 Guay et al. 
A- Intergenic IncRNAs (lincRNA)

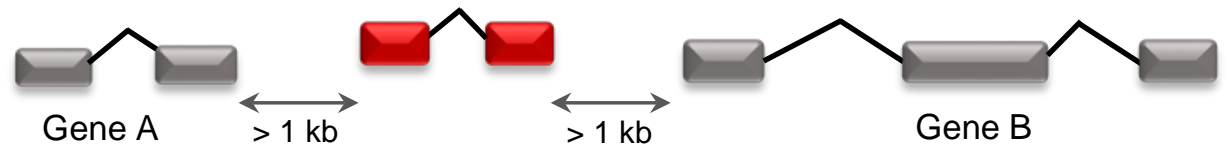

\section{B- Genic IncRNAs}

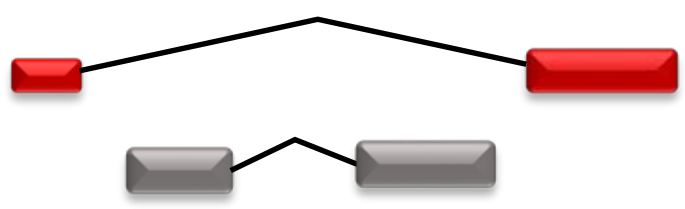

Overlapping

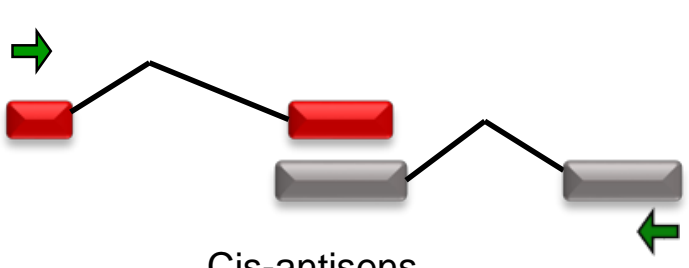

Cis-antisens

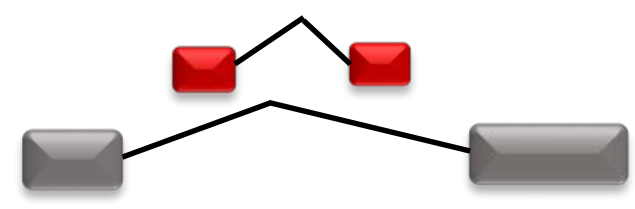

Intronic

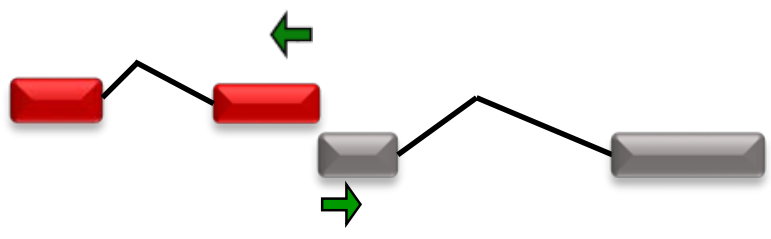

Bidirectional

Legends
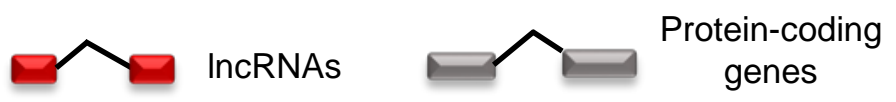

$\Rightarrow \begin{gathered}\text { Sens of the } \\ \text { transcription }\end{gathered}$

Figure 5 Guay et al. 
A - Chromatin organization

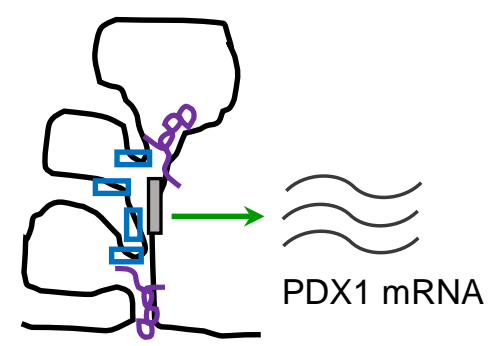

ㅁ Enhancer

8 PLUTO

\PDX1

promotor
B- Chromatin remodeling
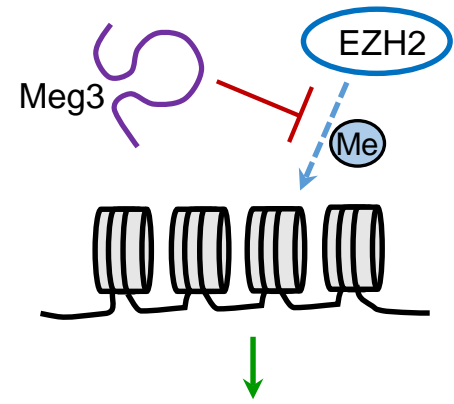

$\operatorname{Rad} 21, \operatorname{Smc} 3, \operatorname{Sin} 3 \alpha$

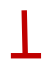

MafA
C- miRNA sponging

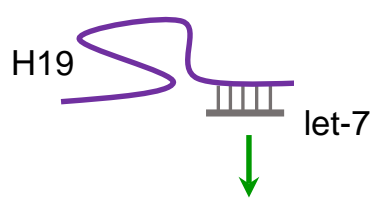

let-7 targets

I

PI3K/AKT pathway

Figure 6 Guay et al. 


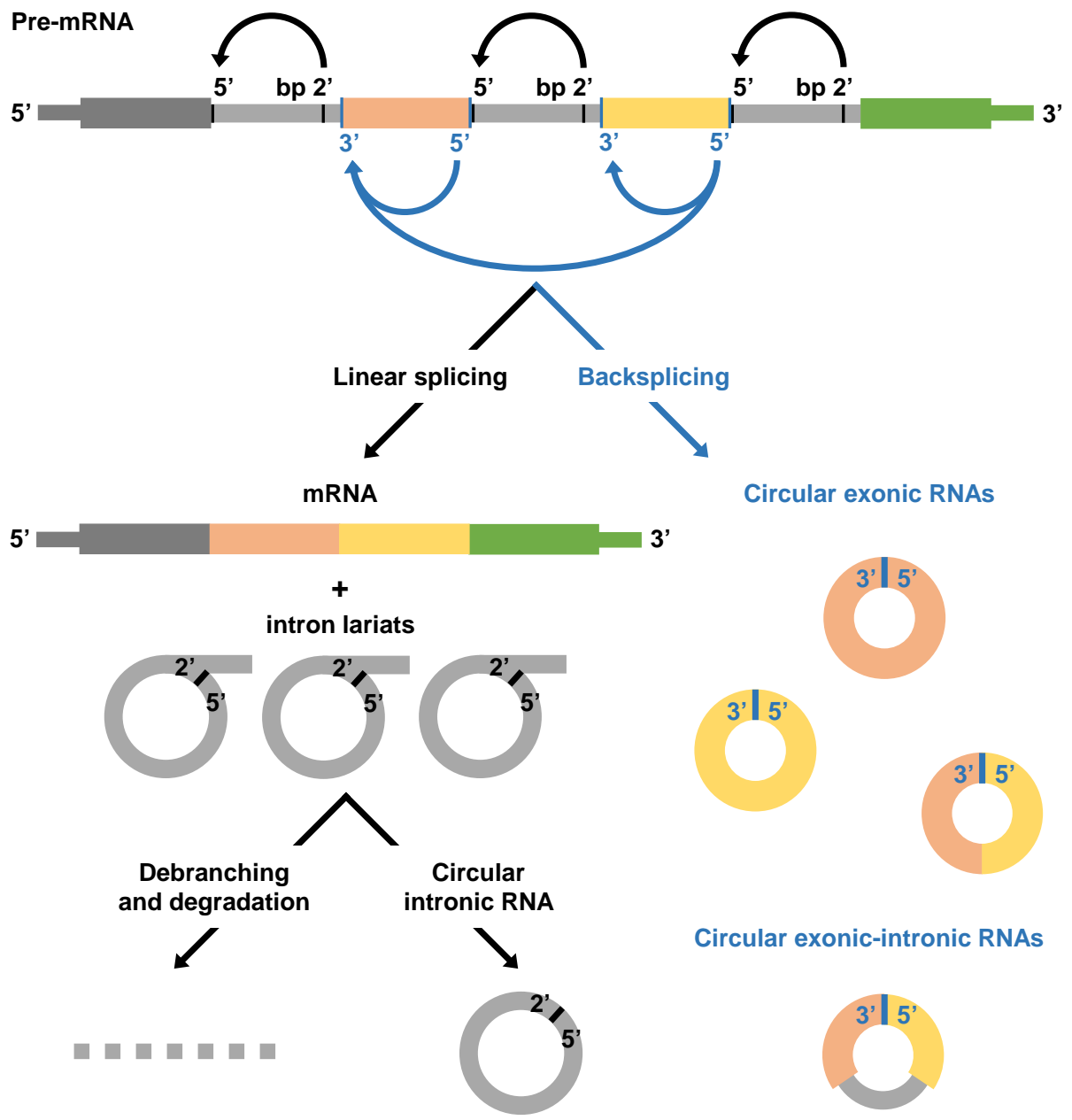

Figure 7 Guay et al. 
A.

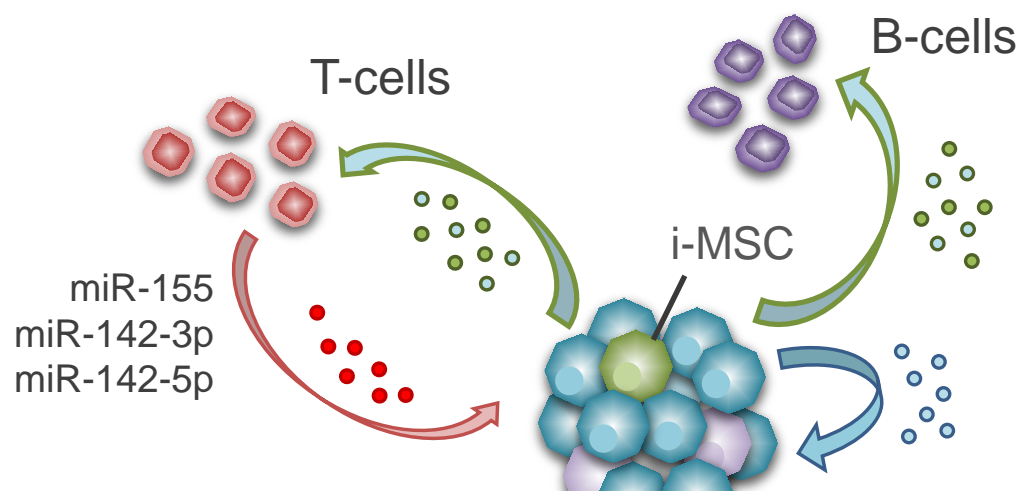

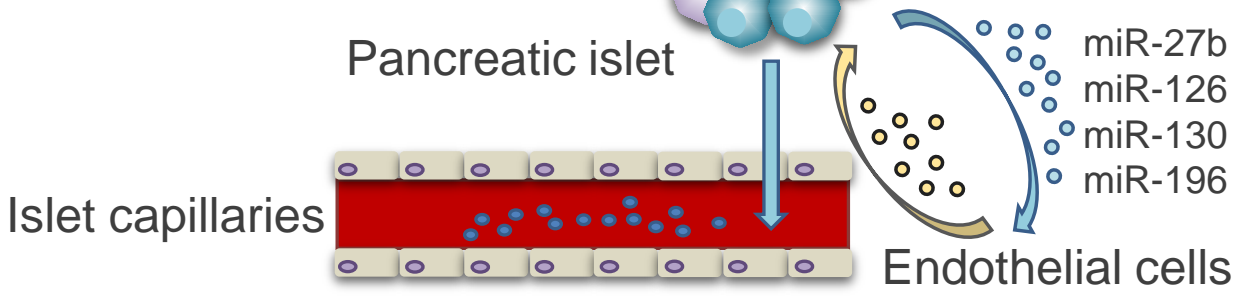

B.

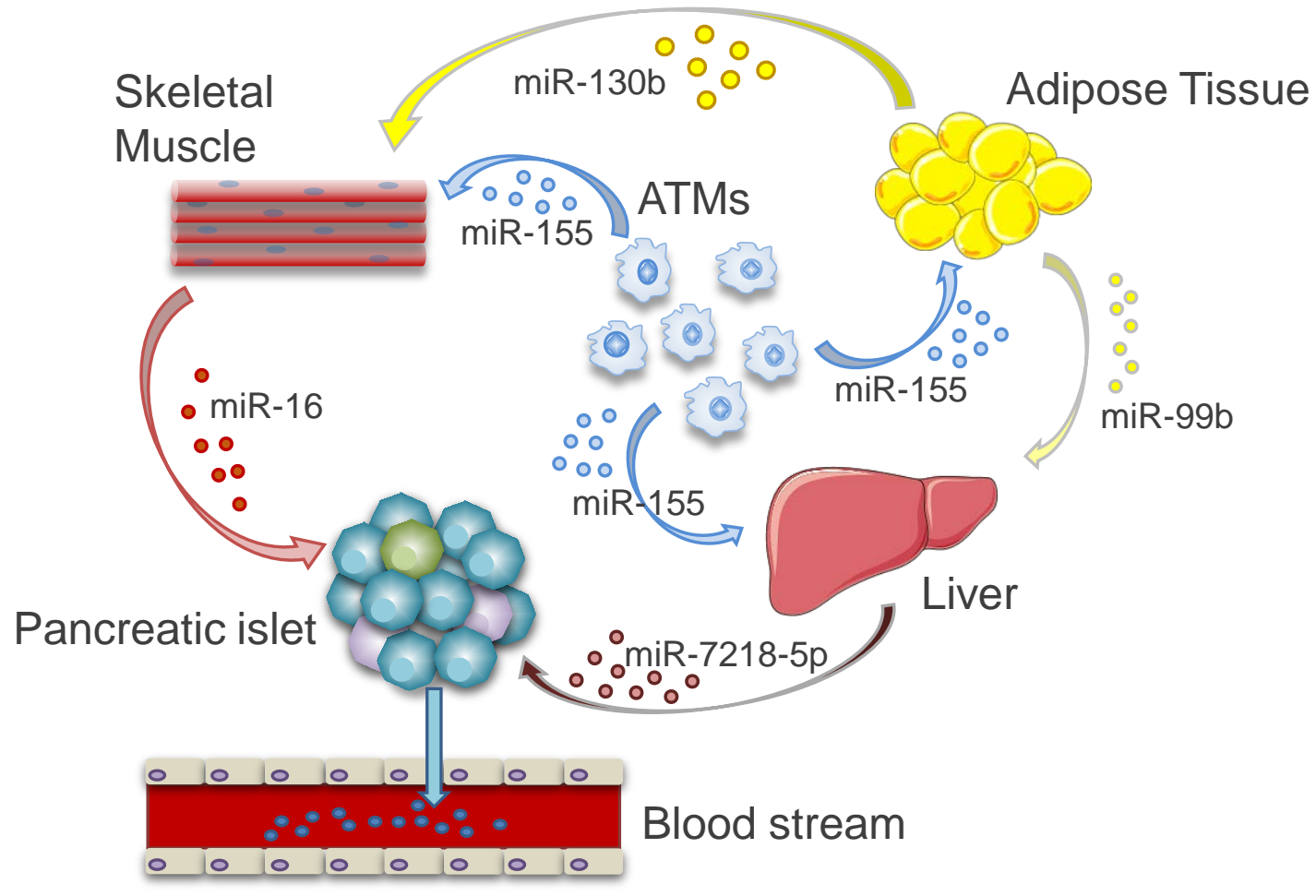

Figure 8 Guay et al. 